Portland State University

PDXScholar

Portland's Multifamily Recycling Program: a Study of Coproduction Policy Implementation and Citizen Involvement

William Barry Messer

Portland State University

Follow this and additional works at: https://pdxscholar.library.pdx.edu/open_access_etds

Part of the Public Affairs Commons, and the Public Policy Commons Let us know how access to this document benefits you.

Recommended Citation

Messer, William Barry, "Portland's Multifamily Recycling Program: a Study of Coproduction Policy Implementation and Citizen Involvement" (1994). Dissertations and Theses. Paper 1194.

https://doi.org/10.15760/etd.1193

This Dissertation is brought to you for free and open access. It has been accepted for inclusion in Dissertations and Theses by an authorized administrator of PDXScholar. Please contact us if we can make this document more accessible: pdxscholar@pdx.edu. 
PORTLAND'S MULTIFAMILY RECYCLING PROGRAM:

\title{
A STUDY OF COPRODUCTION POLICY IMPLEMENTATION
}

AND CITIZEN INVOLVEMENT

\section{by}

WILLIAM BARRY MESSER

\author{
A dissertation submitted in partial fulfillment of the \\ requirements for the degree of \\ DOCTOR OF PHILOSOPHY \\ in \\ PUBLIC ADMINISTRATION AND POLICY
}

Portland State University

1994 


\section{DISSERTATION APPROVAL}

The abstract and dissertation of William Barry Messer for the Doctor of

Philosophy in Public Administration and Policy was presented June 23, 1994 and accepted by the dissertation committee.

APPROVALS:
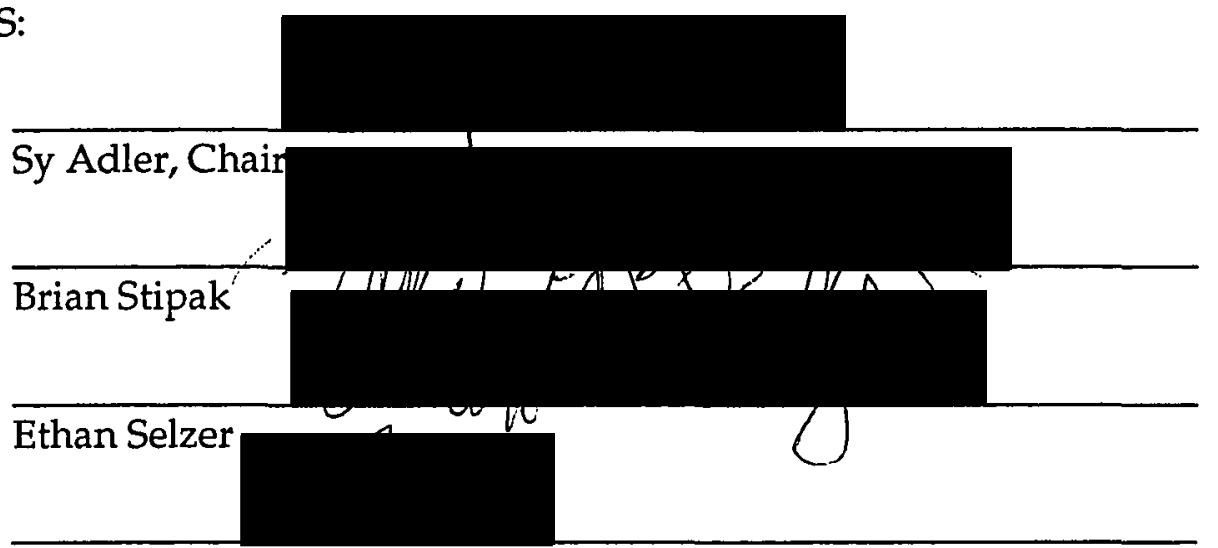

Hugo Maynard

Thomas Harvey, Representative of the Office of Graduate Studies

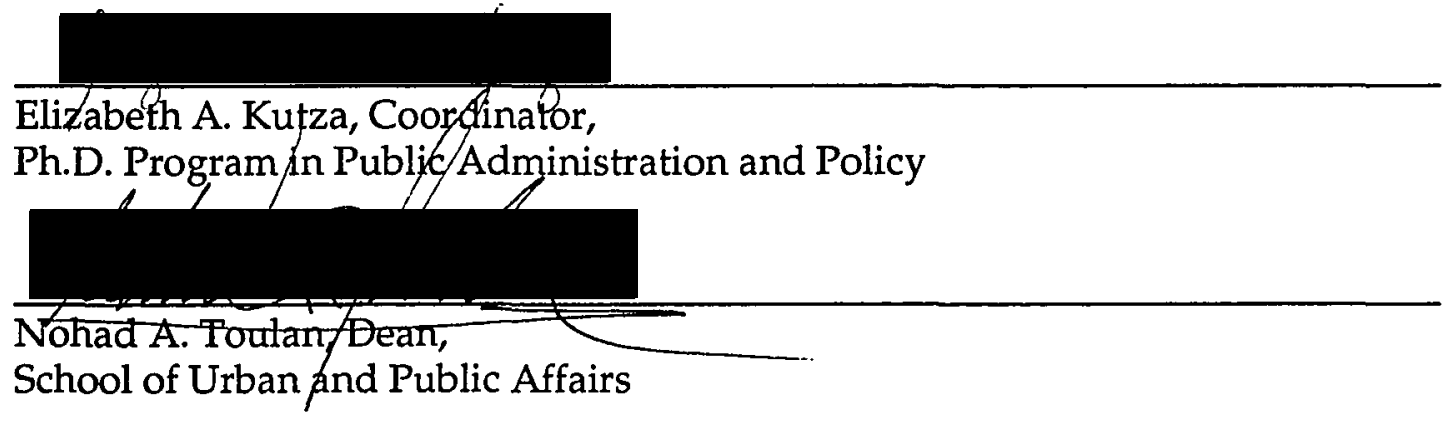

\section{ACCEPTED FOR PORTLAND STATE UNIVERSITY LIBRARY}

by

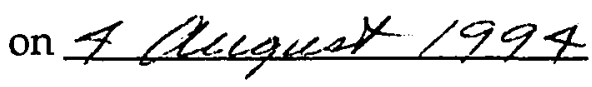




\begin{abstract}
An abstract of the dissertation of William Barry Messer for the Doctor of Philosophy in Public Administration and Policy present June 23, 1994.
\end{abstract}

Title: Portland's Multifamily Recycling Program: A Study of Coproduction Policy Implementation and Citizen Involvement

This study is on coproduction as a governing policy instrument. Coproduction can be understood as the joint production of services by local officials and individual citizens intended to raise the quality and or amount of service provision. The concept of coproduction as developed in this study suggests that urban services are not simply created by officials and delivered to a passive public. Rather that actions of citizens are an integral part of the service production process.

The study purposes are two-fold: (1) to construct a model of coproduction which provides a basis by which citizen involvement in the provision of public services can be fully understood and appreciated; and (2) to examine the usefulness of this model by using it to frame and guide evaluative research on a specific program which targets coproductive participation of citizens. The research examined efforts to implement a program to encourage recycling by residents in multifamily complexes in the City of Portland by involving the direct participation of the managers of the complexes.

The research conducted in this study addressed both the inputs and outcomes of citizen involvement in coproduction. Findings of this research are 
suggestive of the potential importance of both inclusion and volition to furthering citizen involvement in the coproductive process. The level of citizen involvement in producing the programmatic outcomes was by most measures demonstrated to be very important. The results of the investigation in demonstrating the importance of involvement in coproduced programs in generating broader levels of community awareness and involvement, however, were not as conclusive.

The model of coproduction developed in this study provides a potentially useful conceptualization of the process and outcomes of coproduction. The empirical investigation provides an assessment of the nature and strength of the relationship between citizen involvement and the coproductive process in the case of Portland's multifamily recycling program. Both the economic and civic considerations of coproduction which were specified and measured in the research contribute to a number of observations about coproduction as a policy instrument leading to several policy recommendations for programs which are built on citizen involvement. 


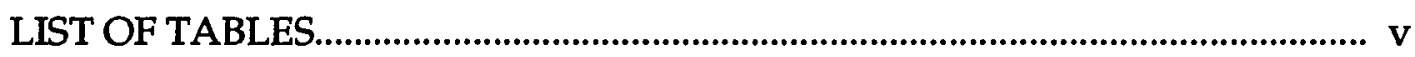

LIST OF FIGURES..................................................................................... vi

\section{CHAPTER}

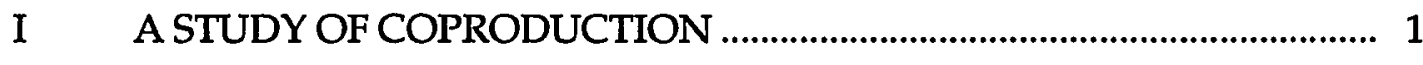

INTRODUCTION..................................................................................... 1

THE CONCEPT OF COPRODUCTION .................................................. 2

Literature Review ................................................................... 2

Toward a definition of Coproduction ................................... 5

COPRODUCTION AND POLICY IMPLEMENTATION ............................... 8

Evaluating Coproductive Policy Implementation................. 10

Coproduction and Policy Implementation

Outcomes ....................................................................................... 14

II MULTIFAMILY RECYCLING POLICY PERSPECTIVES ........................... 18

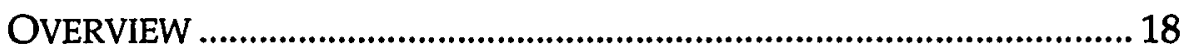

RECYCLING AND PUBLIC POLICY ......................................................... 19

Factors Limiting Policy Success ............................................. 20

Successes with Recycling Policies ........................................... 22

Barriers and Challenges to Multifamily Recycling .............. 24

PORTLAND'S MULTIFAMILY RECYCLING PROGRAM ........................... 28

Background .................................................................................. 28

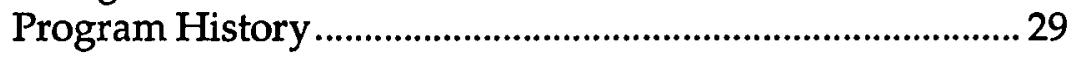

Program structure …………………………………………..... 32

Coproduction Policy Implementation Experiences ............. 32

An Assessment of Coproductive Policy

Implementation .................................................................................. 38

THE MANAGER IN MULTIFAMILY RECYCLING .......................................40

Defining and Understanding the Manager ............................ 40

Conflicting Roles of the Manager ..............................................4 41

Case Illustrations ...........................................................................4 43

The Manager as Citizen Coproducer ...................................... 48 
III A MODEL OF COPRODUCTION AND CITIZEN INVOLVEMENT ........................................................................................ 50

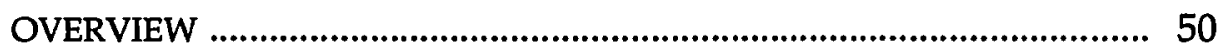

CITIZEN INVOLVEMENT AND COPRODUCTION ................................ 51

Understanding Citizen Involvement................................... 51

Understanding Coproduction ............................................ 54

A Research Design ..................................................................... 56

Research Hypotheses ............................................................... 58

IV RESEARCH DESCRIPTION AND RESULTS .............................................6 60

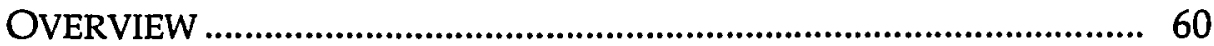

METHOD AND PROCEDURES ............................................................... 60

Research Components and Schedule .................................... 60

Sample................................................................................. 62

Experimental Treatment Description ....................................... 65

Data Collection Methods.......................................................... 67

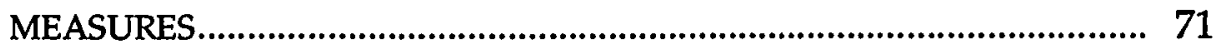

Citizen Involvement .............................................................. 73

Civic Engagement. ..................................................................... 75

Tenant recycling. ….................................................................... 76

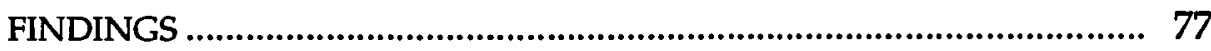

Inclusion and Citizen Involvement ...................................... 77

Volition and Involvement ..................................................... 80

Achieving Program Results. ................................................. 82

Civic engagement and involvement..................................... 87

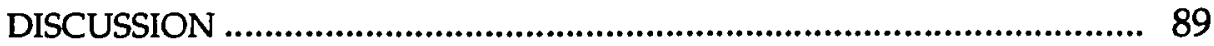

Inputs to Citizen Involvement ................................................ 90

The Programmatic Outcomes of Citizen

Involvement ............................................................................. 92

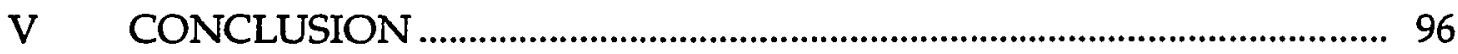

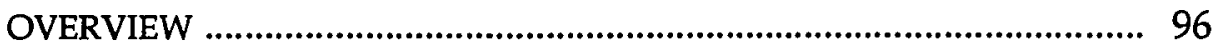

THE THEORY OF CITIZEN INVOLVEMENT AND

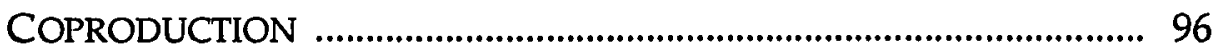

Two Perspectives of Coproduction ........................................ 96

The "Ins" and "Outs" of Citizen Involvement....................... 98 


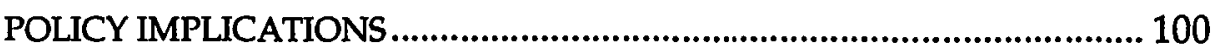

Appropriate Policy Arenas for Coproduction ...................... 100

Citizen Coproducers and Social Roles ............................... 102

Use of Extra Agency Resources............................................. 103

Investment in Citizen Resources ......................................... 104

Mutual Adjustment............................................................ 105

Public Policy and Citizen Inclusion .................................... 106

Coproduction and Community Cohesion ............................ 106

Redistribution of Policy Implementation Resources .......... 108

CHALLENGES FOR FURTHER RESEARCH ......................................... 109

Defining and Measuring Citizen Involvement .................... 109

Inclusion and Volition As Policy Concepts ........................... 110

Building Citizenship through Coproduction ...................... 111

Resolving Uneven Participation ............................................ 112

Institutionalization of Coproduced Efforts ......................... 112

Measurement of Multifamily Recycling Levels ................... 113

REINVENTING COPRODUCTION ................................................. 113

Conflicting Forces in Coproduction ...................................... 114

Generating Civic Agency ..................................................... 117

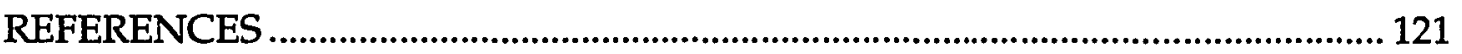

\section{APPENDICES}

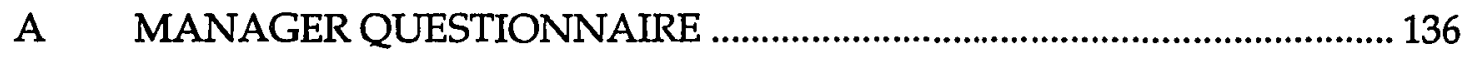

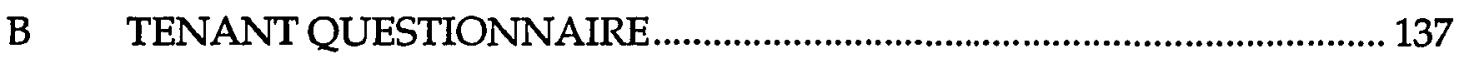

C FIELD OBSERVATION PROCEDURES AND FORMS ......................... 141 


\section{LIST OF TABLES}

\section{TABLE}

PAGE

I RESEARCH COMPONENTS AND SCHEDULE 61

II INITIAL SAMPLE SELECTION: MATRIX MANAGERS RESPONDING TO REQUEST FOR PARTICIPATION BY SIZE AND RENT RANGE OF COMPLEX

III FINAL SAMPLE MATRIX: MANAGER SUBJECTS SELECTED FOR EACH SAMPLE GROUP BY COMPLEX SIZE AND RENT RANGE OF COMPLEX.

IV LIST OF VARIABLES AND MEASURES 72

V MEAN INDEX VALUES FOR MEASURES OF INVOLVEMENT IN TREATMENT AND CONTROL GROUPS.

VI MEAN INDEX VALUES FOR MEASURES OF INVOLVEMENT IN CONTROL AND NON-VOLUNTARY GROUPS.

VII CORRELATION COEFFICIENTS OF MANAGER INVOLVEMENT MEASURES AND RECYCLING MEASURES.

VIII MEAN INDEX VALUES FOR MEASURES OF COMPLEX RECYCLING BEFORE AND AFTER EXPERIMENTAL TREATMENT.

IX MULTIPLE REGRESSION ANALYSIS OF RECYCLING PARTICIPATION IN MULTIFAMILY RESIDENTIAL COMPLEXES 86

$X$ CORRELATION COEFFICIENTS OF MANAGER INVOLVEMENT AND MEASURES OF CIVIC ENGAGEMENT. 87

XI MEAN INDEX VALUES FOR MEASURES OF CIVIC ENGAGEMENT IN TREATMENT AND CONTROL GROUPS 88 


\section{LIST OF FIGURES}

1 COPRODUCTION POLICY IMPLEMENTATION INPUTS AND

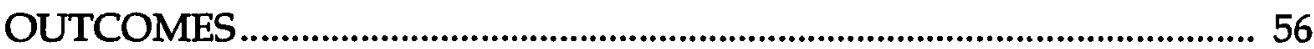

2 RECYCLING IN MULTIFAMILY COMPLEXES: A MODEL OFCOPRODUCTION .................................................................................... 58 


\title{
CHAPTER I
}

\section{A STUDY OF COPRODUCTION}

\author{
INTRODUCTION
}

This study is on coproduction as a governing policy instrument. Coproduction can be understood as the joint production of services by local officials and individual citizens intended to raise the quality and or amount of service provision. The concept of coproduction as developed in this study suggests that urban services are not simply created by officials and delivered to a passive public. Rather that actions of citizens are an integral part of the service production process.

The focus within this study is on the importance of citizen involvement in the delivery of public services. The central question of this research concerns whether citizens can and do influence the content and performance of public programs through their direct participation in the provision of service.

Specifically, the intent of this study is two-fold: (1) to construct a model of coproduction which provides a basis by which citizen involvement in the provision of public services can be fully understood and appreciated; and (2) to examine the usefulness of this model by using it to frame and guide evaluative research on a specific program which targets coproductive participation of citizens. The research conducted in this study utilizes experimental controls to examine efforts to implement a program to encourage recycling by residents in 
multifamily complexes in the City of Portland by involving the direct participation of the managers of the complexes.

\section{THE CONCEPT OF COPRODUCTION}

\section{Literature Review}

In the last decade there has been emerging interest in a set of solutions to urban problems that are focused upon the idea of coproduction. Though coproduction programs have arisen in response to a host of specific problems in one municipality or another - from police protection, to the quality of schools, to municipal solid waste -- coproduction has been of interest to scholars for its potential as a major transformation of the urban political process itself (Percy, 1984; Sundeen, 1985; Thomas, 1990)

Coproduction as solution to urban problems has had its cynics, however. The most cynical critics of coproduction view it as one more expression of a growing impulse on the part of conservative political regimes to transfer public responsibilities to the private individuals (Moe, 1987; Morgan and England, 1988). Such critics question whether or not it is simply an attempt by financially strapped governmental agencies to shift costs of providing services to the voluntary (unpaid) labor inputs of citizen-recipients. A corollary to such criticism would argue that the same citizens might be blamed if services "fail," even though the government agencies had been unable to deal adequately with the problems--a variant of "blaming the victim," (Ryan, 1976).

A second less critical but nonetheless skeptical view, might see coproduction as simply a new label for old ideas, policies, and programs popular in the sixties that emphasized the ideal of local participation in program 
definition and delivery (Hasenfeld and Brock, 1991). Though much of the body of liberal programs has died in the onslaught of the "tax revolts," the ideals that underlay them may now be resurrected in new "clothing" more fashionable to the times.

The proponents of the possibilities of coproduction, on the other hand, point to the possibilities of the concept. Coproduction has been viewed as an important way in which municipal governments can not only be more cost efficient in the delivery of services but also more effective (Brudney, 1984; Sharp, 1980). This is especially true in programs designed to change human behavior (Sundeen, 1988; Percy, 1983; Rosenstraub \& Sharp, 1981).

Other researchers have suggested that coproduction promises to be key in eliminating the relatively low levels of public trust for officials and public institutions, as well as the enduring public resistance to greater government extractions of revenue to address a host of pressing policy challenges (Wilson, 1981; Levine, 1984, Thomas, 1990). In this regard, coproduction is believed to be a promising tactic in both the devolution of policy responsibility and the improvement of government performance.

An additional area in which coproduction holds promise is in the political process itself. Deborah Stone, in differentiating between two models of society, the market and the polis, asserts: "Public policy is about communities trying to achieve something as communities. Unlike the market, which starts with individuals and assumes no goals, preferences, or intentions other than those held by individuals, the polis must assume both collective will and collective effort... (as such) the polis is characterized by a special problem: how to combine self-interest and public interest, or, to put it another way, how to have both private benefits and collective benefits." (Stone, 1988: 14-16). In this view, 
members of society are regarded as more than mere economic individuals acting solely out of self interest.

A second related strain is a body of literature which has concerned itself with the engagement of citizens in matters of public life. Citizenship involves community attachment and matters of public interest (Thomas, 1990; Berry, et al., 1993). Coproductive efforts hold promise as a vehicle for individuals to not only receive private benefits but also to express citizenship and relate to broader community values and interests.

Another even more profound impact can be the result of coproduction as an expression of civic engagement. Commenting on what he sees as the need for a "resuscitation of the political dimension of citizenship," Harry Boyte (1989) calls for a kind of citizenship that implies an active sense of agency, one that is characterized by problem solving and engagement in public life. Citizens in this sense are more than a mere instrument to be used by the machinery of government; they are the machinery of government. Such a view adds much richness and depth to citizen's roles in coproductive implementation strategies.

This study emanates from the belief that coproduction is an important, though relatively undeveloped, concept. Though there has been some attention in the literature given to coproduction there has not been much attention to the potential promise that coproductive efforts can have, not only on the improvement of government performance in the provision of services, but also on the enrichment of the political and community building processes. In addition, there has been little empirical study done to substantiate the value of coproduction as a policy instrument. By furthering the conceptual development of coproduction and linking with empirical research, our understanding of the 
possibilities and potential problems of coproduction will be enhanced, benefiting both the academic as well as the practitioner.

\section{Toward a Definition of Coproduction}

The literature on citizen coproduction has emerged in the past decade largely as the result of theoretical and empirical analyses of urban service delivery. Though there is general consensus in the literature that coproduction involves the recognition of the importance of citizen productive efforts to the effective provision of many urban services, there are varied views put forth by urban scholars on a precise definition of the concept.

Among the first scholars to use the term "coproduction" were Vincent Ostrom and Robert Bish who used the concept in discussions of the relationship of public goods to institutional arrangements for the delivery of urban services (Ostrom and Bish, 1977). Interest in coproduction has been stimulated by empirical examinations of urban services that showed citizens to be actively engaged in many forms of productive contributions to service provision. The actions of citizens can be seen in this light to represent productive inputs, not mere service consumption.

From this recognition of the varied production potentials of those traditionally viewed as "consumers," scholars have sought to develop precise definitions of citizen coproduction. To date, a variety of definitions have been offered.

One definition has been developed at the Workshop of Political Theory and Policy Analysis at Indiana University. Central to the definition of coproduction offered by this group is a distinction between consumer producers and regular producers: the former undertakes productive efforts in order to 
consume more service outputs, and the latter trades produced outputs for other commodities, such as profits or political support (Parks. et al., 1981).

Governmental agencies that produce local services are viewed as regular producers in this context. Coproduction is said to result when both consumer and regular producers undertake efforts to produce the same good or service. There is no requirement in this definition that productive efforts be taken through direct interaction of regular and consumer producers, only that their actions be undertaken more or less simultaneously.

Some urban scholars prefer broader definitions of coproductive behavior. Whitaker (1980) takes the view that many types of interactions between citizens and service agencies should be recognized as coproduction. He would include citizen demands for services, citizen provision of assistance to service agencies and interactions between the two that adjust expectations or actions as instances of coproduction. Whitaker's definition is broader than the previous one in that it encompasses not only citizen productive involvement, but also efforts to enhance service consumption and influence policy-making relevant to service delivery. Coproduction is viewed in this definition to occur in a comprehensive arena of interaction between service agencies and citizen providers.

Another definition is offered by Rich (1981) who sees citizen coproduction as the combined efforts of citizens and service personnel that affect the quantity and quality of urban services. Rich distinguishes between actions that increase service levels and those that detract from them, while counting both as coproduction. He would include both cleanup efforts and littering as types of coproduction of community cleanliness. This definition is broader than others in that it includes citizen actions that harm service levels. 
Still other urban researchers prefer a narrower definition of service coproduction, limiting coproduction to instances of direct cooperative involvement by citizens and employees or service agencies in the production of services. Mlustrative of this approach is the definition offered by Warren, et al., (1982: 43) "Coproduction is defined as those actions by citizens which are intended to augment or contribute to the actions of public agencies and involve conjoint behavior." Not included as coproduction are the civic actions normally associated with citizenship (auxiliary production) and actions taken by citizens totally separate from service agencies (parallel production).

Each of the definitions reviewed above, though differing to some degree in their emphasis and scope, share some common properties and provide a starting point for the conceptual development of coproduction for this study. These common elements are as follows:

1. Coproduction involves private citizens as producers of service. As such, citizens are important contributors in the program implementation process.

2. Citizen participation in service delivery is performed on a voluntary basis. As such, citizen participation in service delivery which is done involuntarily (for example, community service by sentenced offenders) is not considered with this view of coproduction.

3. Coproduction involves interaction between the citizen and the public agency in the service delivery functions. Responsibilities for service delivery are therefore seen to be mutual and conjoint. As such, coproduction is distinguished from privatization in which the service 
production is assigned to the private citizen with little, if any, continuing responsibility by government or direct interaction between the two.

4. Coproduction involves citizen, or consumer, provision of service for public benefit. Though there is frequently private benefit received by the consumer/producer, the measure of coproduction is in the measure of resulting public benefit.

5. Coproduction involves mutual accommodation. Thus, coproduction involves an appreciation and willingness to adjust behavior to comply with the respective roles played by both public agency and citizen provider in service production.

Fundamental to each of these common elements is the involvement of citizens in public policy implementation. Coproduction is essentially different from service implementation models which emphasize services being produced in strictly the public or private sector. Determining the differences between coproduced services and these other models of service production is an important consideration which is examined in the following section.

\section{COPRODUCTION AND POLICY IMPLEMENTATION}

In moving away from viewing the citizen merely as a consumer of public services, the implication of the coproduction concept for government directed change is an important element in the study of coproduction. Rather than viewing government to be the exclusive agent of change, government is instead seen as an agent that motivates or inspires individuals to adopt behavior in conformity with public goals as well as includes their inputs to the policy process. 
Richard Elmore (1987) identified four clusters of government policy instruments: mandates, inducements, capacity-building and system changing. As Elmore (1987: 175) asserted, "Certain types of problems predictably bring into play certain responses from policy-makers: these responses, which we call instruments, entail certain operational characteristics, as well as certain distinctive design and implementation problems..." In actuality, most problems are dealt with by a mixture of these instruments although in some cases one type of instrument will be more prominent (Fosler and Berger, 1982; Salamon, 1989; Salamon and Lund, 1989; \& Waste, 1989). Max Neiman (1988) notes that when regarding aspects of human behavior in "everyday life" as in the case of driving habits, dietary and health patterns and waste disposal there is often great resentment at the use of mandates to alter them. In democratic societies, especially one like the United States with a strong tradition of privatism and resistance to government intervention in personal life (Savas, 1977), the tools and methods available for affecting the array of behavior that comprises everyday life are quite limited. Very often non-coercive, voluntary approaches are those upon which government tends to rely. As such, inducements and capacity building instruments are largely in the nature of coproduction-like actions.

It is the arena of everyday life where the instruments of inducements and capacity building, as well as the concept of coproduction converge. However, as Brudney and England (1983) pointed out, coproduction might occur at insufficiently low levels when left strictly to individually motivated forces, thereby not producing satisfactory aggregate changes. They and others (Rich, 1981; Parks, et al., 1981) have distinguished between individual coproduction (the free, unallocated, non-stimulated completely free market level) and 
collective coproduction (the level of citizen produced behavior stimulated by government actions). Collective coproduction arises from government actions in the inducements and capacity building categories and not the mandates or systems changing categories. Moreover, collective coproduction, while generated by individuals, often for self-interest reasons, produce benefits for the public. As in the case of the subject of this study, a program designed to promote recycling in multifamily complexes, may generate private benefits for the owners and managers (e.g. lower garbage bills, new equipment, etc.); it also produces community benefits in the form of waste and pollution reduction, conservation of resources, need for fewer and smaller land fills, etc.

\section{Evaluating Coproductive Policy Implementation}

Coproduction can be assessed in terms of both the implementation process and the resulting programmatic outcomes. As implementation researchers have noted (Goggin, 1984) the characteristics of the implementation process are not to be confused with the product of what happens as a result of implementation. Implementation performance should be divorced from its consequences, or its programmatic performance (Bardach, 1977; Ripley and Franklin, 1982; Mazmanian \& Sabatier, 1983; Goggin, 1987). Thus, the study of policy implementation must concern both the inputs and outcomes of efforts to achieve programmatic results. In this study, coproduction implementation will be viewed along both lines of inquiry: the important factors which are involved in a coproductive implementation process and the important factors that contribute to the results or programmatic outcomes of that process.

The distinguishing feature of coproduction policy implementation is the shared role and responsibilities between the government and the citizen service 
provider in the delivery of public goods and services. Appreciating and understanding the factors that contribute to the involvement of citizen providers is therefore key to guiding efforts to evaluate a given coproduced program implementation process. The study of coproduction, as well, holds promise for new perspectives on the policy process. But involvement of citizens directly in the implementation process itself not only contributes new perspectives, it raises some difficult questions which add to the debate of many fundamental issues that have existed among policy implementation researchers for some time. The following section reviews those issues and examines how coproductive policy implementation can enrich and challenge our understanding and appreciation of the policy process in a democratic society.

"Top down" vs. "bottom up." The notion of a rigid dichotomous distinction between policy making and policy implementation has for the most part been abandoned and replaced with more realistic assessments that policy continues to be made during implementation. There continues to exist, however, the debate among implementation researchers as to the direction from which policy gets made or changed (Sabatier, 1987; Linder and Peters, 1987). This debate is over the validity of what has been referred to as the "textbook policy process" (Nakamura, 1987). In this view, characterized by Harold Lasswell $(1956,1963)$, policy is viewed as emanating from elected public representatives and implemented by official agents. As such, the policy process is seen as sequential, differentiated by function and cumulative.. Challenging this notion have been those that view the actual policy process, at least in some policy arenas, as not nearly so orderly (Weiss, 1982). Martin Rein (1983:128) notes, "The (policy) process is not one of graceful, one-dimensional transition from legislation to guidelines and then to auditing and evaluation. Instead it is 
circular or looping." In these cases, policy is viewed as being shaped by the implementation process in which policy participants exist in a much less bounded and fluid world (Kingdon, 1984; Nakamura, 1987). Policy from this perspective is seen to be more of a "bottom up" process as opposed to a "top down" one. Much has been written regarding the descriptive accuracy as well as the normative implications of both views. Suffice it to say, different policy arenas offer challenges and barriers in which both views have relevance and importance. In considering the means of coproduction, however, each perspective evokes different roles and meanings for citizen involvement. Therefore, the extent to which citizen involvement in the implementation process contributes to the entire policy process is a matter of key importance to the debate and a matter of central concern in this study.

Adaptation and change. Even the most arduous supporters of the classical conception of the policy process acknowledge that policy change during implementation is necessary. Recognizing that the context in which policy is made is frequently different than when implementation occurs, most would agree that change and adaptation are the expected outcomes of implementation and the norm in contemporary policy-making. Further, as Charles Fox (1987: 130) contends, "if mutual adjustment, compromise and accommodation are judged to be democratic in the legislative policy making sphere, there is no reason to deny a similar accolade to the implementation sphere." But in such a process, a tension exists between adapting to needed changes during implementation and maintaining accountability in the implementation process. As Dennis Palumbo (1987: 99) puts it, "Unless we can show how implementation agencies can be held accountable when this (change) occurs, we will not have an adequate theory of implementation...(Such a theory) 
must explain what kinds of changes are likely to occur during implementation and how citizens can influence the direction of these changes in a democracy." Thus, understanding and addressing accountability in the policy process remains a matter of paramount concern in implementation research.

Accountability. Michael Lipsky (1980: 160) maintains that public agent accountability is determined in terms of both whom the agent is accountable to and how the agent behaves in compliance to their expectations. By these standards, "top down" views of the policy process admittedly have the advantage of clarity: simply conceived, implementors are accountable to those who make the policy and for achieving explicit policy expectations. With the blurred distinctions invoked by needed forces for policy change and influences emanating from "bottom up" perspectives, the matter of accountability is considerably complicated (Ferman and Levin, 1987).

The coproductive policy process adds a new dimension to the problem of adequately maintaining accountability while allowing for needed policy changes. Whitaker (1980) notes that citizen coproducers are important in influencing policy by both their demand and provision of services. Coproduction increases the interaction between citizens with the personnel of service agencies. This interaction may provide service agencies with greater information about the service needs and concerns of citizens, and may allow them to adopt strategies to bring service pruduction more in line with citizen needs. In this way, coproduction provides an expanded arena but a more direct process in which agency accountability can be measured. Such citizen inputs within the implementation process both enhance policy understanding and inform needed changes which are essential in determining and measuring accountability. Such a process makes policy adaptation more feasible as well as 
potentially more accountable. Since ultimately public policy in a democracy arises from and is accountable to the citizenry, coproductive processes enhance the policy process with increased public involvement.

But other possibilities within coproductive efforts keep the dilemma of accountability in public policy implementation in focus. Observers of coproduction have expressed concerns that higher levels of direct public involvement obscures accountability by diffusing and possibly diverting the needed accountability of government agents (Morgan and England, 1988). Others have noted collectively coproduced benefits can potentially devolve to only those likely to respond to government provided inducements and capacity building programs. In addition, those benefiting from the higher, collectively coproduced benefits may well be already the better off (Neiman, 1988). Such possibilities necessarily keep concerns about accountability within the implementation process well founded.

Thus, the study of coproduction as means of policy implementation provides important opportunities for viewing and potentially clarifying troublesome questions debated by the researcher and faced by the practitioner. Coproduction also introduces some new dilemmas. In this study, features which are inherent to the policy process under examination will be assessed with an eye toward the forces which can potentially add clarity to these troublesome issues that have fueled debates within policy research.

\section{Coproduction and Policy Implementation Outcomes}

In summarizing the scholarly work on citizen coproduction, Percy (1984) suggests a set of propositions relating citizen coproduction to service outcome. 
These propositions are as follows: (1) Coproduction is positively associated with higher levels of urban services provided in the community; (2) Coproduction is associated with lower budgetary costs for provision of current service levels; (3) Coproduction increases citizen knowledge of service technology and self-assurance that their actions can make a difference; (4) Citizen coproduction of services may increase other forms of citizen participation. These propositions provide a basis by which to approach the evaluation of the outcomes of coproductive implementation efforts.

Program effectiveness. Inherent to the proposition that coproduction leads to increased program effectiveness is the notion that direct citizen participation in service can provide inputs to the delivery of service which not only increase the number of inputs but are also in some ways superior to that which can be provided by public agents. Citizen inputs and cooperative involvement have been seen to have the strongest effect in those services aimed at transforming human beings or their attributes (Percy, 1983; Brudney and England, 1983; Sundeen, 1985; Ferris, 1986; Brudney, 1990). Important to this dimension is the quantitative contributions that citizens make in the provision of service.

Program efficiency. Some advocates of coproduction see citizen efforts as a means of reducing the costs of producing urban services. Budgetary costs are reduced to the extent that paid personnel are replaced by "free" citizen volunteers. Rich (1981:60) argues that "if seemingly small savings from active coproduction can be realized across different city services, the lowered costs constitute a substantial boon to the city budget." While budgetary savings may result with citizen coproduction, it is clear that there are limits to the extent of savings that can be realized. Budgetary savings are limited by both the costs of 
supporting the involvement of citizen coproducers in service production and also by the transfer of monetary, time and opportunity costs (Brudney, 1985). Thus, consideration of both the costs and any savings realized in achieving the desired coproduced program result becomes important.

Community Involvement. Direct participation by citizens has been seen as an important indication of attachment to community (Capek and Gilderbloom, 1992; Steinberger, 1984; Sundeen, 1985; Berry, et al., 1993). Robert Bellah et al., (1985) characterize two cultural value strains present within modern society: the culture of separation and the culture of coherence. The authors go on to note that though much of the driving force behind modernity is found in..."individuation and separation, (however) we have never been, and still are not, a collection of private individuals. Rather, human beings and their societies are deeply interrelated, and the actions we take have enormous ramifications for the lives of others." (Bellah, 1985: 282-84). Recognizing this interrelationship between ourselves and society and acting accordingly is the essence of community and an important dimension to be considered as an outcome of coproductive efforts.

Civic Engagement. Participation in the production of services, or what Harry Boyte (1993: 19) calls "the practical work of agency and civics," has been considered by many to be the true basis of citizenship. Citizen involvement in service production provides experience and knowledge about the dilemmas and opportunities associated with community problem solving. This knowledge may lead to greater appreciation by citizens of government agents and to greater citizen agent cooperation, not only through coproduction but other expressions of public life. It has been suggested, as well, that coproductive involvement in service delivery may lead citizens to engage in other forms of participatory 
behavior related to local governance (Percy, 1984; Thomas, 1990). Wilson (1981) argues that coproductive involvement with service agencies provides citizens with the opportunity to monitor the activities and performance of service agencies. The knowledge gained and assurances that citizen produced services can make a difference contribute to the sense of empowerment, or efficacy, that the coproducer may have. Thus, an appreciation of the measure of citizen participation is an important dimension by which coproductive efforts can by evaluated.

Framed within these perspectives is the proposition which serves as a guide to this study: that coproduction is a key policy instrument for government both in its instrumental role of providing services in an efficient, effective and accountable manner and in its integrative role of fostering citizenship and community coherence. The next step in this study is to consider the specific issues and policy components which shape the coproductive implementation process and outcomes found in the City of Portland's multifamily recycling program. 


\title{
CHAPTER II
}

\section{MULTIFAMILY RECYCLING POLICY PERSPECTIVES}

\author{
OVERVIEW
}

To approach an understanding of the City of Portland's multifamily recycling program, one must first address the dominant considerations pertinent to both the policy content and implementation process within this program. First of all, the program addresses recycling within multifamily residences as a means of solid waste reduction within the City of Portland. As such, it is useful to examine the body of literature and informed experiences which contribute to an understanding of the important factors which influence recycling behaviors. For this study of special interest as well are the unique situational factors that exist within multifamily residential settings. Secondly, the program is built on a model of coproduction which involves the partnership between the implementing agency and multifamily building manager. As such, an understanding and appreciation of the parties to the partnership and the issues that both enhance and constrain the participating partners in that process is useful.

In this chapter, each of these elements will be examined with an eye toward the features which hold promise for enriching our understanding of coproduction as a policy implementation strategy. Specifically, the topics covered in this chapter include the following: (1) an examination into factors which contribute to recycling participation and policy level responses in 
addressing those factors in multifamily residential settings; (2) a review and analysis of the experiences which have informed and guided Portland's efforts to adopt coproductive program strategies in the city's program; and (3) a profile of the multifamily building manager as citizen coproducer in the City's multifamily recycling program.

\section{RECYCLING AND PUBLIC POLICY}

Household recycling has received much governmental and media attention in recent years. This attention is in large measure the result of what is perceived to be a crisis in the amount of solid waste generated in urban communities in this country. Though there is considerable disagreement over the exact amount, estimates of solid waste disposed annually by each individual in this country is over one ton (Rathje, 1992). The dramatic rise in the amount of waste generated combined with the rapidly filling existing landfills and increasing difficulty to site new ones, has resulted in what is perceived to be a "garbage crisis." This "crisis" has been the basis for much legislative activity.

Several states have enacted legislation which require local jurisdictions to initiate waste reduction and recycling efforts within their jurisdiction. California and Oregon, for example, have recently passed legislation requiring local jurisdictions to reduce their waste to mandatory levels. Recycling has been one of the most important strategies in municipal waste reduction efforts. Many jurisdictions have turned to curbside residential recycling collection programs and have focused on households and residential waste as prime targets to achieve these solid waste reduction goals. A brief examination of factors which 
have had an effect on the level of success in these efforts is discussed in the following section.

\section{Factors Limiting Policy Success}

As much attention as recycling has received, policy makers who target increased recycling participation found themselves frequently in an allusive and difficult policy arena. The reasons for this are principally centered on three inherent factors which have proved to limit the success of public policy efforts to increase recycling.

Recycling as everyday behavior. Recycling has been referred to as "everyday activity" (Vining and Ebreo, 1990). In this realm of behavior most researchers agree that personal motivation is critical. Government success in motivating and/or changing personal behaviors has long been problematic. Similarly, policy options requiring recycling are as suspect in effectiveness as they are difficult to enforce.

"Government's problem." In addition to the problem of government trying to change personal behaviors, are the contradictory sentiments frequently found within the citizenry. Though the activity of recycling requires individual effort, there is a widespread sentiment among many that works in opposition to public solutions. Stern, Dietz, and Black (1986) found that many people hold the government responsible for solving certain kinds of collective problems (including environmental problems), and such a belief can be employed by individuals to justify their own inaction. A different but related problem exists with the promotion of recycling behaviors. Though there has been an increased attention to environmental concerns and a general increase in stated willingness from a large element of the population to help the environment, research has 
shown a relatively low correlation between environmental attitudes and behavior (Vining and Ebreo, 1990). Frequently on these issues, there is more verbal commitment and less actual follow through.

Lack of extrinsic reward. Raymond De Young (1986) and others (Katsev and Pardini 1988) have demonstrated that there is little reward to the participant recycler and have examined the value of extrinsic rewards in promoting recycling. In this research there is little to suggest that extrinsic rewards for this activity can be anything but marginally effective and are temporal to the reward itself. The relatively poor markets for recycling material and the general inability of most municipal governments to financially subsidize this activity at a meaningful level, limits greatly what rewards and inducements the local jurisdictions can attach to these activities.

In addition, there are other issues inherent in recycling behavior which limit the ability of local government to affect. Research has demonstrated that the influences on one to recycle are for the most part indirect. Infrequently do community members directly witness much less experience the pollution and problems associated with waste disposal. For the individual to be concerned with lessening these problems, they must connect to a broader community context -- this is a global activity with little direct benefit to the individual. In this sense, recycling can be somewhat viewed as a form of altruism (Hopper and Nielsen, 1991).

Thus, the problems faced by policy makers and those responsible for implementing programs promoting recycling behaviors are sizeable and are frequently at arm's length from government intervention. In spite of the difficulties encountered, however, there have been some successes. Research 
into the reasons for success have discovered some key ingredients to success which are reviewed below.

\section{Successes with Recycling Policies}

As previously noted, recycling is an activity done with a broader context. Many of these elements government can address. Some of the contextual factors that have been cited in research to limit recycling participation include lack of requisite information or skills, the amount of personal effort and inconvenience involved, minimal or delayed rewards, and lack of social support approval for pro-environmental behaviors. (Lipsey, 1977) Examples of policies which have enjoyed success address these contextual issues (Reid, et al., 1977).

Convenience: Curbside recycling collection programs have a short but impressive history. Much of the success of these programs are attributed to the increased convenience of being able to place household recycling at the curb (Luyben and Bailey, 1979). The importance of convenience to this success is underlined by research which has demonstrated that even the increased convenience of having collection of the recycling bin and the garbage collection on the same day can make a dramatic difference in recycling participation (Glenn, 1992). Overall, factors which contribute to making recycling convenient, are consistently noted as the most important situational influence on the behavior (Folz, 1991a; Byrd, et al., 1989; Reid et al., 1976).

Social Modeling: The influence of social support for pro-environmental activity has been proven to be important in determining recycling behavior (Burn and Oskamp, 1986). In this regard, the curbside collection program initiated by local jurisdictions has established a positive and reinforcing inducement for recycling (Vining and Ebreo, 1989). By neighbors putting 
recycling bins out at the same time of the week (i.e. collection day) the visible display of community support for this activity has been suggested to have an important influence on the desire and motivation to recycle.

Community Support: Closely related to social modeling as an inducement of recycling is the influence that demonstrations of general community support have on individual recycling. Research on the effectiveness of neighborhood associations in promoting recycling has been demonstrated to be effective in the promotion of recycling. Such themes as taking pride in one's community and doing one's part have been the keynote for many public supported efforts to increase recycling.

Efficacy and recycling. Similarly, a high sense of personal efficacy with regard to helping to solve environmental problems has been found to be positively related to pro-environmental behavior (Huebner and Lipsey, 1981). Knowing or feeling that one can make a difference in solving problems such as the "garbage crisis" appear to contribute to recycling participation. Public education programs have been designed to raise personal efficacy by increasing the understanding of how individual wasting behavior not only contributes to the problem but is the key to the solution .

Financial Incentives. Though the use of extrinsic rewards to induce pro environmental behavior has enjoyed limited success, there is to some extent an increased motivation for recycling when reinforced with such incentives (Katzev and Pardini, 1988). The most important successes in this area have been to place deposit fees on items for recycling, where the purchaser of an item pays up front for the container and is refunded for the deposit on return. The success of this approach has even extended in some European communities to include such items as large appliances and even cars (Resource Recycling). As much 
success as this approach has had, there is the disincentive for increased transaction costs which limit the applicability of such an approach.

\section{Barriers and Challenges to Multifamily Recycling}

This study examines strategies to increase the recycling participation in households within multifamily residents. As such, an examination of situations faced by residents in multifamily housing can help demonstrate problems confronted by programs which address recycling in these settings. A number of case examples of tenants' experiences and perspectives that have been encountered over the course of this study will be cited to help illustrate the barriers and opportunity in multifamily recycling.

The issues associated with recycling in multifamily housing are somewhat unique (Katzev, et al., 1993; Blake, et al., 1991; Yuhas and Hyde, 1991). Unlike single family dwellings, multifamily units contain a number of barriers that often make it difficult for individuals to recycle. Many factors which have contributed to success in single family residences are either missing or are not sufficiently present in multifamily settings to achieve success in recycling. Living space in multifamily housing is usually limited. Thus, the ability to separate and store recyclables in the living unit is usually a problem. Collection containers are often far removed from the living unit and there is no real financial consequence to a tenant for failing to recycle (i.e. higher garbage fees, etc.). Widely different physical structures and management systems in multifamily complexes require different collection systems and approaches to implementing a recycling program. In addition, the temporality of residence by many multifamily dwellers strain the ability to inform and build patterns of behavior which favor recycling. 
Community support systems within multifamily residences tend to be different from single family residences as well. Recycling as an act of social responsibility is done within other contexts of social behavior. Since the act of recycling for most tenants does not have intrinsic reward (i.e. lower garbage rates passed to them, no revenue from selling the material, etc.) it must be done within a context which links the behavior to broader community or environmental values and/or the shared values of those which comprise one's community. As such, the statement made within the immediate living environment can either reinforce or distract from those values. This is illustrated by the tenant who recently moved to the area and took an apartment in a complex which had a recycling program. Upon signing the lease agreement she was given a recycling "kit." She initially wondered why recycling was such a "big deal" here in this area, unlike what she was exposed to in the area from which she moved. At first she didn't recycle but after witnessing what she interpreted to be everyone else recycling, she began to recycle. A year later she reports herself to be "an avid recycler."

On the other hand, if indeed there is no sense of support in the community in which you live (i.e. the multifamily complex) for personally held values, an adverse affect on recycling can occur. This was made poignantly clear by one tenant who when being interviewed about recycling admitted that they used to recycle, but discontinued when they consistently saw the large amounts of disposable diapers in the refuse dumpster. Commenting that "if people who live here don't care enough about the environment to use reusable diapers, I'll be damned if I'm going to worry about my two or three cans a week that I could recycle." 
The barriers to community within multifamily environments are intensified by the physical location of the complexes. Frequently the residences are in dense commercially zoned areas, where intrusions of traffic, noise and limited residential space limit the amount of social activity and mobility. These intrusions have been demonstrated to have adverse affect on the livability and social cohesion within these environments (Foley, 1980). Living in these environments, though densely populated, can also produce isolation. This is exemplified in the case of the tenant who, when interviewed, confessed to being unaware of the recycling collection system which had been at her complex for over a year and was within 50 feet of the entrance to her apartment. Lack of motivation to recycle was not the issue in that she made special trips in her car to take recyclables to a recycling collection center several miles away.

Other pressures which diminish community and social life within residents of multifamily complex is the result of what has been observed to be the commodification of living space in rented multifamily complexes (Gottdiener, 1985; Harvey, 1973). To render it profitable, living space must be broken up, leveled or "pulverized" into abstract space. In the process, "community" is transformed into "commodity," and life space is transformed into space that is for sale to the highest bidder (Capek and Gilderbloom, 1992). Such a process attenuates the social influences which can contribute to reinforcing pro-social or pro-environmental behaviors (Hormuth, 1991). An expression of this was evident in one tenant response. Distrustful of the manager who was suspected by the tenant of selling the recycling material collected at the complex for a "profit," the tenant disavowed any interest in recycling because they didn't want the manager to "make any more money" off of them than was already being made. 
Just as there are the barriers faced in multifamily residential complexes, so too are there many possibilities that exist in these environments for furthering recycling programs. Though living space is limited, there is frequently space on the grounds for large collection receptacles for recycling material. Such collection systems provide the added convenience of being able to "dispose" of the recyclables in the collection system any time of the day or week. There are the possibilities for prompts and educational reminders for residents in these complexes due to the close proximity of the units and the common spaces that usually exist. This was the case with one tenant who, when interviewed about recycling, reported that they started recycling because they began to feel guilty passing by the recycling collection containers on the way to the garbage dumpster.

Overcoming the barriers and enlivening the potentials for success have been seen by researchers to necessarily involve the manager in large measure (Kambur and Messer, 1992; Yuhas and Hyde, 1991; Wassman, 1991; T'Kach and Schoenecker, 1990; Gruder-Adams, 1990). Attending to and maintaining central recycling collection facilities, providing prompts and educational material for residents, contributing to a positive social and community spirit by countering the community debilitating effects of commodification; these are supports all potentially within the manager's sphere of influence. As such, the direct involvement of managers appears to be a potentially important ingredient in public efforts to increase recycling in multifamily residences. To begin to examine the potential of the manager as a coproducer in this area of public policy, we can turn attention to the City of Portland's multifamily recycling program, which is built on the partnership between the city's implementing agency and the managers of multifamily residential complexes. 
PORTLAND'S MULTIFAMILY RECYCLING PROGRAM

\section{Background}

The multifamily recycling program operated by the City of Portland offers a number of opportunities to examine the possibilities and limits of coproduction. The program is in many ways a model of coproduction: the participation on the part of the citizen provider is voluntary; the role played by the agency and the manager is mutual and conjoint toward the ends of promoting recycling; and the program promises a mixture of private and public benefits. There were, however, a number of limiting factors which have been faced by the City in their efforts to develop and implement such a program. Experience in working with multifamily managers in policy arenas was limited. The role played by the manager in contributing to the tenants living environment which promotes or detracts from collective behavior was for all intents and purposes not fully known or appreciated in policy arenas. Applied research to inform policy in this regard was scarce. Though differences in social and political behavior of renters and managers has been noted (Gilderbloom, 1985; Gilderbloom and Appelbaum, 1988; Capek, 1989) little research has been conducted on how social and political participation of renters are affected by managers of multifamily complexes. Therefore the city's initiation of a policy implementation strategy which focuses on multifamily recycling and the manager as citizen coproducer was a venture into relatively uncharted territory. Reviewing the history, content and structure of the City's program as well as examining the experiences of those that have shaped the program will provide 
insights into the important issues pertinent to coproductive efforts in such a policy arena. These topics will be discussed in the following section. Much of the information for this section was generated from interviews and discussion from key staff and policy level personnel within the City's department that oversees the program.

\section{Program History}

Efforts to start a multifamily recycling program began in 1988 with a study to determine the barriers that existed to successful recycling programs in multifamily complexes. The study was needed according to the city's recycling program manager for two reasons. First of all, there was interest in extending the residential recycling program to include multifamily residences as part of the overall city's efforts to expand recycling and lower the city's solid waste stream. Secondly, there was the recognition of the potential barriers that are faced in multifamily complexes that were needing to be overcome if recycling was to be successful in these settings. The study examined multifamily complexes and surveyed managers and tenants to determine what problems and possibilities for recycling were in multifamily complexes throughout the City. Based on the study, a "demonstration" project was begun in 1989 when a large multifamily complex was equipped with containers for recycling and tenants were given educational materials on recycling.

An evaluation of the demonstration project yielded two important conclusions. First of all, many of barriers that exist in multifamily complexes could be overcome and a successful program could be implemented in most if not all complexes. Secondly, cooperation with the manager was an important element in both overcoming barriers and in having a successful program. Both 
of these findings were consistent with some of the initial results of other programs in other jurisdictions that were initiating multifamily recycling programs (Hormuth, 1991; Yuhas and Hyde, 1991).

Based on this information the City developed an initial program which included the purchase of recycling equipment which would be made available free of charge to the owners of multifamily complexes to help begin recycling in their complexes. Provision of this equipment was predicated on an "owner release agreement" by which the owner agreed to properly utilize and care for the equipment. Also, the city offered technical assistance to managers to assist them in siting the equipment and educating the tenants on recycling.

Though the first two years of the program were not referred to as a pilot program, in the view of the City staff manager, the program was still an extended survey of how to achieve success in multifamily recycling. The program at that point in time was not viewed as a long term program to equip all multifamily complexes with recycling equipment. In fact, according to one administrator, if the staff had submitted a plan to the City Council at that time for a multi-year program to have all of the 3000 multifamily complexes equipped with city provided equipment, approval would have "most certainly been impossible."

In 1992, three years from the beginning of the program, city staff initiated an evaluation of the program with the intent being to finalize a City policy for multifamily recycling. The need for such a policy was driven by a number of developments. First of all, the State of Oregon had passed legislation for a statewide program to reduce the amount of solid waste and increase recycling and required cities to adopt waste reduction and recycling strategies which included multifamily residences. Secondly, the city had just implemented a city-wide 
curbside recycling collection for single family residences and there was growing pressure for multifamily residences to be included. In addition, a newly hired administrator in the city bureau which administered the program was interested in reviewing program policies and developing policy rationales for all the programs in the solid waste department. This was done to "solidify" future directions for the City's solid waste reduction strategies. As a result city staff prepared a policy for the multifamily recycling program to be reviewed and approved by City Council.

The policy developed by staff was based on the following premises: (1) that residents of multifamily complexes should have equal access to do recycling as residents of single family residents; (2) that recycling programs implemented in multifamily complexes should meet certain program standards of collection equipment, collection services and resident information which were determined to be appropriate for multifamily complexes; and (3) that the City should provide the necessary equipment and assistance to start the program in complexes in which managers agreed to maintain the equipment and promote the program to the tenants in exchange for the support received from the City. The agreement between the City and the manager detailed the joint responsibilities of each party.

The policy to continue the provision of recycling collection equipment to all multifamily complexes in the city's service area as amended by the policy plan developed by staff was approved by City Council. Thus, what began as a pilot project to demonstrate the possibilities of multifamily recycling became a city-wide program with the objective of a universal program throughout the entire city. 


\section{Program Structure:}

The principle responsibility for implementation of the multifamily recycling program is with the Solid Waste and Recycling Division within the Bureau of Environmental Services. Staff for this program includes one program planner who is the principle staff for the operational details of the program and a program manager who was initially responsible for overseeing the program, but has spent a decreasing amount of time on the program and places a great deal of responsibility and credit for the program on the incumbent program planner position.

From the beginning of the pilot program, the City contracted with Portland State University (P.S.U.) to assist in program implementation. Specifically, P.S.U. students and faculty, acting as representatives of the City, provide on-site assistance to owners and managers in implementing the program at their complex. This includes working with the managers in identifying the appropriate collection equipment and location within the complex, helping to distribute educational materials to tenants, coordinating collection services with the hauler and assisting with any problems that are encountered by the manager or owner in starting the program at their complex. In addition to providing these services, P.S.U. monitors each complex involved in the program and reports to the city staff on the results of the program.

\section{Coproduction Policy Implementation Experiences:}

The Portland program is built on a coproduction implementation strategy. An essential element of this program strategy is the joint cooperation 
and participation of the manager. This is evident in the very structure of the program. First of all, the manager's participation is voluntary. Secondly, the manager must agree to the terms of the program before implementation. This agreement is documented in an "owner's release agreement" which is required of all managers before the City will approve of the complex to be included in the program (see owner's release agreement as attachment). Lastly, the continued cooperation and participation of the manager is seen to be needed for the program to succeed. The continued participation which is needed is in the form of on-going maintenance of the recycling equipment, facilitation with the tenant and the hauler, as well as promotion of tenant recycling as stipulated in the owner's release agreement. Thus, the manager functions as provider of services to the tenants in cooperation with the recycling agency in an effort to obtain and increase recycling participation and prevent contamination of recycling among the households within the complex.

A closer examination of the elements of the process will yield insights as to forces which shape and contribute to such a coproductive strategy. Malcolm Goggin (1987) suggests four dimensions along which policy implementation processes can be understood: (1) commitment: i.e. what is the will of the implementing mechanisms to achieve the results consistent with the fundamental underlying principles of the program; (2) capability: i.e. what is the skill of those in the implementing mechanism to achieve the results utilizing the implementation strategies of the program; (3) adaptability: i.e. what mechanisms exist for adaptation and accommodation of unforeseen needs and/or new opportunities for success; (4) accountability: i.e. what level of responsibility exist within the implementing mechanisms to account for the program's performance. These dimensions provide a useful structure to review 
the process which is structured around the involvement of the citizen service provider.

Commitment. The basis of commitment for this program is found in two fundamental principles embedded in city policy and expressed by staff. The first is the importance of extending an equal opportunity for recycling enjoyed by single family residences to multifamily residents. The second is the centrality of the manager in the process. These two guiding principles at the core of the program, however, are potentially at odds. The opportunity to recycle is for households, but the control for that opportunity is in the hands of the manager. The commitment to the role of the manager is clear. This is reflected in the assertion by City staff that "the program was intended to put the control in the hands of the manager." This position is consistent with what is considered to be the "guiding inspiration" of the program; namely "to get into the community and empower the people" -- a view which is attributed to the P.S.U. faculty that conducted the original study and was instrumental in getting the City initially involved with this program. But by basing the program on the voluntary participation of managers, there will be some multifamily residential households that are not provided with the opportunities that exist elsewhere due to the unwillingness of the manager to participate. Reconciliation of this conflict is addressed through an aggressive strategy comprised of inducements and capacity building efforts directed toward the manager. Through the provision of durable equipment of considerable value and a program of education, training and technical assistance the city hopes to persuade even the most reluctant manager. But even these do not work for some. At this point there is no serious efforts to make the program mandatory which is further 
evidence of the commitment on the part of the City to the importance of and appreciation for the role of the manager in the program.

Capability. The cooperative nature of the program is reinforced by its very structure. According to the City staff, the equipment which is purchased by the City "is an inducement for participation by the (manager) in the program. But once in the program the (manager) is able to (participate) at a level they choose and from their own perspectives." This results in a "decentralized system" where important decisions on how to run the program within each complex is made by the manager because "they know what they are doing." Though the role of the manager is respected and appreciated there are efforts to "guide" their involvement in several ways: the publication and distribution of "how to" manuals, conducting training sessions and extensive on-site technical assistance. These elements as well as the equipment are viewed not just as inducements to get the program started in the complexes, but to "orient" and "motivate" the manager to the value of having a recycling program. In this regard, staff are quick to point out that the inducements are much broader than just appealing to the potential financial or mandatory elements of the program. Thus, the tools to capably manage a recycling program are actively promoted in the program implementation and are strategically linked with motivation and value building elements to support what is seen to be a long term contribution that managers will make. As summed up by one city staff, "even though the equipment is expensive, the real investment of this program is in the people who will make the difference."

Accountability. With the citizen coproducer comes a new challenge and set of opportunities to address issues of accountability. The City's program to invest in equipment and people largely outside of the "control" of the City, 
redirects many of the principle elements of accountability in more formalized "top down" processes. Though the letter of agreement between the manager and the City reinforces mutual responsibilities, there is no real means to "enforce" the managers participation and subsequent success of the program at their complex. The message given to managers in this program does not stress the potentially mandatory nature of the program. This is done even though there are laws which give the City an opportunity to mandate participation in the program. The principle reason behind this is the perceived need for assuring a voluntary program. Accountability for achieving the objectives of the City and complying with state mandates are thus a mutual responsibility for the government and citizen coproducer. To represent that bond, the City and the manager mutually agree to responsibilities for recycling in the form of an Owner's agreement. Accountability is reflected in another important way within the program. The equipment provided in the program is an essential element of the program. Not just as an inducement to managers to participate in the program but also in the "statement" made by the equipment. The equipment provided is a considerable financial investment on the part of the City. Recycling collection "shelters" cost approximately $\$ 400$ a piece. Larger complexes can be equipped with 10 or more of these shelters. Such costs are justified by what is seen to be an important element of the program. "We want the equipment for recycling to be on a par with the dumpster;" a view offered by City staff to refer to the importance of providing durable and substantial equipment which reflects the "importance" of recycling. Also, there is recognition of the manager's perceived reluctance to equip their own complexes with this quality of equipment if they had to purchase it themselves. This somewhat cynical perspective of the manager's personal motivation is, as has 
been previously indicated, reconciled as the cost of "inducement" to participate in the program. Once in the program the manager is committing to many other obligations and assuming responsibilities for assisting with recycling that are far greater than the costs of the equipment. This perspective is reflected in the observation made by one City staff that the multifamily complex is not defined merely as a way of purchasing and distributing recycling equipment, "it is a program of public involvement." The equipment is merely a starting point. Adaptability. Another important element of the program is the dynamic nature of the program. As noted by one City staff, "the program is never the same two years in a row." This feature of the program is seen to be the direct result of its implementation strategy and design. This dynamic is the result of the two partnerships in the program: the participation of P.S.U. in the program and the cooperation with the manager. From its very beginning, the program has been seen as a designed approach to learning what works and what doesn't in achieving success in multifamily recycling. Key to this strategy is the relationship with the contracting agency. An important role P.S.U. performs in program implementation is research and evaluation. The fact that P.S.U. is an educational institution which is participating in program implementation is seen as an important ingredient in making the program dynamic. As noted by city staff, "contracting with P.S.U. and having students and faculty involved (in program implementation) has resulted in the program constantly being 'researched,' resulting in more attention on program details and ways the program can be improved than if we had contracted with some other type of organization." Changes in the program are also attributed to the feedback from the managers on the program. The interaction with managers from the very beginning of their involvement has provided what is seen as a strong basis for 
making adjustments to the program that have resulted in improvements. This interaction has provided the basis for many changes in the program since its inception. These changes have included modifications in the design of the equipment, the content and form of tenant informational materials, as well as ways to best promote recycling with diverse cultural and special population groups.

An Assessment of Coproductive Policy Implementation

In assessing the different elements of the Portland multifamily recycling program several themes emerge which help guide further examination into the possibilities for coproduction as a means with which to effectively solve community level problems and encourage citizen involvement. As seen in the case of Portland's multifamily recycling program, the issue of citizen involvement dominates the policy landscape. The commitment to involve citizens in the multifamily recycling program flows from other broad based commitments and experiences that the City of Portland has with citizen participation in city programs (Adler and Blake, 1990; Berry, et al., 1993). In the multifamily recycling program, opportunity exists for citizens to not only participate in the delivery of service but also to be involved in decision making and problem solving as part of the implementation process. The importance of this type of involvement is especially important given the potential barriers and problems inherent in implementing a multifamily recycling program. Managers who are in a key position to shaping many of the contextual elements which have been demonstrated to be important in recycling participation potentially make their role as a partner in such a program essential. 
In the City's program many of the opportunities and challenges that are confronted in this policy arena are exhibited. Involving the citizen coproducer at a level beyond a mere instrument of delivering a predetermined service but empowering the coproducer to direct the program is an important element of the program. Empowered positions within the citizenry come at a cost, however. The time and expense invested in the program are by many standards high. Increasing capabilities as well as addressing the values that are foundations for the pro-social behavior is not quick or inexpensive. But if success in policy arenas such as recycling are to be effective and long lasting, such an investment is seen to be necessary.

There are other costs to such a strategy as well. Conflicts with other program purposes have resulted. In this case, the degree to which the policy for extending opportunities for recycling to multifamily households is achieved is largely determined by the manager. The long term gains by such an approach, however, holds the promise for much greater ultimate success with the voluntary and committed involvement of the coproducer.

Program accountability, while being potentially more diffuse and less formal than in a "top down" policy process, is achieved in ways that hold the promise of being broader and more meaningful within the context of democratic society. The City program has created a policy arena in which a much broader element of the population shares in the stakes. Those that invest their time and are empowered to be in control of their program, share in the responsibility for its success. Such a strategy with an element of the population which potentially plays an important role in affecting tenant recycling behavior potentially accesses the coproducer to matters of broader community concern. Concerns persist, however, that not all managers are participating and as such some 
multifamily residents are not being given the opportunity to recycle. This disparity of service is seen to be a direct result of the voluntary nature of the program.

A final area of experience which has emerged from this examination is the increased potential for policy level learning through the involvement of citizen coproducers. Adaptations and change are a fundamental prerequisite for policy implementation. By spreading responsibilities and experiences throughout a broader spectrum of society, greater potential access is gained to the requisite knowledge that best comes from informed experiences. The City's experience with this program has demonstrated that managers who contribute to the process are uniquely capable of knowing the elements of success and effectively applying that knowledge.

These experiences suggests rich potential for coproductive policy strategies in addressing a wide range of community wide concerns. As suggestive as this discussion may be, however, a more systematic examination into the conditions and forces which potentially shape these possibilities is needed. It is important to examine more closely the characteristics of the manager, their work and potential place within a coproduced policy arena. This will help guide and inform the elements of that study.

THE MANAGER IN MULTIFAMILY RECYCLING

\section{Defining the Multifamily Residential Manager}

There are many differences in the types of managers of multifamily residential complexes. They may be the owner or part owner of the complex or 
an employee of the owner. They may be singularly responsible for the complex or share that responsibility with their spouse or a partner. They may have employees working for them or not. They may be "full time" or "part time" managers. The important distinguishing characteristics of managers, though, as defined in this study are two fold: (1) they live on the premises of the complex and (2) they are viewed by tenants as the responsible party for the complex.

Managers within the multifamily residential complex are viewed in this study to be in a position to potentially influence behavior and even attitudes of the resident toward the production of social goods and services. Unfortunately, the manager as a social influence agent, has been an infrequent subject of study. Thus, there is little in the literature to help inform this discussion. In this section a brief exploration into the manager's work within the multifamily environment and examination of the matters which frequently shape their perspectives will help in understanding their potential role within a coproductive program implementation strategy. These observations come as a result of the extensive work of the investigator over the past 4 years in interacting with managers on the city's recycling program.

\section{Conflicting Roles of the Manager}

The managers role is in many ways enigmatic and paradoxical. On the one hand they are in a position of power over the lives of the tenants: they control whether tenants can move or stay in the complex; they have the ability to go into tenants private living space; they make decisions which affect the quality of life of tenants. On the other hand their position is one of subservience to the tenants: they are called upon to repair things that don't work, they have to clean 
up after tenants; their own living space is frequently a "public" space for tenants to come to when they need something.

In addition, managers' perspectives of tenants are framed by their position within the multifamily complex. The manger is frequently required to deal with the negatives of the behavior of their tenants. Activities that dominate the manager's work and interaction with residents include such things as collecting rent and having to deal with the late payers, cleaning and repairing damage caused by irresponsible tenants, dealing with inconsiderate and at times belligerent behavior, etc. Such disagreeable tasks produce a generally negative perspective regarding the tenant group as a whole. Even though a relatively small percentage of the tenants fall into problem categories, the amount of time and attention paid to them tends to override the more positive interactions and behaviors of other tenants. The result can be a generalized cynical and even suspicious view of tenants. In this regard the manager is akin to other roles and professions which are forced to mostly deal with behavioral exceptions in society (e.g. police).

In addition to the cynicism is a limited frame of reference that results from a work place that is also in many cases their living space. In this arena, the managers are "on call" seven days a week, 24 hours a day. The pervasiveness of this situation frequently results in a frame of community reference that is bounded by the perimeter of the complex. Yet their interaction with the community members (i.e. the tenants) are dominated by the many problems which are frequently only associated with a very few tenants.

Anyone spending time with managers at their place will most likely hear certain themes emerge as they characterize their work. Four such themes appear consistently: (1) the seemingly endless request of their time to perform someone 
else's chores; (2) the lack of appreciation and gratitude for the work they do; (3) the lack of consideration, indifference and outright stupidity of tenants; and (4) the need to keep control of what tenants can and cannot do within the complex. These themes and their variations are an important part of most manager's mentality and are instrumental in shaping their perspectives about those inside and outside of the complex. When most managers are presented with the opportunity (or as in some cases the requirement) to be involved in recycling, one or more of these themes will likely emerge in their response. As such, recycling is a frequent target of skepticism and even contempt. But also recycling is an opportunity to connect with broader and potentially more positive influences and interactions with tenants. Experiences that managers have had and choices that they have made with the recycling program can lead in either direction and have for different managers. A number of case illustrations drawn from the experiences of the investigator in working with managers on recycling programs can help put these points in perspective.

\section{Case Illustrations}

"One more chore." Managers are frequently feeling besieged by demands on their time for many things, many of which have little perceived relevance. Potentially time consuming tasks with issues associated with building maintenance, fair housing reporting, rental payment accounts, and so forth occupy a visible and cumbersome part of the manager's work. Frequently the actual burden imposed by these responsibilities is less than the perceived burden. Nonetheless, there is frequently a substantial workload which confronts the manager on any given day. Therefore, the anticipated problems of more maintenance and organization that are associated with recycling cause 
many managers to resist such a program as being yet another endless chore. The potential problem imposed by recycling is magnified with special circumstances faced in some multifamily residences. Such was the case with one who managed a complex with a high percentage on non-English speaking tenants. From the very beginning of the recycling program at her complex, there was a great deal of contamination in the recycling containers causing much work for her and bringing her close to the point of abandoning the recycling program. In cleaning the recycling collection containers of the garbage that was frequently put there, she discovered a large number of cat food cans. This puzzled her because she knew (or at least thought she knew) there were no cats being kept by tenants in the complex. In her investigations, she discovered that the residents were buying the cat food for their families because the cans had a picture of a fish on the label and were inexpensive. They were not aware that the food was intended for cats (food given to pets in their native culture was not something bought at the market). The discovery of this put the manager on the trail of a whole set of discoveries and new perspectives about her tenants. One such result was that she now saw the problem of contamination as a problem of language and cultural differences. Just as the tenants were buying food based on pictures she concluded that possibly recycling could be taught with visual prompts. Thus, she devised a system of hanging properly prepared recycling items by a string beneath the opening of each recycling container. The result was immediate and impressive. Recycling participation dramatically increased and contamination was all but eliminated. Such an experience was both gratifying and empowering. Not only did it reinforce her belief that her efforts can make a difference but introduced a new level of understanding and appreciation for the residents in the complex; an experience that led to her 
establishing a contact with a multi-cultural community center in the neighborhood to help her better understand the tenants in her complex.

"Thankless work." Opportunities to deal with tenants in behavior arenas which address matters of broader community importance and concern are infrequent for managers. Recycling offers one such opportunity. Recycling for some managers has the intrinsic satisfaction of having done something good for the environment and participated in community supported activity. This satisfaction is magnified when managers discover some unexpected surprises with recycling at their complex. Such was the case of the manager of a large older complex undergoing extensive remodeling and repairs of the building to bring the building into compliance with a number of deficits in the building and fire code. The task of remodeling was causing a number of problems with tenants who were inconvenienced by the work and saw little direct benefit to themselves that was to result from the type of work that was being completed. The difficulties of the remodeling and the harassment from tenants were quite wearing on the manager who felt caught in the middle of a "no win" situation. During the remodeling process, the basement to the building had to be closed for several weeks. This closure prevented tenants from having access to the recycling containers which were located in the basement To his surprise, by the end of the first week that the basement was reopened, there was an overwhelming amount of recycling material. Observing this, the manager concluded that the tenants had been storing their recycling for the entire period of the remodeling, a period of nearly three months. This was very surprising to him especially given the exceedingly small quarters of the living units and limited resources of the largely low income residents in the complex. For him this response was a confirmation of his work. The impact of the program and 
his previous efforts to stress the importance of recycling with them had made a difference to the point that the tenants were willing to be inconvenienced by storing these materials in their residences until they could once again use the recycling shelter.

"Tenants just don't care." Many times a source of frustration for managers is the problem experienced with tenants putting materials out for recycling which are not part of the collection program. This frequently results in the manager having to clean around the recycling area and sort through the acceptable and non acceptable items--a time consuming and very disagreeable task in many cases. For many managers, this is viewed as an indication of an uncooperative and disinterested tenant population. A less cynical view, however, would see this in a different light. Such was the case with one manager who upon examining the material that was improperly deposited in the recycling bins recognized that much of the material was "recyclable" in that the items were imprinted with the "chasing arrows" recycling symbol. A new interpretation of the problem resulted from this discovery. The problem was not that the tenants "just don't care," but rather that they are interested in recycling as much as they can. The manager decided what was needed was a more complete collection program to support the tenants interests in recycling. This prompted the manager to put out an extra container by the recycling collection bins for "other recyclables." This quickly led to several new developments including less contamination, more material being recycled and discussion among tenants about some of the current problems with recycling labeling and markets. Also, subsequent contacts of the recycling hauler for the complex from the manager about this problem resulted in some of these "new" recycling materials being picked up by the hauler. In this case, seeing through the 
problem and viewing it with less cynical perspectives produced a number of positive results.

"Maintaining control." Managers are in positions of potential power and control of the lives of tenants. One area this is apparent is in the potential access to the living units of the residents. Though the effects of this control has not been the subject of systematic study (Rohe and Stegman, 1994), most tenants are well aware that the space they are living in is potentially monitored by the manager. Also, the managers frequently expect the worse when it comes to the care that tenants are taking of the living units. This contributes to a potential tension between tenant and manager which can be dysfunctional to a supportive and positive living environment. This was the problem faced by one manager who had been dealing with a problem of infestations of pests in the complex. The complex was an older building and comprised of many senior citizens. The manager suspected that many of the tenants were not properly cleaning their units or managing their refuse which was contributing to the problem. It was difficult for her to address this problem with the tenants because she felt they were very proud and would not appreciate her confronting them on household management problems they might be having but were too proud to admit. When the recycling program was introduced into the complex, it gave the manager an opportunity to address the problem in an innovative manner. Part of the equipment that the manager secured for the new recycling program was individual unit baskets for storing the recyclables in the tenants' units until they were brought to the central collection area in the complex. In distributing these bins to each of the tenants and informing and demonstrating how to recycle, the manager was able to provide access to the tenants and their units. Taking advantage of this, the manager took the opportunity to give advise and 
assistance on how to organize the refuse and recycling in their units which would control the infestation problem. Thus, the manager reported that the recycling program was not only a success it was also an opportunity to address other tenant problems without "affronting their dignity."

\section{The Manager as Citizen Coproducer}

In each of the above cases, managers exhibited a range of creativity and involvement with the residents of their complexes resulting in both a successful program at their complex but also one that furthered their awareness and appreciation for the impact that they can have on the behavior of the residents in their complex. In each case, the problems that were faced were ones that are inherent in the nature of the work and the relative position of the managers to their tenants. In these cases, the inclination of the manager to address problems from a position of cynicism, yielded to a response of support and informed judgment. As such, the case illustrations demonstrate both the opportunities and constraints of the manager as a citizen coproducer in the recycling program in multifamily residential complexes.

Constraints on Managers. As previously discussed, recycling behavior is built in large measure on attachment to global issues, efficacy and community. But for the manager in their environment these measures are challenged and constrained by competing forces for their time and interest. They control the living environment of others but they also work as the caretakers of a living environment for others. They are susceptible to having to spend the greatest amount of their time dealing with matters resulting from the inconsiderate actions of the least cooperative residents. Programs such as recycling which require cooperation from tenants are therefore generally suspect from these 
perspectives. Such efforts will be likely viewed as more caretaker work dealing with uncooperative residents. The few extrinsic rewards for recycling are little compensation from this perception.

The potential of community involvement for the managers is frequently defined by and indeed limited to their interactions with residents within the complex. The managers are in a position to have a great deal of contact with residents (a prerequisite of community building) yet infrequently relate their involvement with the residents in their complex to their sense of community. The forces of commodification of the living space limit as well as discourage community spirit from these perspectives.

Opportunities. The case illustrations cited above suggest that managers are in a position to greatly influence attitudes and behaviors of tenants in community building and pro-environmental behaviors. They have the place, time and responsibility to know and affect the living environment of the residents. Thus, their position is crucial to the extent that recycling is affected by these factors. In addition, there is the intrinsic rewards from involvement and support of a program that is generally appreciated by many if not most residents, and opportunity to be involved and identified with a task that does not have the onerous overtones of many of their other tasks.

In sum, the manager is uniquely situated to be a policy partner in such a program as recycling. Yet the sometimes conflicting and paradoxical elements of their role within the multifamily environment compete with their willingness and ability to participate in such a policy arena. 


\title{
CHAPTER III
}

\section{A MODEL OF COPRODUCTION AND CITIZEN INVOLVEMENT}

\author{
OVERVIEW
}

Within the policy sphere of coproduction there exist not only new opportunities to increase the effectiveness of government services but also important and challenging possibilities in broadening and enriching citizen involvement. As has been demonstrated in the case examples of managers interacting with the demands of the recycling program at their complex, the potential of the citizen coproducer is more than a mere "tool" of government (Hood, 1983). Rather, coproduction is a policy means for making citizens full partners with government representatives on common ground in solving important problems within the community. In this sense, coproduction extends both the mechanism and the opportunity for "citizen agency" (Boyte, 1989). Similarly, as seen in the review of the City of Portland's multifamily recycling program, coproduction holds promise for revitalizing government agency by providing a means of invigorating public institutions and challenging public servants to see themselves as citizen partners rather than mere purveyors of goods and services to a body of passive citizen consumers.

The preceding chapter focused attention on the set of issues and forces which contribute to the City of Portland multifamily recycling program. The possibilities of coproductive policy strategies emerged from that discussion. In 
this chapter the key elements which contribute to citizen involvement in a coproductive process will be reviewed. In addition, a model of coproduction will be constructed which focuses on the role of citizen involvement in the policy implementation process. And finally, the questions which frame the research designed to empirically inform key assumptions made in the model of coproduction will be presented.

\section{CITIZEN INVOLVEMENT AND COPRODUCTION}

\section{Understanding Citizen Involvement}

Among the possibilities of coproduction are an empowered and involved citizenry which contributes to service and problem solving of issues which are both difficult and unsuitable for government agents to unilaterally address. In addition, through the coproductive process government agents access new inputs and have opportunity to raise their level of appreciation and understanding for community problem solving processes within the community. In essence, enriched citizen involvement is both the cause and result of coproduction in its fullest, most optimal expression.

Competing forces within both government and citizen arenas exist, however, which tend to challenge and potentially weaken citizen involvement and thus attenuate the possibilities of coproduction. The building of viable partnerships envisioned in coproductive strategies are vulnerable to the potentially disinterested and uninformed citizenry and cletached and encumbered government mechanisms. In order to fully realize the possibilities of coproduction, therefore, an enhanced understanding of the elements which contribute to citizens being involved in viable partnerships with government in 
solving community problems is essential. In short, a model of coproduction which is built on the fundamentals of citizen involvement is needed. In this chapter an examination of the critical elements that both serve to enhance and possibly constrain citizen involvement will be examined. With this as a background, a model of coproduction will be developed which will guide the research conducted in this study. The analysis in the preceding chapter is instructive to what the important contributions citizen involvement can make to the policy process. A review of those elements follow.

Recycling is an activity that takes place as a part of everyday behavior and as such are matters of personal choice, value and motivation. Recycling is also an important part of the solution to a set of community and environmental issues posed by mounting solid waste dilemmas and energy resource depletion. As such there is a public good that makes the activity the object of public policy. But government faces limits in how it produces this good. As Gordon Whitaker has explained (1980:24), "Whether it is learning new ideas or new skills, acquiring healthier habits, or changing one's outlook on family or society, only the individual served can accomplish the change. The agent can supply encouragements, suggest options, illustrate techniques, and provide guidance and advice, but the agent alone cannot bring about change." Thus, for problems of everyday life government has tended to emphasize inducements and capacity building strategies as opposed to mandates or system changing actions. Such instruments as inducements and capacity are what largely characterize coproduction-like government solutions to such problems (Neiman, 1988).

Recycling has been referred to as the "premiere example of the collective coproduction of a local government program." (Folz, 1991a: 223). As such, there has been much success experienced in raising the level of coproduction of this 
good, but the problems and constraints faced within multifamily environments have put new challenges on government. As research has shown, though recycling largely stems from one's own personal motivation, there are a number of situational factors which contribute to the behavior. Convenience and the social context of one's immediate environment strongly influence such behaviors. The multifamily residential setting and the role of the manager in those settings are potentially important in both influencing personal motivation of the tenant and addressing the situational factors which contribute to recycling. This has been the basis of the City of Portland's program. In addition to prompts and education directed to the community at large, the city has made concerted efforts to coproduce the program in multifamily residences with the manager.

Key to the city's policy is the strong commitment to the importance of citizens in both making their own choices and in supporting their roles as coproducers. Managers have been empowered with both choice and opportunity for involvement. The costs and level of effort required in so-doing are not insignificant, however. The recruitment, training, equipment and technical assistance add to a considerable public investment, but long term gains of building an informed and active partner in multifamily recycling are seen to be worth the price.

The manager, on the other hand, faces a personal and work world which does not easily embrace recycling. The demands and inconsiderate actions of tenants, the absence of incentives, the structural barriers and limitations of physical plant facilities to say nothing of the more insidious pressure of tenant commodification, all potentially distract from such a pro-social behavior as recycling. In spite of these pressures, managers have in many instances 
responded with high levels of involvement. The results of this involvement has been both furthering the level of success of the city recycling program and enriching their own community understanding and civic involvement in the process.

\section{Understanding Coproduction}

In the first chapter the concept of coproduction was reviewed from a number of perspectives offered by previous research. Building from those conceptualizations and incorporating the experiences within the City of Portland's multifamily recycling program, a construct of coproduction can be formed which focuses on the key element of citizen involvement within the policy process.

Coproduction involves citizens as problem solvers. Coproduction as a policy strategy is distinguished by the direct involvement of citizen's in the implementation process. Involvement results from being provided with the opportunity to be included in the implementation process. Portland's approach is built on a strategy of involvement through inclusion. That is, cooperation is enriched through empowerment and meaningful roles which provide access to new understandings and a chance to participate in problem solving processes on the part of the coproducer. As was seen in the case examples, managers responded to their role as coproducers of recycling and were functioning in expanded capacities as problem solvers in coproducing recycling in their complex.

Coproduction is voluntary. Coproduction is built on the voluntary participation of citizens. In addition to the opportunity to be included in the implementation process, the coproducer must see the importance of their 
involvement. As in the case examples reviewed, citizens have competing demands on time and interest. Thus, to move from personal to public life and be a participant in problem solving roles is both demanding and requiring high levels of will on the part of the citizen coproducer.

Coproduction expands access. Coproduction is effective in producing outcomes which are elusive and hard to access by government agency. In the case examples, managers demonstrated knowledge of and access to the practical issues of the real world and their tenants. Acting on that knowledge enabled problem solving to occur. In the policy arenas addressing every day behaviors these are the citizen capacities which are many times the differences between success and failure in public policy implementation.

Coproduction builds citizenship. Coproduction accesses other civic engagements for the citizen coproducer. The experiences within the coproductive processes empower citizen agency through involvement and informed experiences. This possibility is seen in the cases of both the manger in the case example whose new level of multi-cultural understanding led to participation in community center activities, as well the manager whose reinforced experiences within his own complex later led to his becoming the chair of a recycling committee for an association of multifamily managers.

From these presuppositions it is possible to construct a model of coproduction which frames the research design to further examine the possibilities. Toward that end, Figure I illustrates the factors which contribute to coproductive efforts that have emerged from the previous analysis of the implementation process within the Portland program. Factors that relate to both the policy implementation process and the results of that process are considered. Specifically these factors are seen to involve (1) the "inputs" of citizen 
involvement to the process which include the opportunity and resources for citizen involvement and the choice of citizens to be involved; and (2) the programmatic "outcomes" of the process which include the increased awareness and capacity of government and increased problem solving and service provision as well as increased citizen engagement.

Inputs (Policy Implementation Process)

\begin{tabular}{c|c} 
Government \\
Coproducer
\end{tabular} \mid $\begin{gathered}\text { provides the opportunity and } \\
\text { support for citizen involvement }\end{gathered}$ Citizen
Coproducer considers importance and becomes involved
Outcomes (Programmatic Results)

gains access to experiences and capacities of citizens

informed experiences contribute to other expressions of citizenship

Figure 1. Coproduction policy implementation inputs and outcomes.

\section{A Research Design}

Two fundamental issues inherent to the concept of coproduction have emerged in this discussion. Both must be addressed to further understanding 
and appreciation of the contribution that coproductive policy strategies hold. The first concerns understanding the forces which potentially contribute to the involvement of the citizen coproducer. The second concerns the potential importance of involvement by the citizen coproducer in affecting the outcomes of public policy. These concerns provide the organizing themes of the research conducted in this study and generate four essential questions on which that research focuses. Specifically, these are as follows: (1) do government agency efforts to define and support levels of participation for the citizens contribute to higher levels of citizen involvement in the coproduced program? (2) is the citizen's will to participate associated with the level of opportunity for involvement in coproduced programs? (3) to what extent does the involvement of the citizen coproducer contribute to achieving desired programmatic outcomes? and (4) to what extent does increased citizen involvement in coproduced program efforts contribute to the enhancement of citizenship and engagement in broader civic matters.

To approach these questions, it will be useful to consider a way of organizing the relevant issues suggested by this analysis. As seen in Figure 2, the implementation process is represented by the relationship between the recycling agency and the manager. In this model, the implementation process is represented by the relationship between the recycling agency and the manager, and consists of the recycling agency providing opportunity and support to the manager for involvement (i.e. inclusion); and the manager having opportunity and choice for involvement (i. e. volition). The programmatic outcome is represented by the relationship between the manager and tenant recycling participation and consists of the manager's role as a citizen service provider contributing to the level of tenant recycling (i.e. influences); and the experiences 
in the recycling program broadens (i.e. engages) the managers awareness and participation in other community and civic matters.

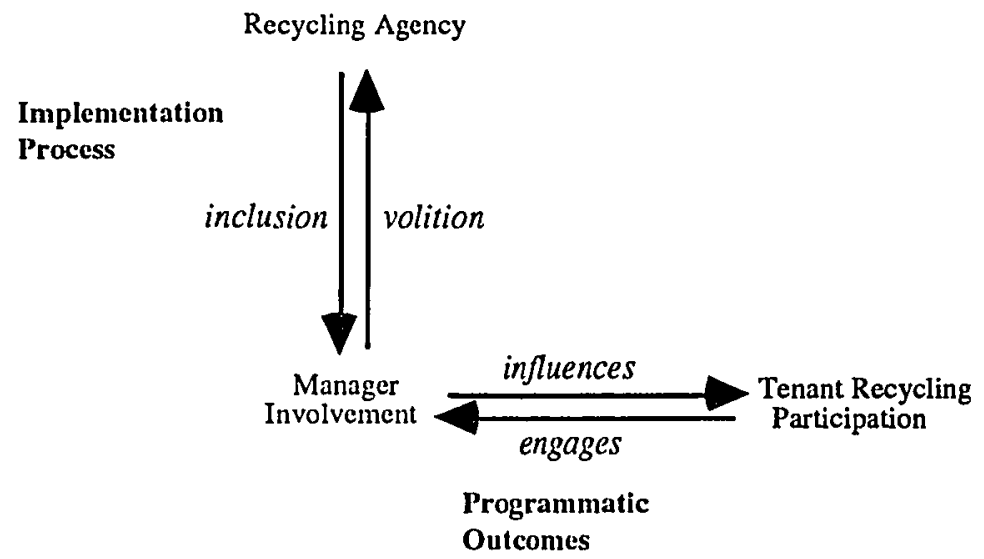

Figure 2. Recycling in multifamily complexes: a model of coproduction.

\section{Research Hypotheses}

The fundamental position of this study is that coproduction is a key policy approach in both government's instrumental role of providing services in an effective, efficient and accountable manner and in its integrative role of fostering citizenship and community coherence. Furthermore, this study is built on several fundamental assumptions regarding the implementation process and programmatic outcomes of the multifamily recycling program in the City of Portland. The roles played by the recycling agency and the manager together form the implementing mechanisms of the coproductive efforts to further recycling in multifamily complexes. The interaction between the managers and the implementing agency are key in the implementation process. The role 
played by the manager in ultimately influencing the level of tenant participation in recycling is key to the programmatic results. Thus, the hypotheses for this research are: (1) that the level of citizen involvement in service delivery is enhanced by and positively related to the level of effort on the part of the implementing agency to involve the citizen service provider's participation; (2) that the level of success in achieving programmatic outcomes is positively related to the level of involvement of the citizen coproducer; and (3) that the level of involvement of citizen providers in coproductive efforts broadens and enhances community attachment and citizenship. The chapter that follows will discuss a body of research conducted to test these hypotheses and examine the findings and issues which emerge from that research. 


\title{
CHAPTER IV
}

\section{RESEARCH DESCRIPTION AND RESULTS}

\author{
OVERVIEW
}

In this chapter the research conducted which addresses the principle issues posed in the model of coproduction developed in this study will be presented. Specifically, the issues with which this research is concerned are as follows: (1) the importance of inclusion and volition to levels of citizen involvement in coproduced programs; and (2) the importance of citizen involvement to achieving program results and engaging citizen coproducers in broader civic matters. To address these issues a research program was conducted which included participants in the City of Portland's multifamily recycling program. The sections in this chapter are (1) a description of the elements and procedures followed in conducting the research; (2) a presentation and display of exhibits which describe the results of the research; and (3) a discussion of the key findings which emerged from the research.

\section{METHOD AND PROCEDURES}

\section{Research Components and Schedule}

The research conducted in this study consisted of a number of survey and field observation components completed over the course of a 12 month period. The research program utilized both experimental and non-experimental 
research designs (Cook and Campbell, 1979). Table I summarizes those components and the schedule followed in completing each component.

TABLE I

RESEARCH COMPONENTS AND SCHEDULE

$\begin{array}{cll}\begin{array}{c}\text { Sequence } \\ \text { (weeks) }\end{array} & \text { Research Component: } & \text { Research Subjects: } \\ 1-6 & \text { Initial manager contact } & \text { All managers on City recycling program } \\ 2-8 & \text { 1st manager conference } & \text { Voluntary managers only } \\ 9-10 & \text { Study group selection } & \text { Both voluntary and non-voluntary managers } \\ 10-12 & \text { 2nd manager conference } & \text { Managers in treatment group only } \\ 12 & \text { 1st focus group } & \text { Managers in treatment group only } \\ 10-16 & \text { Initial recycling measurement } & \text { All study sites } \\ 16-20 & \text { 3rd manager conference } & \text { Managers in treatment group only } \\ 16-32 & \text { Program enhancements } & \text { "Treatment" sites } \\ 32 & \text { 2nd manager focus group } & \text { Managers in treatment group only } \\ 32-36 & \text { Final recycling measurement } & \text { Sites in all } 3 \text { study groups } \\ 36-42 & \text { Tenant survey } & \text { Tenants at all study sites } \\ 42-52 & \text { Final manager interview } & \text { All managers in all 3 study groups } \\ 44-48 & \text { Implementing agency survey } & \text { Staff members of implementing agency }\end{array}$

Completion of Research Components. Due to the amount and length of the field work and number of tenant interviews to be conducted the investigator employed the assistance of two graduate students experienced with the Recycling Education Project and P.S.U. The assistants were given thorough instruction in the methods and protocol of the research. Field journals and 
completed survey instruments were regularly checked for completeness and accuracy.

Sample

Sample Universe and Selection Process. Selection of managers for the sample was drawn from the list of complexes which participated in the City of Portland's multifamily recycling program described in Chapter III. All of the on-site managers that began participation in the City's program during the period of time from July 1992 through June 1993 were sent letters before the program was to begin at their complex, requesting their participation in a special project. The managers were informed that a number of managers were needed to participate in the special project to assist in evaluating the multifamily program in the City of Portland. They were informed that their participation in the project, if they volunteered and were selected, would require additional time and effort than what was normally required as a participant in the recycling program but that their assistance was important in furthering the effectiveness of the program.

Managers that were sent this letter were requested to return a "letter of interest" indicating whether (1) they were interested in assisting in this project and available to do so at this time; (2) were interested in working on this project but were not available at this time, or (3) were not interested at all in being involved in this special program assessment. The letter was sent to 123 managers. Follow-up calls were made to managers not responding within three weeks of the initial letter. As a result of that letter and two follow-up calls, a total of 99 managers responded representing $80 \%$ of all those contacted. Of the 99 received, 34 (34\%) indicated an interest in participating, 19 (19\%) indicated an 
participating. Managers responding to the request were then grouped by the size and rent range of their complex. Table II, Initial Sample Selection Matrix summarizes the responses received from the managers.

\section{TABLE II}

INITIAL SAMPLE SELECTION MATRIX

MANAGERS RESPONDING TO REQUEST FOR PARTICIPATION BY SIZE AND RENT RANGE OF COMPLEX

Average rent range/ 1 bedroom unit/month

\begin{tabular}{|c||c|c|c|c|}
\hline $\begin{array}{c}\text { Complex Size } \\
\text { (\# of units) }\end{array}$ & $\begin{array}{c}\text { High } \\
>\$ 450\end{array}$ & $\begin{array}{c}\text { Medium } \\
\$ 325-\$ 450\end{array}$ & $\begin{array}{c}\text { Low } \\
<\$ 325\end{array}$ & Total \\
\hline \hline Large & $\mathrm{I}=3$ & $\mathrm{I}=2$ & $\mathrm{I}=3$ & $\mathrm{~N}=8$ \\
Over 40 units & $\mathrm{N}=2$ & $\mathrm{~N}=3$ & $\mathrm{~N}=3$ & $\mathrm{~N}=8$ \\
\hline Medium & $\mathrm{I}=3$ & $\mathrm{I}=5$ & $\mathrm{I}=4$ & $\mathrm{I}=12$ \\
15-40 units & $\mathrm{N}=2$ & $\mathrm{~N}=4$ & $\mathrm{~N}=7$ & $\mathrm{~N}=13$ \\
\hline Small & $\mathrm{I}=2$ & $\mathrm{I}=9$ & $\mathrm{I}=3$ & $\mathrm{I}=14$ \\
Under 15 units & $\mathrm{N}=5$ & $\mathrm{~N}=12$ & $\mathrm{~N}=8$ & $\mathrm{~N}=25$ \\
\hline \hline Total & $\mathrm{I}=8$ & $\mathrm{I}=16$ & $\mathrm{I}=10$ & $\mathrm{I}=34$ \\
& $\mathrm{~N}=9$ & $\mathrm{~N}=19$ & $\mathrm{~N}=18$ & $\mathrm{~N}=46$ \\
\hline
\end{tabular}

I: Respondents interested and available to participate $(n=34)$

$\mathrm{N}$ : Respondents not interested in participating $(n=46)$

Sample Size and Characteristics: The sample selected consisted of 45 subjects; 15 subjects in each of three study groups. The size of the sample was determined by three considerations. First it was important to have a sufficient number of managers from complexes in each of the categories which met sample criteria for matching sample groups. Secondly, there were the practical constraints of resources and time to complete the survey and field work required for each subject in the sample. The last consideration was the problem of potential sample mortality. The research design required a period of time of almost a year to complete. The field and survey work to be completed at each 
complex in the study required the same manager to be at the subject complex for the entire period. In this design sample replacement was not feasible.

During the study period several difficulties were encountered which resulted in several managers being dropped from the sample: four managers changed positions from the subject site, two managers in the treatment group could not continue in the experimental program due to personal reasons, two managers from the non-voluntary group refused interviews and one site from the control group was dropped from the sample due to difficulties that were experienced with completing the required field research due to factors beyond the control of the investigator in three complexes. This left 36 subjects in the sample; 12 in each of the study groups. These changes and occurences in the sample resulted in a slightly uneven distribution within each of the study groups. Table III exhibits the number of complexes that were in the final sample by each of the selection criteria categories as well as demographic characteristics of the tenants based on a survey of tenants from each of the study group complexes.

\section{Sample Assignment to Treatment and Control Group. Managers who} volunteered to participate in the special program were matched by characteristics of their complex and randomly assigned to either the treatment or control group. Those assigned to the treatment group were notified and requested to sign a "permission to participate" letter. Those managers assigned to the control group were sent a letter thanking them for their willingness to participate but advised that they were not needed at this time since a sufficient number of volunteers were available. Those managers who did not volunteer to participate were matched by complex characteristic and randomly selected for the non-voluntary control group. 
TABLE III

FINAL SAMPLE MATRIX

MANAGER SUBJECTS SELECTED FOR EACH SAMPLE GROUP BY COMPLEX SIZE AND RENT RANGE OF COMPLEX

\begin{tabular}{|l||c|c|c|}
\hline Characteristics of Tenants and Complexes & $\begin{array}{c}\text { Treatment } \\
\text { Group } \\
(\mathrm{n}=12)\end{array}$ & $\begin{array}{c}\text { Control } \\
\text { Group } \\
(\mathrm{n}=12)\end{array}$ & $\begin{array}{c}\text { Non- } \\
\text { Voluntary } \\
\text { Group } \\
(\mathrm{n}=12)\end{array}$ \\
\hline \hline Number of Complexes with over 40 units & 3 & 4 & 3 \\
\hline Number of Complexes with 15-40 units & 4 & 5 & 4 \\
\hline Number of Complexes with under 20 units & 5 & 3 & 5 \\
\hline \hline Avg. rent for 1 bdrm unit over $\$ 450$ & 5 & 4 & 4 \\
\hline Avg. rent for 1 bdrm unit $\$ 325$ to $\$ 450$ & 3 & 4 & 5 \\
\hline Avg. rent for 1 bdrm unit under $\$ 325$ & 4 & 4 & 3 \\
\hline \hline Avg. tenant education; grade level completed & 12.4 & 12.7 & 12.9 \\
\hline Avg. tenant income & $\$ 20,341$ & $\$ 21,421$ & $\$ 19,346$ \\
\hline $\begin{array}{l}\text { Percent of households with children } 16 \& \\
\text { under }\end{array}$ & $41 \%$ & $28 \%$ & $37 \%$ \\
\hline
\end{tabular}

\section{Experimental Treatment Description}

The experimental treatment was designed to provide a structured opportunity for participants to be involved in the city's multifamily program at higher levels of involvement than normal program participation required. Thus, the treatment represented efforts on the part of the implementing agency to be more inclusive of citizens in coproductive program efforts. The experimental program to be administered to the treatment group consisted of two elements: 
(1) increased responsibility given to the manager as the citizen service provider, and (2) increased support from the implementing agency.

Increased Manager Responsibilities: The managers in the treatment group were requested to contribute efforts to assist the city in maximizing tenant participation in recycling in multifamily complexes throughout the city. The assistance requested from each of the managers included three activity areas. First of all, each manager in the treatment group was requested to keep track of the level and quality of recycling from their complex by making weekly inspections of the recycling and refuse containers. Each manager was provided with a notebook consisting of forms to complete on a weekly basis for two fourweek intervals: once at the beginning of the treatment program and then again three months after the first four week interval had completed.

Secondly, after the initial four week observation was made of tenant recycling participation, each manager was requested to determine what, if any, improvements they would like to try to increase recycling participation and/or reduce problems at their complex based on what they observed from the weekly inspections. Each manager that identified desired improvements was encouraged to implement those improvements.

Finally, each manager was requested to participate in meetings with other managers in the treatment group to (a) share their personal experiences with recycling at their complex with other managers in the treatment group and (b) assist in evaluating the overall program and provide recommendations to the City for improvements in the program which would increase recycling.

Increased Support from the Implementing Agency. As part of the treatment, the agency provided support to assist the manager. The managers in the treatment group were contacted throughout the study period by telephone 
and by in-person visits. These contacts were made every two weeks to discuss the progress of the study and to determine if any assistance was needed by the manager. In addition, increased support was provided to managers who needed assistance to help improve the recycling program at their complex. The assistance available included such things as help with printing tenant newsletters, translations of recycling brochures into foreign languages, information on recycling materials, etc. This assistance was provided only as requested by the manager.

Experimental Treatment Controls. The design of the experimental program treatment was to determine the effect of inclusion of the manager in increased programmatic responsibilities and higher levels of involvement in the program at their complex. As such, care was taken to not prescribe individual program enhancements for the recycling program at their complex. Any involvement in the recycling program at their complex over and above the actual components of the treatment was at their own discretion. The increased support from the representatives of the city agency was available only if requested by the manager. Thus, the structure for increased involvement was provided for each of the managers but the extent of their actual involvement and the level of assistance provided was based on their own initiative.

\section{Data Collection Methods}

Data collected as part of this research were from two principle sources: surveys and field observations. In addition, two focus group panel discussions were conducted with members of the treatment group only. This was done to gain additional insights into the experiences of managers in the treatment group. The utilization of these methods allows for a more complete assessment and 
measurement of key concerns of this research than would be produced by reliance on any one method.

Manager interviews. Interviews of all the sample subjects were conducted in person using a common survey instrument. (See Appendix A.) The surveys were conducted to ascertain self-reported information about the experiences with the recycling program and other attitudinal measures pertinent to the research. Each manager was contacted at the end of the study period for permission to be interviewed as part of this study. All 36 managers in the final sample were interviewed in person by the investigator. The subjects were advised that the results of the survey were to be confidential and their identities would only be known to the investigator and the results of the interviews would be reported in summary form.

Tenant interviews: In addition to the manager interviews, tenants from subject multifamily complexes were interviewed using a common survey instrument (See Appendix B). Data collected from the tenant survey was in regard to their recycling participation, attitudes to recycling, perceptions of the manager's role to support recycling and background demographics on the households. As with the manager interview, they were advised that the results of the survey were to be confidential and results would only be available to the researcher and reported in summary form. Subjects for the tenant interviews were randomly selected from the unit numbers following established random sample selection procedures. The sample size for each of the complexes was determined on the basis of $25 \%$ of the total number of units in the subject complex. In complexes with fewer than 20 units, a minimum of 5 units were selected for the sample. Subjects for the tenant survey were adult members of the household who were principally responsible for or knowledgeable about 
refuse disposal and recycling activities of the household. Substitutions were made for households which were not available and/or refused to be interviewed on a preassigned determination.

Survey Instruments. Survey instruments that provided a standardized measurement across the different sample groups were utilized. In the manager survey a combination of closed entry as well as open ended questions were used. Closed entry questions which required a response were utilized to communicate the same frame of reference to all respondents and to allow for ordinality to the responses (Converse \& Presser, 1988). A "refuse to answer" response, though not given as an option was treated as missing data in the analysis. In addition, questions measuring behavior and activity levels of the respondent were formatted as closed entry, with standardized levels of response given as options (i.e. "frequently," "sometime," "seldom, if at all"). Though this approach requires the respondent to define their own meaning of each response, it has the advantage of allowing a standardized measure for comparison (Shuman and Presser, 1981).

In measuring respondent opinions, question formats with a standardized scale were utilized. Questions evaluating respondent experiences and levels of awareness utilized a ten-point scale labeled at either end by opposing positions. For questions regarding opinions and attitudes of the respondent, a Likert scale question format was utilized (i.e. "strongly agree," "agree," "disagree," "strongly disagree"). In these questions a "no opinion" option was given. Researchers have noted that "no opinion" responses can sometimes be a choice by the respondent to a question that is difficult to understand and/or a highly charged controversial issue to which the respondent does not wish to reveal their opinion. Even though the questions used in these survey instruments are not 
likely to be vulnerable to either problem, two precautions were taken. First, wherever possible questions were patterned after established and proven survey question models. Secondly, inter-item reliability tests were performed on questions that were used to construct index variables critical to this study to identify possibly misunderstood questions as well as poorly specified variables. In addition, respondents were advised that the selection of a "no opinion" option was a legitimate response to filter responses and minimize respondents offering an opinion when they really do not have one.

Field Observations. Research in this study involved the measurement of amounts of solid waste diversion by recycling (Riley, 1992) and the quality of recycling (i.e., level of contamination) at each of the subject multifamily complexes. The method utilized in conducting the field observations and the field observation forms are described in Appendix C. Each complex in the study was visited by the investigator or research assistant to determine the amount of recycling and refuse that was generated at the complex. The measurements of both refuse and recycling were recorded weekly over the course of two 4-week intervals; once at the beginning of the study period and approximately 3-5 months subsequent to the first measurement period. In addition to the amounts of recycling, contamination levels in the recycling were assessed using a standardized criterion. A final area of observation included an assessment of the situational factors which contributed to the convenience of use of the recycling collection system by tenants in the complex and a rating of the convenience level was made on the basis of the assessments. Each of these field visits and measurements were recorded in a field observation log for each of the weeks of the measurement period. 
Focus Groups. To assist in the assessment and evaluation of the data two focus panels were conducted. These panel discussions were conducted with managers in the experimental treatment group. One of the these panel meetings was at the beginning of the study period and the second was at the completion of the study period. The purpose of these focus discussion groups was two fold. First of all, the meetings were conducted as part of the experimental treatment. The meetings were one element of an increased level of inclusion of the manager in the policy implementation process. Secondly, the meetings afforded an opportunity to explore managers 'perspectives and experiences with the recycling program at their complex. The advantage of using a focus group as a means of data collection and evaluation for this study is in the interaction that occurs between managers who have had a common activity. As such, ideas and perspectives that would not emerge in field observations or surveys do emerge with this type of interaction (Morgan, 1988).

\section{MEASURES}

A number of variables of multiple items were constructed in the research analysis. This was done to generate a single index measurement of several items central to this study. In some cases a global variable was constructed from a number of sub-scale variables to capture the multiple dimensions of key theoretical constructs (Carmines, 1988). Calculations of scale reliability for these multi-scale variables were performed by using inter-item correlations. All items included in the multi-scale variables contributed to an increase in the scale reliability. A list of the variables and Cronbach's alpha coefficient for the multiscale variables constructed with two or more items is included in Table IV. 


\section{TABLE IV}

\section{LIST OF VARIABLES AND MEASURES}

Variable:

Manager Involvement

Participation

Commitment

Motivation

Civic Engagement

Community

Coproduction

Total Recycling

Tenant Recycling

Complex Recycling

Control Variables

Tenant Income

Tenant Education

Tenant Age

Recycling Convenience
Measure (Cronbach's alpha coefficient is given in parentheses):

Global measure contains 10 items on how respondents assess their involvement in the recycling program at their complex. The three subscales (participation, commitment and involvement) are used in this measure. (Alpha $=.83$ )

Subcale index of four items which pertain to the direct activities the manager regularly performs to promote and assist tenant recycling. (Alpha $=.75$ )

Subscale index of four items on how respondents assess their commitment to be involved in the program. (Alpha = .73)

Subscale index of two items on how respondents assess their motivation to be involved in the recycling program. (Alpha = .83)

Global measure contains 5 items on how manager respondents assess sense of community and participation in their community and civic responsibilities. (Alpha $=.77$ )

Subscale index of three items on how manager respondents assess their sense of community, whether or not they have participated in community problem-solving activities and personal efficacy. (Alpha $=.63$ )

Subscale index of two items on how manager respondents assess the likelihood of co-participation in community problem solving. (Alpha $=.75$ )

A global measure of 5 items comprised of tenant reported and independently observed recycling participation. (Alpha $=.69$ )

A subscale index of three items on tenant reported levels of recycling and motivation to recycle. (Alpha $=.50)$

A subscale index of two items of independently observed recycling participation at the complex calculated on a weekly average of 8 weeks of observation. (Alpha $=.71$ )

An aggregate measure of the average income level of tenant respondents for each complex to be used.

An aggregate measure of the average education level (grade completion) of tenant respondents for each complex.

Age of tenant respondent.

An index of two assessments of the convenience of recycling systems in the complex based on proximity and accessibility. 


\section{Citizen Involvement}

The importance and multidimensionality of citizen involvement in coproduced programs is a central concern in this study. Researchers have viewed citizen involvement to include not only the direct activities of the participant but also the disposition of involvement (Haeberle, 1987; Berry, et al., 1993). Involvement in this study is considered to include not only activities that are instrumentally involved in achieving programmatic outcomes, but also considerations of the motivation and commitment levels of the citizen coproducer to participate. Citizen involvement as modeled in this research is considered to be both a dependent variable and an independent variable. As a dependent variable, involvement is considered to be a result of both the inclusion of the citizen in the coproductive process and the volition of the citizen coproducer to be involved. As an independent variable, involvement is modeled to contribute to coproduced program results as well as measures of broader civic engagement of the coproducer.

Participation. Coproduction involves the direct participation of citizens in the delivery of goods or services (Rich, 1981; Brudney, 1985). As such, the level of participation of citizens is an essential measure of the coproductive implementation process. The measure of participation in the study was created from responses from managers to questions regarding the number and frequency of activities and duties that the manager performed in regards to supporting the recycling program at their complex. Potential areas of support were read to the manager and they were asked the ones they performed and at what level of frequency they performed that activity. A "participation" index was then calculated for each manager on the basis of their responses by 
multiplying the frequency that each of the activities were performed and then adding the total score.

Commitment. The second attribute of involvement specified in this study regards the commitment level of managers to be involved in the program. Commitment has been the frequent subject of social research and has been found in some studies to be an important contributor to social participation. (Lewin, 1947; Heberlein and Warriner's, 1983; Pardini and Katzev, 1983; Katzev, 1994). Commitment has however, been considered in two different ways: as a desire to perform or as an explicit pledge to perform (Katsev, 1994). In this study commitment is viewed in the context of the former meaning; that is the desire or willingness of the citizen to participate. The method in which this variable was specified and measured was fashioned after a model developed at Michigan Survey Research Center in which community members are being queried about their level of commitment to being involved in community activities. An index variable was constructed from responses that managers made to statements of potentially discouraging occurrences. The response choices were one of the following: "would likely," "could possibly" or "not likely" to discourage them from continuing participation. A "commitment" index was calculated from the sum total of all individual response scores.

Motivation. The third and final attribute of involvement utilized in this analysis is the level of motivation to be involved with the recycling program. Specifying and measuring indicators of motivation of participation in community activities has been the subject of much social research and has been addressed and measured in numerous ways (Oskamp, et al., 1991). In this study, a simple, direct self-reported measure was deemed most appropriate. Managers were asked to indicate on a scale of 1 to 10 , with "1" being low and 
"10" being high in the level of motivation they consider themselves to have "to do whatever is needed to make recycling a success at their complex." In addition to this, managers were read statements which compared their motivation to support the recycling program to other responsibilities they had at the complex. The combined measures of these two items comprised the "motivation" index.

\section{Civic Engagement.}

Coproduction is viewed as a process of engagement: both in contributing to the community and acquiring knowledge and skills. Experiences gained in coproductive efforts are viewed in this study as contributing forces to broader levels of interest and participation in community level issues on the part of the coproducer. Thus, the level of community attachment and civic participation of the coproducer are specified to be dependent variables to manager involvement in the recycling program. Two different sets of indicators for this dimension were utilized. The first concerns the level of community awareness and involvement of the coproducer and includes three measures: (1) sense of community; (2) involvement in efforts to improve community, and (3) sense of civic capacity or efficacy. Means to measure for these attributes were borrowed from questions developed by Michigan Survey Research Center to measure citizen community involvement. The second dimension of civic engagement modeled in this research concerns the coproductive process itself. Though coproduction is an expression of community involvement, it is also an expression of partnership with government. As such, it is viewed as broadening the engagement of citizens (as well as government) in civic matters. The presence of government in the implementation, however, can potentially either 
contribute or detract from citizen involvement (Sundeen, 1988). Therefore, a "coproduction" index variable was constructed to measure of the approbation of government/citizen partnerships which included two dimensions: (1) the level of appreciation for citizen and government partnerships; and (2) the likelihood to get involved with local government in solving community level problems in the future.

\section{Tenant Recycling}

Tenant recycling is modeled to be a dependent variable to the measures of public involvement. Two measures of tenant recycling were used in this research: self-reported measures by the tenants themselves and observed measures recorded by the investigator.

Self-reported recycling measures: Tenants were asked in the survey as to their recycling participation along three dimensions: (1) the number of recyclable materials regularly recycled; (2) the estimated amount of total household refuse recycled; and (3) their motivation to recycle using the 1 to 10 scale. Responses of tenants were calculated and averaged to form a single measure for each multifamily residential complex in the study. The three dimensions were then used to construct a three item single "tenant recycling" index.

Independently observed recycling measures. The second measure of recycling was at the multifamily residential complex level and was comprised of two elements: (1) the percent of refuse recycled per unit in the complex; and (2) the observed contamination levels in the recycling in the same period of time. Both of these were averaged for each of the two 4-week periods of time using the measurement technique described earlier in this chapter. A four item 
"complex recycling" index variable was then constructed for each complex. A single global measure of "total recycling" contains the three items in the self reported tenant recycling index and the four items in the independently observed measures of recycling.

\section{FINDINGS}

The results of the research are presented in this section. The results include differences in mean values of the variables in each sample group and the $\mathrm{t}$-statistics with associated p-values for examining statistical significance. In addition, correlation and regression analyses have been utilized to examine the association between independent and dependent variables specified in the model. The small number of cases in the sample result in substantial sampling error. Because of this, when trends in the sample data have clear theoretical value they are discussed as substantive even if not statistically significant. The discussion will make use of both the differences in observed data between the sample groups as well as significance levels.

\section{Inclusion and Citizen Involvement}

To examine the importance of inclusion within a coproductive policy process to the level of involvement of the citizen service provider, managers from the treatment group and the control group were compared. Those managers participating in the treatment program were assigned substantially higher levels of responsibility in the recycling program by being included in efforts to assess the City of Portland's multifamily recycling program. This increased responsibility included documenting recycling participation, 
participating in group meetings to discuss and evaluate the program and formulating recommendations for program improvement. The control group was matched to the treatment group in several ways. First, they had volunteered for the treatment program and can be assumed to have a similar level of interest in the recycling program. Secondly, they all had begun the recycling program at their complex at approximately the same time and were provided with the same type of recycling collection equipment at their complex. And lastly, they managed complexes that were similar in size and rent range with identical recycling collection equipment. Therefore, differences of involvement observed in the two groups of managers can potentially be a measure of difference produced by their increased role and inclusion in the coproductive efforts of the treatment. Table $V$ exhibits the results of comparing the differences between the control group in each measure of involvement specified in the model.

TABLE V

MEAN INDEX VALUES FOR MEASURES OF INVOLVEMENT IN TREATMENT AND CONTROL GROUPS

\begin{tabular}{lccc}
\hline Variable & $\begin{array}{c}\text { Means } \\
\text { Treatment Group } \\
(\mathrm{n}=12)\end{array}$ & $\begin{array}{c}\text { Means } \\
\text { Control Group } \\
(\mathrm{n}=12)\end{array}$ & $\begin{array}{c}\text { Difference of means: } \\
\text { "t" statistic } \\
\text { and probability* }\end{array}$ \\
\hline Participation & 4.58 & 3.67 & $\begin{array}{c}1.44 \\
(.08) \\
\text { Motivation }\end{array}$ \\
Commitment & 8.58 & 8.03 & .81 \\
& 5.08 & 5.41 & $(.19)$ \\
Total Involvement & & & -.43 \\
* one tail probability & 18.04 & 17.11 & $(.34)$ \\
& & & $\mathbf{1 . 1 0}$ \\
& & & $(.14)$
\end{tabular}


Overall, subjects in the treatment group were observed to have on average a moderately higher score in the measure of "total involvement" than the control group. There was some irregularity, however, observed in the different subscale measures of involvement. The most substantial difference between the experimental and control groups was observed in the "participation" variable $(t=1.44 ; \mathrm{p}=.08)$. The observed differences in means between the two groups meant that subjects in the experimental group on average regularly performed nearly one additional activity to support the recycling program at their complex than did subjects in the control group.

Levels of the measures of "motivation" among subjects in the sample were observed to be marginally higher in the treatment group than in the control group with the difference being less than one third of a point on a scale of one to ten in motivation level. The small difference in means between the two sample groups is not surprising in considering that subjects in both groups had volunteered for the special project and were most likely to be similarly motivated to be involved in the recycling program in their complex. The results do show that there was little difference that being in the treatment made to the subjects' level of motivation.

In measures of the "commitment" level of coproducers, there is even more question about the influence of inclusion. In this measure, subjects in the control group were observed to have a slightly higher level of commitment than subjects in the treatment group. Though the difference in the comparison is small and statistically insignificant, the direction of the difference is of some interest. Possibly the higher level of participation can have a negative effect on the commitment levels of coproducers in that there is an increased task burden 
and possible "burn out" which would make the coproducer more easily discouraged from continued participation.

In sum, evidence from these results suggest that higher levels of direct participation in activities associated with the program did result from greater inclusion in the program. The small and statistically insignificant differences in levels of motivation and commitment, however, limited the amount of difference observed in the overall measure of involvement in the program between subjects in the two groups.

\section{Volition and Involvement}

A second important input to the implementation process specified in the research model concerns the level of personal volition of the citizen to be involved in coproduced program efforts. To examine the importance of voluntarism on actual involvement, the sample group of managers which declined to volunteer for the treatment was compared to the group of managers who did volunteer but were not assigned to participate in the treatment program. The subjects in each of these study groups were matched in several respects: they each had the same opportunity to participate in the City's recycling program; they had the same level of program support; they had been in the recycling program about the same length of time; and they manage complexes of similar size and rent range. Therefore, any differences observed between these two groups of managers can be attributed at least in part to different levels of volition. Using the same measures of involvement as were used in comparing the treatment and control group to these two groups of managers we can determine what potential influence the element of voluntarism has on the level of involvement in the program. The results of the comparison of 
means in the variables of manager involvement between the two groups and the t-statistic with associated p-values are presented in Table VI.

\section{TABLE VI}

MEAN INDEX VALUES FOR MEASURES OF INVOLVEMENT IN CONTROL AND NON-VOLUNTARY GROUPS

\begin{tabular}{lccc}
\hline Variable & $\begin{array}{c}\text { Means } \\
\text { Control Group } \\
(\mathrm{n}=12)\end{array}$ & $\begin{array}{c}\text { Means } \\
\text { Non-Voluntary Group } \\
(\mathrm{n}=12)\end{array}$ & $\begin{array}{c}\text { Difference of means: } \\
\text { "t" statistic } \\
\text { and probability }\end{array}$ \\
\hline Participation & 3.69 & 3.17 & .73 \\
Motivation & 7.00 & 5.42 & $(.22)$ \\
Commitment & 5.41 & & 1.63 \\
& & 4.50 & $(.06)$ \\
Total Involvement & 16.17 & & 1.15 \\
*one tail probability & & 13.08 & $(.13)$ \\
& & & 1.64 \\
\end{tabular}

Differences in levels of involvement between the control group and the non-voluntary group were observed to be substantially greater than between the treatment group and the control group. Also, unlike the results of the treatment and control group comparisons, the difference in the measure of "participation" between subjects in the control group and the non-voluntary group was observed to be the least significant of all the sub-scale measures of involvement $(\mathrm{t}=.73 ; \mathrm{p}=.22)$. The difference in the "motivation" level of subjects in the control group and the non-voluntary group, however, was observed to be substantial $(t=.1 .63 ; \mathrm{p}=.06)$. Subjects in the control group were observed to have on average one and one-half point higher levels of motivation on a scale of one to ten than the subjects in the non-voluntary group. Differences in the 
means of the measure for "commitment" between the two groups were observed, as well, with subjects in the control group having higher levels of "commitment" on average than subjects in the non-voluntary group.

In the overall involvement level index variable the subjects in the control group compared to the non-voluntary group were observed to have substantially higher levels of involvement $(t=1.64 ; p=.06)$. This finding is suggestive of an important relationship that exists between the level at which one is predisposed to volunteer their time and effort in a coproduced program and the level of involvement in the program that results.

\section{Achieving Program Results}

The research model utilized in this study specifies the achieving of desired program results as a key area of programmatic outcomes associated with higher levels of citizen involvement in coproduced programs. The goal of the multifamily recycling program is to decrease solid waste disposal amounts and increase recycling in multifamily residences. The role of managers is viewed as an important element in achieving that goal. Thus, the contribution that managers make to increased recycling in their complex occupies a central point of consideration in this study.

To determine the importance of the involvement of the manager as a citizen service provider in the coproduced program, each of the measures of involvement were correlated to levels of recycling observed at the complexes and the results of the correlation are presented in Table VII. The measures of recycling included in this analysis are derived from two types of observations: (1) recycling that was self-reported by the tenants (i.e. the total number of materials regularly recycled, the estimated percent of household refuse recycled, 
and the reported level of motivation to recycling); and (2) recycling measures independently observed by the investigator (i.e. percent of refuse recycled and contamination levels in recycling). The measure "total recycling" is the aggregate of the combined self reported and independently observed recycling measures.

TABLE VII

CORRELATION COEFFICIENTS OF MANAGER INVOLVEMENT MEASURES AND RECYCLING MEASURES

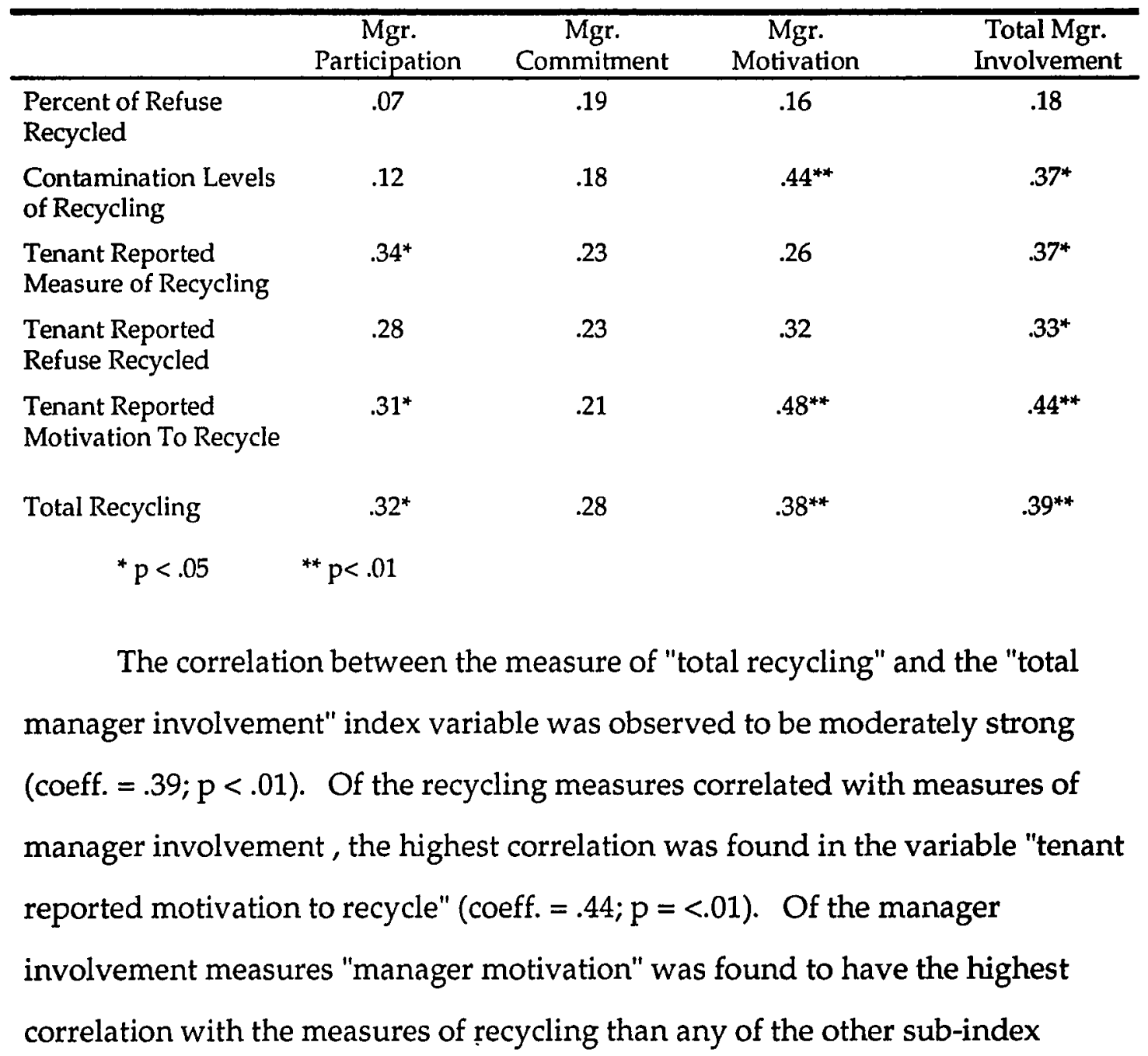


variables (coeff. $=.38 ; \mathrm{p}<.05$ ). A relatively consistent level of correlation in most measures of recycling is suggestive that the amount of manager involvement in the recycling program is positively related to higher levels of tenant recycling. The low correlation found in the "percent of refuse recycled" measure, however, raises some question to this finding.

A second analysis of the data performed concerns the differences observed in tenant recycling as a result of the experimental treatment. By comparing the means of tenant recycling before and after the treatment the effect that the experimental treatment had on recycling levels can be assessed. Table VIII presents the mean index values for both measures of refuse recycled and contamination levels observed in the pre-treatment period (t1) and the post treatment period ( $t 2)$. The percent of refuse recycled measure is reported as an average percent of total refuse recycled for each of the two 4-week measurement periods. The contamination measure is reported as the value assigned to total levels of contamination observed in each four week measurement period, with the higher value being an indication of lower contamination levels.

TABLE VIII

MEAN INDEX VALUES FOR MEASURES OF COMPLEX RECYCLING BEFORE AND AFTER EXPERIMENTAL TREATMENT

\begin{tabular}{lccc}
\hline Variable & $\begin{array}{c}\text { Means t1 } \\
(\mathrm{n}=12)\end{array}$ & $\begin{array}{c}\text { Means t2 } \\
(\mathrm{n}=12)\end{array}$ & $\begin{array}{c}\text { Difference of means: } \\
\text { "t" statistic } \\
\text { and probability* }\end{array}$ \\
\hline Percent of Refuse Recycled & 19.17 & 19.33 & $\begin{array}{c}.74 \\
\text { Contamination }\end{array}$ \\
* one tail probability & 12.23 & 13.76 & 1.83 \\
& & & $(.04)$
\end{tabular}


The results of the mean comparison between $\mathrm{t} 1$ and $\mathrm{t} 2$ demonstrate a mixed result. Contamination improvement was observed to increase by one and one-half points $(t=1.83 ; p=.04)$ on a scale from 0 to 16 , with "16" representing no observed contamination over the entire 4-week measurement period. However, virtually no differences in the "percent of refuse recycled" measures were observed. These findings suggest the importance of the experimental treatment program in increasing the quality of recycling by reducing the level of contamination experienced but leave questionable the importance of the treatment to increasing levels of recycling.

The analyses of manager involvement and tenant recycling presented up to this point do not control for possible influences of other variables in accounting for the observed differences in recycling between the subjects in the sample. To control for these a regression model was specified and the results are presented in Table IX. As modeled, the dependent variable is "tenant recycling" which is the aggregate index variable of self reported levels of tenant recycling. The independent variable is the manager involvement index. The control variables include both demographic characteristics (i.e. age, income, and education level of tenants) and situational factors (i.e., the convenience of using the recycling collection system in the complex as determined by proximity of and barriers to the recycling collection containers). Both demographic characteristics and convenience factors have been strongly linked to recycling participation by other research (Vining \& Ebreo, 1989; Oskamp, et al., 1991; Folz, 1991b, Blake, et al., 1991). Thus, if the manager involvement has a statistically significant regression coefficient when controlling for the characteristics of the tenant demographics as well as situational characteristics of the recycling system, then levels of recycling were determined to be significantly influenced 
by the level of manager involvement. The sign of the coefficient indicates the direction of the change.

TABLE IX

MULTIPLE REGRESSION ANALYSIS OF RECYCLING PARTICIPATION IN MULTIFAMILY RESIDENTIAL COMPLEXES

\begin{tabular}{lc}
\hline $\begin{array}{l}\text { Independent } \\
\text { Variable }\end{array}$ & $\begin{array}{c}\text { Standardized Regression } \\
\text { Coefficient }\end{array}$ \\
\hline Manager Involvement & $.227^{*}$ \\
Average Education Level of Tenants & $.278^{*}$ \\
Average Income Level of Tenants & -.013 \\
Age of Tenant Respondent & -.121 \\
Convenience of Recycling Shelter & $.331^{* *}$ \\
\hline $\mathrm{R}^{2}$ & .484 \\
F-ratio & 5.791 \\
Significance of F & .01 \\
Number of Cases & 36 \\
& $*<.05$
\end{tabular}

In this regression, the level of manager involvement is seen to be a significant determinant of recycling as reported by tenants. Though the level of influence is determined to be somewhat less than the convenience features of recycling and the education level of tenants, there is evidence in these findings of the importance of the manager's role in influencing tenant recycling.

In sum, the findings are suggestive of the importance of the involvement levels of managers in the program in not only increasing the level of recycling, but also the quality of recycling (i. e. lower contamination levels) from tenants in their complexes. In considering the different sub-index variables of involvement, the dispositional attributes of the manager's involvement, 
specifically measures manager motivation, were observed to be more closely associated with tenant recycling than participation measures. Similarly, the motivation levels of tenants to recycle appear to be more closely associated with manager involvement than other measures of recycling. Tenant reported measures of recycling were found to be associated with manager involvement. There are questions raised in these findings, however, on the importance of the manager's involvement in increasing the level of recycling when considering recycling measures that were independently observed. These questions cast some concern about the conclusiveness of the findings.

\section{Civic Engagement and Involvement}

The second area of investigation seen to be an outcome of involvement in coproduced programs is an expanded level of community and civic involvement on the part of the coproducer. Table X exhibits the correlation coefficients of the measures of manager involvement and the measures of civic engagement as specified in the research model.

TABLE $X$

CORRELATION COEFFICIENTS OF MANAGER INVOLVEMENT AND MEASURES OF CIVIC ENGAGEMENT

\begin{tabular}{lcccc}
\hline & $\begin{array}{c}\text { Mgr. } \\
\text { Participation }\end{array}$ & $\begin{array}{c}\text { Mgr. } \\
\text { Commitment }\end{array}$ & $\begin{array}{c}\text { Mgr. } \\
\text { Motivation }\end{array}$ & $\begin{array}{c}\text { Total Mgr. } \\
\text { Involvement }\end{array}$ \\
\hline $\begin{array}{l}\text { Community } \\
\text { Involvement }\end{array}$ & -.05 & .10 & .13 & .09 \\
Coproduction & $.37^{*}$ & .24 & .24 & $.37^{*}$ \\
$\quad{ }^{*} \mathrm{p}<.05$ & ${ }^{* *} \mathrm{p}<.01$ & & &
\end{tabular}


The results of the correlation between the measures of civic engagement and manager involvement are mixed. A low correlation is seen to exist between manager involvement in the recycling program and the manager's involvement in the community. On the other hand, in correlating the measure of "total manager involvement" and "coproduction" (i. e. the appreciation and willingness to be involved in partnerships with government in addressing community problems) a moderately strong correlation was found to exist (coeff. $=.37 ; \mathrm{p}=<.05$ ). In considering the sub-scale measures of involvement, the strongest correlation is found in the measure of "manager participation" and "coproduction" (coeff. $=.37 ; \mathrm{p}<.05)$.

To examine more closely the effect of involvement on factors of civic engagement the treatment group was compared to the control sample group. This is done to consider the importance of inclusion and higher levels of participation in coproduced programs in influencing the level of civic engagement of the citizen coproducer. The results of the comparison of means in these variables are presented in Table XI.

TABLE XI

MEAN INDEX VALUES FOR MEASURES OF CIVIC ENGAGEMENT IN TREATMENT GROUP AND THE CONTROL GROUP

\begin{tabular}{lccc}
\hline Variable & $\begin{array}{c}\text { Means } \\
\text { Treatment Group } \\
(\mathrm{n}=12)\end{array}$ & $\begin{array}{c}\text { Means } \\
\text { Control Group } \\
(\mathrm{n}=12)\end{array}$ & $\begin{array}{c}\text { Difference of means: } \\
\text { "t" statistic } \\
\text { and probability* }\end{array}$ \\
\hline $\begin{array}{l}\text { Community } \\
\text { Involvement }\end{array}$ & 4.17 & 3.13 & 1.49 \\
Coproduction & 4.67 & & $(.10)$ \\
& & 3.17 & 1.84 \\
Total Civic & 8.83 & & $(.05)$ \\
$\begin{array}{l}\text { Engagement } \\
\text { * one tail probability }\end{array}$ & & 6.30 & 1.79 \\
$\quad$ & & $(.06)$
\end{tabular}


In the results, the treatment group was observed to have a higher mean in measures of "civic engagement" than the control group $(t=1.79 ; p=.06)$. Likewise, subjects in the treatment group were observed to have higher levels of "community involvement" $(\mathrm{t}=1.49 ; \mathrm{p}=.10)$; and "coproduction" $(\mathrm{t}=1.84 ; \mathrm{p}=$ $.05)$.

In summary, the results provide two levels of evidence. First of all, when the level of manager involvement was correlated with measures of civic engagement the results were mixed. There was little evidence in the findings to suggest that community involvement as specified in the research model is tied to the program involvement levels of the coproducer. This result is disappointing to the presumption that such involvement is associated with being more aware and involved with broader community matters by the citizen coproducer. There was evidence in the results, however, that the level of manager involvement is associated with positive attitudes about citizen/government partnerships in coproduced programs. Secondly, when comparing the treatment group with the control group, the levels of civic engagement were observed to be different, with subjects in the treatment group being observed to have higher levels of both community involvement and more favorable attitudes toward citizen/ government partnerships. This result is suggestive of the importance of inclusion in coproduced programs to other attributes of community and civic participation.

\section{DISCUSSION}

The research conducted in this study has considered both the inputs to citizen involvement (i.e., inclusion and volition), and the outcomes of citizen 
involvement (i.e., the achievement of program results and civic engagement). The research has focused on measures of these elements and has sought to demonstrate the importance of each to the implementation process as expressed in the city of Portland's multifamily recycling program. A discussion of the key findings of this research follows.

\section{Inputs to Citizen Involvement}

The first set of concerns addressed by the research in this study is the importance of inclusion in increasing the level of citizen involvement in coproductive implementation processes. The treatment administered in this study gave both the opportunity and responsibility to the citizen service provider to be involved in the recycling program at higher levels than what was normally the case in the city's recycling program. The areas of responsibility assigned to treatment group members included not just the routine custodial responsibilities of the recycling equipment and service, but rather opportunities to participate in problem solving processes. When the levels of involvement of the treatment and control groups were compared, there were differences observed in the participation levels in the program, with subjects in the treatment group participating in more activities to support the recycling program at their complex. This result can be interpreted as evidence for the importance of inclusion to securing a higher level of participation in coproduced programs and as such is consistent with other research which has investigated the potential of policies which seek to extend public involvement through broadening inclusionary implementation strategies. Bacot, et al., (1993) conclude that more intensive efforts on the part of implementing agencies to seek the input on optimal strategies have the potential of turning disinterested 
citizens into "citizen experts" who not only coproduce service but inform policy. The results from this study, however, give cause to limit the conclusiveness of this finding. That is, the differences in the other aspects of involvement, namely levels of motivation and commitment, were observed to be non-appreciably different between the treatment and control groups. This could be suggestive that the increased involvement in the program as measured by direct participation could be short term if not sustained with sufficient levels of motivation and commitment on the part of the citizen coproducer to stay involved in the program.

The second input to citizen involvement specified in the research model is the effect of the volitional level of the citizen coproducer to be involved in the program. This variable was controlled by comparing the levels of involvement of the voluntary control group and the non-voluntary group. The results of this comparison demonstrated a relatively large and significant difference between the two groups in the overall measure of involvement and in the dispositional sub-scale measures of motivation and commitment. There was a nonsubstantial difference observed in participation levels of subjects in the two groups. In considering the importance of these findings two issues emerge. Managers who volunteered and were willing to contribute more of their time to the recycling program would appear to be more motivated and committed to the recycling program. Therefore, the results can be viewed as confirmation of this assumption. Secondly, the fact that there were relatively substantial differences in motivation levels and less substantial differences in the actual participation levels suggests a potential discrepancy between what people say is important to them and what they actually do. Such a discrepancy has been 
noted in other research on professed environmental attitudes and actual behavior (Vining and Ebreo, 1990).

\section{The Programmatic Qutcomes of Citizen Involvement}

Furthering Recycling. Of central importance to this study is the potential importance of the manager in influencing the level of tenant recycling. In this regard, the different analyses completed in this research provide evidence that the role the manager plays with regards to the recycling program makes a difference in the outcomes of recycling. The role of the manager in influencing levels of recycling participation of tenants is potentially similar to other roles that have been observed to be effective in influencing recycling participation of others. Researchers in curbside recycling programs for single family residences have observed the influence that block leaders have had on the recycling levels of households in their neighborhoods. The purpose of the block leaders approach was to introduce people who might influence the opinions and behavior of others in recycling through frequent interpersonal contact. Investigations of programs which have utilized the block leader approach have led researchers to conclude that block leaders can actively shape recycling norms and behaviors (Hopper and Nielsen, 1991). The relatively strong association between manager involvement and what tenants reported as both their motivation and practice of recycling suggests that managers do shape tenant recycling attitudes and self-reported behavior.

The measures of the level of actual tenant recycling are of some concern to these findings, though. As noted, the tenant reported measures of recycling were observed to be the measures of recycling most consistently associated with manager involvement. However, the potential influence of the manager on 
actual tenant recycling is brought into question in independently observed measures of recycling. In these measures, the association between manager involvement and tenant recycling is less evident. This problem can be partially explained by difficulties inherent in the method of measurement used in this research. Actual measures of recycling, were obtained by estimating volumes of both recycling and refuse. Though standardized methods were used for estimation, levels of compaction of material in the containers can affect perceived volumes in some cases by sizeable amounts. In addition, over the course of field research, circumstances were encountered where both refuse and recycling were not in containers compounding the problem of estimation. Thus, this method of measurement creates the potential for over or underestimating the actual amount of refuse recycled. For this reason, the tenant reported measures, though also prone to sampling and measurement error, are potentially more useful in this study. This does not, however, completely remove the concerns over the conclusiveness of findings in regards to actual amounts of recycling that was observed and used in this analysis.

Another important individual measure of recycling which demonstrated an important association with manager involvement was in the area of contamination. Lower recycling contamination were observed in complexes with higher manager involvement. Though this result could be interpreted to mean that the more involved manager is merely cleaning up after tenants who improperly prepare or separate their recyclables, there is evidence that this is more the result of the effectiveness of managers who spend time with education and communication with tenants. This is mostly evident in numerous feedback from managers in the treatment program who reported having to spend less time cleaning up when they invested more of their time in supporting the 
program by concentrating on ways to educate and make more tenants aware of proper recycling.

Furthering Civic Engagement. The second outcome of involvement specified in the research model regards the level of community and civic engagement on the part of the citizen coproducer. In considering the relationship between levels of involvement in the coproduced program and measures of involvement in the community the results of the research were mixed. The results of correlation analysis failed to provide evidence to support the assumption that higher levels of involvement in coproduced programs are associated with broader expressions of community involvement. When the element of inclusion was considered by examining the effects of the experimental treatment program, however, there was some limited evidence provided that expressions of increased participation in coproduced efforts are associated with increased measures of community involvement. There may be some light shed on the inconclusiveness of the evidence when considering issues inherent in the measures of community involvement used in this research. Expressions of community awareness and involvement occur over time. The relatively short time frame in which the study observed differences in these measures limits the possibility for capturing what effects that longer term participation in coproduced programs will have on civic engagement. Also, in considering the case illustrations in which managers expressed anecdotally experiences in the recycling program which addressed elements of community awareness and appreciation, there are quite possibly individualized experiences which over the long term will produce greater involvements in the community. In measures of coproduction, there was more conclusive evidence that levels of involvement in the program contribute to this sub-index measure of 
civic engagement. Correlation coefficients were seen to be relatively strong between measures of manager involvement and coproduction. Also, members of the treatment group were on average more prone to have positive attitudes toward government in general as partners in both recycling and community problem solving. In this regard, possibly the combined effects of being involved with the recycling program and having access to higher levels of communication and support from the implementing agency are contributing factors to this higher sense of partnership. Managers in the treatment group confirmed this in expressing positive experiences in the program which would make them inclined to work with local government again in addressing important community problems. 


\title{
CHAPTER V
}

\section{CONCLUSION}

\author{
OVERVIEW
}

The purpose of this study was two-fold: (1) to construct a model of coproduction which provides a basis by which citizen involvement in the provision of public services can be understood and appreciated, and (2) to examine the usefulness of this model by using it to frame and guide evaluative research on a specific program which targets coproductive participation of citizens. In this concluding chapter, the implications of the model and research to both the theory and practice of coproduction as well as the need for further research will be considered. In the final section consideration will be given to the need for renewing expressions of active citizenship and some thoughts will be presented on how that can be done within the coproductive policy processes.

\section{THE THEORY OF CITIZEN INVOLVEMENT AND COPRODUCTION}

\section{Two Perspectives of Citizen Involvement and Coproduction}

Coproduction has commonly been considered in the literature to be a partnership between public and private entities in achieving public benefits. Though most researchers on coproduction agree on this basic characterization, there are key differences in perspectives of coproduction as a means of policy 
implementation. These differences are largely the result of how public benefit is characterized and understood which in turn largely determines the character of the partnership that is envisioned within coproductive efforts. For purposes of discussion, views of coproduction can be seen as either having an economic or a civic perspective. From the economic perspective, coproduction is largely viewed as a means for the improvement of government services; that is, as a means of raising the amount of production or the efficiency of the production of goods and services for public consumption. The partnership that exists between government and the citizenry from this perspective is one characteristic of an economic relationship, with citizen consumers being able to trade their services for more consumption of public goods or lower costs. As such, citizens involved in the process raise the amount or quality of public goods and services of which they will be consumers. Citizen involvement from this perspective is largely driven by private interests. As Richard Rich (1981: 63) states, citizen participation results "as a calculated response to opportunities in the citizen's environment (and the) calculation involved is 'rational' to the extent that people are expected to weigh the anticipated costs and benefits of alternative actions, and to choose the alternative offering the greatest net benefit." From this perspective citizen involvement in the coproduction process appears more as a set of transactions between government and citizens, with each party bargaining for the right mix of costs and benefits.

A civic perspective of coproduction considers not just the delivery of goods and services but also a more involved citizenry in the coproduction process. In this perspective citizens are more than potential consumers of benefits derived from their involvement in the implementation process, but are active participants with government in solving problems within the community. 
As Gordon Whitaker observes (1981: 244), "In some public service delivery situations, agents and citizens interact to establish a common understanding of the problem and what each of them can do to help deal with it." In this process, a transformation of citizen and government agency occurs based on their joint consideration of a problem. As such, partnership is not so much viewed as a transaction between two parties governed by economic rationale, but rather one that is characterized as an interaction among public agency and citizen coproducers in joint participation within a process of problem solving. The result being a more responsive and responsible system of governance and an enhanced conception of citizenship (Brudney, 1985).

\section{The "Ins" and "Outs" of Citizen Involvement}

This study has considered both the economic and civic perspectives of coproduction. The thesis of this study has been that coproduction involves both instrumental goals of increasing the quantity and quality of goods and services and integrative goals of furthering citizenship engagement. The model of citizen involvement and coproduction developed in this study provides a framework for understanding and a guide for investigation into coproductive processes. Central to the model is citizen involvement. Citizens directly participating in the delivery of goods and services is what distinguishes the coproduction implementation process from other policy forms. As a policy means, citizen involvement has been viewed in this model to be both the result of the coproductive process as well as a key in determining the results of the process. Thus, both the inputs and the outcomes of citizen involvement are central to understanding coproduction. In the model, inputs to citizen involvement in coproductive processes were specified to be from both 
government sources and the citizens themselves. Government is seen to provide the inducement, opportunity and support for citizen involvement. The citizen brings a level of capacity, interest and willingness to be involved. Both the inclusionary inputs of government and volitional inputs of citizen combine to establish the basis for citizen involvement. The outputs of citizen involvement in coproductive processes involve both the production of public benefits and the increased levels of civic engagement of the coproducers.

The research conducted in this study addressed both the inputs and outcomes of citizen involvement in coproduction and provided an opportunity to investigate the relationships between citizen involvement and the coproduction implementation process and outcomes within this model. From this research emerged a number of findings that provide substantiation to some of the key assumptions and leave additional questions as to others. Findings of this research are suggestive of the potential importance of both inclusion and volition to furthering citizen involvement in the coproductive process. In this regard, considerations which contribute to the citizen's will to participate appeared relatively more important to eventual involvement than efforts made by government to include the citizen in the process. As to the outcomes of coproduction, a mixed finding resulted from these investigations. The level of citizen involvement in producing the programmatic outcomes was by most measures demonstrated to be very important. The results of the investigation in demonstrating the importance of involvement in coproduced programs to citizenship was not so clear. Citizen enhanced expressions of community attachment and civic capacity associated with involvement were not clearly demonstrated to be important but indications that higher levels of inclusion in coproduced programs were more clearly associated with community 
involvement. The second measure of civic engagement, namely the favorable disposition of the citizen coproducer toward citizen/government partnership, was observed to be greater with higher levels of citizen involvement as well.

In sum, the model developed in this study provides a potentially useful conceptualization of the process and outcomes of coproduction. The empirical investigation provided in this study helps assess the nature and strength of the relationship between citizen involvement and the inputs and outcomes of the coproductive process in the case of Portland's multifamily recycling program. Both the economic and civic considerations of coproduction which were specified and measured in the research contribute to a number of observations about coproductive implementation processes in public policy. A discussion of those policy implications follows.

\section{POLICY IMPLICATIONS}

In addressing the problem of implementing recycling within multifamily residences, the City of Portland has implemented a policy strategy built on coproduction. The investigations that were conducted on this program yield a number of observations of policy relevant issues which could guide other coproductive efforts in similar policy arenas.

\section{Appropriate Policy Arenas for Coproduction}

Portland's multifamily recycling program has been shown to be both voluntary and inclusive of citizen partners to coproduce the desired benefit of multifamily recycling. Both premises have been substantiated by the experience 
of the program. Recycling involves the individual in activities associated with everyday behavior. As such, policies addressing recycling depend greatly on the motivation and commitment of participants. Voluntarism, therefore, can be seen as an appropriate basis for such a policy designed to result in higher levels of recycling. Secondly, recycling is demonstrated to be affected by situational factors of convenience and social support. Managers of multifamily residences have access and contribute to these factors. As such, a partnership which establishes the place of the manager as a key policy component in furthering the implementation of the program is seen to be well founded. Coproduction can be viewed to have broad application in other arenas where personal behavior and/or potential benefit accrue to citizens. Such arenas as crime prevention, education and environmental protection have been demonstrated to be important areas for coproductive strategies. As successful as these efforts have been, caution must be exercised as to how generalizeable these experiences are to other policy arenas. Some problems facing the community may well be outside of the coproductive strategies as a main policy thrust. For example, approaching the problem of toxic waste clean-up of contaminated sites, the federal Superfund policy combines a strategy of prosecution, direct government intervention and accommodation to achieve clean-up of sites under private ownership. In this program where the stakes are high and responsibility is limited, participation may only be available through stricter measures of prosecution and enforcement. But even in this arena, the need for voluntary cooperation of the private entities has been viewed to be a critical link to successful implementation (Church and Nakamura, 1993). 


\section{Citizen Coproducers and Social Roles}

In this study, managers of multifamily residential complexes were examined as citizen coproducers in a public program to expand recycling participation. To determine the applicability of strategies and outcomes experienced in this program to other policy arenas it is appropriate to consider the unique role which is played by managers in the program. As noted, the role of the manager as a coproducer is integral to their broader social role within the multifamily environment. Their position is one of potential influence of other coproducers of recycling, namely the residents of the complexes which make personal choices on recycling. The manager's participation in coproductive efforts with the City, however, is mixed with and potentially confounded by other responsibilities and perspectives which are inherent in their managerial position. As such, their role as a coproducer offers unique opportunities as a partner in implementing a recycling program, but also their role puts special demands on coproductive policy strategies. Involving the manager as a coproducer in recycling on the one hand, affords the opportunity to have greater impact on more potential recyclers, but on the other hand, presents the need to provide high levels of understanding and support of their position by the implementing agency. Other social roles within the community occupy similar positions as managers as potential citizen coproducers. For example, neighborhood store owners and clerks who regularly interact with resident customers could be involved in coproduced strategies of neighborhood crime reduction and prevention; or individual trades persons such as builders, car mechanics, gardeners, could be involved in coproduced strategies of energy savings, neighborhood enhancement or even environmental protection. 
Positions such as these are in potentially influential positions over the day to day practices and perspectives of other citizen coproducers in community improvement and public service activities and as such offer a potentially rich and varied community problem-solving resource for policy implementation.

\section{Use of Extra Agency Resources}

Portland's multifamily recycling program is unique in another way. As a coproduced program, the City has involved a partnership with not only the managers but with Portland State University as a partner with the implementing agency. In this relationship, the resources and involvement of a large educational institution working in concert with the City of Portland, provides a sizable base of agency support and legitimacy to the program. The role played by Portland State is recognized by the City to be not just the mere extension of the City but also an increase in resource and an expanded focus of the program. This has resulted in a program more responsive to needed change and innovation. In addition, this partnership is an assurance to citizen coproducers of the city's commitment to the community members that attempts are being made to ensure that resources are available for community problem solving and successful implementation. Such an approach is informed by other experiences and observations of successful coproduction implementation. Richard Sundeen (1985: 399) provides guidance that "the local administrator must give close attention to an additional set of externally related roles with the purpose of bringing in new resources or capturing existing, but unused, resources for coproduction." Richard Rich (1981) has seen the value in such arrays in creating conditions that will stimulate volunteerism by citizens -- for example, ensuring that adequate resources are available for problem solving, reducing the costs of 
communicating with local government, and presenting government as an ally in efforts to improve the community and the decentralization of decision-making. The partnership between the City and Portland State University provides an array of institutional and community resources which ultimately support the role of the citizen coproducer.

\section{Investment in Citizen Resources}

Much of the initial enthusiasm for coproduction among policy makers was the impulse of cost savings by off-loading government expenses to volunteers within the community (Moe, 1987; Morgan and England, 1988). But more careful examination of coproduction implementation processes reveal other realities. Jeffrey Brudney (1985:474) observes, that in coproduction..."the costs of service delivery can be expected neither to decline nor to remain constant. The key issue for productivity assessment is whether the increase in costs is surpassed by gains in service amount and/or quality." As seen in Portland's program, the cost for the program are largely associated with inducement and capacity building functions of the coproducer. Clearly, the cost of the recycling equipment born by the City is an inducement to the program. The costs associated with supporting the role of the manager on the program, however, is at least as great if not greater than the cost of the equipment. But as the City staff administrator for the program stated, "the investment of this program is in people." The investment is seen as warranted by the City in securing the long term service provided by the manager in promoting the recycling program to the tenants. The importance of the manager in providing the on-site support and promoting the use of the recycling as well as solving problems promise to make the program more effective than if government had 
bypassed the manager's direct involvement. As researchers of coproduction have noted, however, the potential costs associated with citizen involvement and costs of efforts to involve other groups as "citizen experts" can be extensive (Bacot, et al., 1993; 38).

\section{Mutual Adjustment}

Gordon Whitaker (1980:245) observes that a fundamental prerequisite for citizen involvement in coproductive efforts is that "citizens, as well as agents, must be willing to recognize the legitimacy of the public policies the agents are charged with implementing. Citizen participation in the reciprocal transformation of agent and citizen expectations and actions is a means for making services most effective." Such mutual adjustment does not, however, involve the interaction of equals. The service agent almost always has greater resources. Greater authority gives the official more ability to prescribe actions. But as Friedson (1968) in a study with doctor/patient relations and Morris (1974) in a study of prison guard/inmate relations have noted, efforts to adjust human behavior through the use of greater authority does not always work. Authority, like the tasks of implementation themselves, must be shared to induce the kind of personal change which many citizens' problems seem to demand. In the case of managers functioning as coproducers, the question of authority is multidimensional. The manager occupies a position of perceived authority within the multifamily environment. Recycling, however, is a personal act which is subject to an individuals own will. Managers as coproducers in a recycling program must translate the authoritarian elements inherent in their position to the supports and adjustments needed to influence the personal behavior of tenants to recycle. In addition, within the context of the recycling 
program, the authority of program implementation is shared between the manager and the City. Consensus and mutual adjustment between public and citizen agent are continuous throughout implementation. As the City's program administrator noted in regards to the manager's role, the "power" is with the manager; the city views their role as offering guidelines and increased capacity to inform and prepare the manager for their role in the program.

\section{Public Policy and Citizen Inclusion}

Policy arenas such as recycling, which are mostly dependent on citizen innovation, require widening the spectrum of citizen stakeholders in the implementation process. Therefore, by considering policy strategies to increase stakeholders through inclusion and involvement will likely increase the kind of initiation and innovation required for program success. In considering the inputs of involvement by inclusion, it is also important to consider the support for expanded citizen roles in coproductive efforts. In that regard a number of managers in the treatment group expressed the importance to them to know that there was assistance that could be provided in their roles within the program. As one manager observed, it was "one thing for me to know that my (nonEnglish speaking) tenants needed a translated brochure (on recycling), it was another thing for me to have to find someone to translate it." With the help of the implementing agency, the translation was done.

\section{Coproduction and Community Cohesion}

Richard Sundeen (1985) notes that coproduction increases the need for local administrators to take on new roles or modify their current roles based on the level of community cohesion that exists. In communities which have a high 
degree of cohesion, the administrator role is more defined by facilitation and brokerage. This involves helping to identify needs and citizen resources within the community to address those needs. In communities with less cohesion, facilitation and brokerage activities must be preceded by community development strategies which consist of ways to increase the education, empowerment and community awareness of members in the community. In approaching the multifamily environment and managers as coproducers of recycling, a number of barriers were faced which potentially limited the managers from participating in the program. Many of these barriers such as isolation, conflicting roles, and cynicism about tenant cooperation are inherent to their position as manager within the complex. The tasks of the coproduction of recycling must, therefore, include opportunities and support for building a sense of involvement of the manager to overcome these barriers. The investigations in this study consider the importance of coproductive involvement of citizens in building increased capacities and incentives to be involved in broader community and civic activities. Unfortunately, the results in this regard were demonstrated to be somewhat mixed. The limitations of a relatively short time frame for this research which would allow for measurement of any of the community building "effects" of coproduction, may well be a major source of the problem in this regard. Experiences and levels of awareness in community activities take time. As we saw in the case examples of managers participating in the program, however, indications of community building processes were evident in their experiences: empowerment coming from self-discovery and confirmation of their work; sense of community coming from new levels of understanding about the tenants; and isolation and cynicism being overcome by successfully connecting to higher levels of understanding of 
issues in the community and greater appreciation of the tenants in the complex. In these cases, the opportunity to be involved and the support for the involvement of the manager as problem solver and decision maker was an important element in contributing to the manager's increased capacities and awareness. These experiences are suggestive of the importance of implementation strategies which provide opportunities in community building activities and as such could be seen as an important element in guiding other coproductive policies where citizen coproducers face similar barriers to participation in public programs.

\section{$\underline{\text { Redistribution of Policy Implementation Resources }}$}

Citizen involvement requires not only interest of the participant to be involved but the capacity and opportunity to be involved. These prerequisites work to the potential detriment of those who have fewest resources to invest. In addition, there are those as well who lack sufficient interest but occupy a position in which their participation is needed to successfully implement the program. Such has been the case with the City of Portland's program where there has been an uneven distribution of participation on the part of managers in the program throughout the city. This has created a portion of the city's population without access to the recycling program at their complex, creating a potential lack of performance and accountability of the program. Such policy strategies as increased inducements and/or greater efforts to inspire or solicit involvement of the reluctant participant may be needed in order to eliminate this disparity. Not all researchers, however, are so convinced that efforts to involve sufficient number of coproducers through voluntary means can occur even using greater inducements and supports. Max Neiman, (1988) in studying 
government efforts to elicit voluntary energy conservation efforts through the coproduction activities of relying mostly on information diffusion and assistance to households, concluded that the program produced little in the way of energy savings beyond those expected by ordinary market responses to price changes. Because of this, the potential for some type of government coercion might be needed to operate, albeit in tandem with coproductive strategies, if the goal of providing all multifamily residents the opportunity for recycling in their complex is to be accomplished.

\section{CHALLENGES FOR FURTHER RESEARCH}

The City of Portland's multifamily recycling program has been demonstrated to be a success in both accomplishing the policy objectives of expanding recycling into multifamily residences and in engaging the active participation of managers in a strong partnership with the City. The degree of success in recycling in multifamily residences is both impressive and instructive to other coproduction efforts. But there are questions which still persist which limit the conclusiveness and genteralizability of the findings. The questions arise as a result of limitations faced by this research as well as some unresolved critical issues faced by the program.

\section{Defining and Measuring Citizen Involvement}

The key variable for the research conducted in this study was the involvement of citizens in coproduced programs. There are problems, however, associated with efforts to define and measure citizen involvement. In this study, 
citizen involvement was seen to involve both behavioral and dispositional indicators. Specification of citizen involvement and the use of multiple indicators is potentially problematic. Though the specification of this concept was modeled after other similar studies in citizen involvement (Haeberle, 1987), there is generally a shortage of studies which have operationally defined and used the concept in other than one dimensional terms specific to the subject of research such as voting, membership in volunteer associations, etc. (MacNair et al., 1983; Rosener, 1978). In addition, indicators used in this study for the variable of citizen involvement were self-reported and potentially influenced by the nature of the research. That is, managers in the treatment group had a more visible and consistent relationship with the investigator and as such could have felt motivated to overstate their involvement. Though efforts were made to limit this in the investigation there is the potential problem of "over reporting" that could have persisted. These problems suggest the need for further research to validate the indicators used to measure citizen involvement before confidence can be established in the role that this variable has in coproductive implementation processes.

\section{Inclusion and Volition as Policy Concepts}

The concepts of inclusion and volition were examined in the context of this study as key independent variables in determining citizen involvement. Both of these concepts were operationally defined in the research design: inclusion referring to the higher level of responsibility and involvement in the policy process of managers in the treatment group; and volition referring to the willingness of managers to volunteer for the treatment program which included those subjects in the treatment and control groups. Though this approach to 
characterizing the two concepts were useful for purposes of this study, there are important questions about these concepts which have arisen from this study. Implicit in this study is that inclusion refers to broader levels of citizen involvement within the policy process other than just participation in a nominal service delivery process. Inclusion involves citizen assessments and problemsolving functions as well. This, however, raises questions as to how these and other means of citizen involvement should and could contribute to influencing the quality and quantity of public policy and service provision. Though the inclusion of citizens in the broader levels of policy development and implementation in coproductive processes has been the subject of scholarly attention (Percy 1986; Bacot, et al, 1993), there remain important issues of citizen inclusion in policy implementation strategies which require further investigation. Though the various factors of voluntarism was beyond the scope of this study, the importance of the citizen's will to be involved in public programs and considerations affecting the "supply and demand" (Sundeen, 1986) of volunteers occupies an important part of continuing investigations in coproductive policy research. For example, the findings of this study are suggestive of an important difference between levels of participation in terms of time and effort between the subjects in the sample groups who were volunteering their time in the program. A fruitful area of investigation would be to examine the factors which contribute to those differences.

\section{Building Citizenship through Coproduction}

As previously noted, citizenship enhancement which may occur through involvement in coproduction is difficult to observe in a study which does not consider these effects over time. In this study, there was limited evidence that 
was observed which suggested the importance of involvement in coproduction to measures of community awareness on the part of citizen coproducers. Important indicators of this potential did emerge through anecdotes of managers' experiences as well as in the measures of increased levels of citizen investment in the coproductive process. A broader and more conclusive understanding of the effects of coproduction in building civic engagement, however, remains for further investigation within a longitudinal research design.

\section{Resolving Uneven Participation}

The City's commitment to voluntary participation in coproduction to address the City's goal of equal opportunity for recycling to all households of multifamily residential complexes is at risk of being unmet through the current inducements offered by the program. As such, problems previously noted that coproduction devolves to the most willing and able to participate could limit the ultimate success of the program. As to whether the current strategy requires modification from reliance on inducements and voluntary participation will need to be addressed in additional study.

\section{Institutionalization of Coproduced Efforts}

The City's strategy to utilize managers as a partner in the efforts to attain and sustain recycling participation in multifamily residences has a short history. This combined with the problem of the mobility of managers in moving to different complexes raises questions about the ability of the City to sustain a program based on the active participation of managers. In addition, research 
has questioned the longevity of the changed behavior based on programs of inducement and external support (Katzev and Pardini, 1987). To determine the degree to which such programs as the City's multifamily recycling efforts can be institutionalized and the extent to which coproductive efforts will endure over time will require further research and longitudinal study.

\section{Measurement of Multifamily Recycling Levels}

One of the difficulties encountered in this research concerned the method of measuring the level of recycling in multifamily residences. Refuse and recycling are in most cases collected in aggregate containers in centralized areas within the complex. Measurement of the amounts of refuse and recycling are problematic in these circumstances in that the containers are large and irregular shaped and compaction of material varies, making volume estimation difficult. Further research is needed which has access to the resources necessary to obtain more reliable measurement methods (e. g. weight based measures).

\section{REINVENTING COPRODUCTION}

The theory of coproduction poses a language and a set of concepts by which to design and implement innovative service delivery systems. Experiences with coproduction, as with Portland's multifamily recycling program, demonstrates the potentials of such a policy approach for improving urban service delivery systems and enhancing citizenship. Much of the potential that coproduction has for innovation in urban services, however, is subject to a number of forces which both distract and divert its potential. The 
distractions from coproduction as a legitimate form of urban service delivery come from those that see coproduction as an illegitimate means of reducing needed public resources to address urban problems. The diversion of the potential for the concept has come from the proponents of privatization who promote government reform by turning more of the responsibility of government to the private sector where efficiencies are seen to be much greater. Current interest in "reinventing government" (Osborn and Gaebler, 1992) is a recent expression of the impulse to increase the privatization of government functions. Simultaneous to these distracting and diversionary forces, on the other hand, is a growing amount of scholarly attention to the need for active citizenship and for a rejuvenation of democracy. Such arguments give renewed relevance to coproductive processes. In concluding this study, therefore, it is useful to examine more closely the contemporary forces which challenge new expressions of coproduction. Thus, what follows is a brief discussion on the need for and the means to reinventing coproduction.

\section{Conflicting Forces in Coproduction}

Coproduction is above all things else a strategy of partnership. This is both its potential strength and possibly its biggest liability in considering its application for addressing urban problems. Partnerships between public and private entities hold the promise of combining resources and broadening both participation and ownership in addressing urban problems. But partnerships between parties of dissimilar interest and disparate resources can be ineffective at best and counterproductive at worst. Harry Boyte (1993) makes the observation that what we have in American society are citizens on the one hand who are in tune with private matters but who know little of what is needed to 
involve themselves with matters of public consequence; and, a public sector on the other hand which for the most part is preoccupied with purveying goods to citizen "clients" and not in tune with their own citizenship much less citizen building processes. Thus, partnerships comprised of "private citizens" and "public servants" who are coming from such fundamentally different interests and perspectives are ill-situated to meaningfully address matters of public interest.

A second fundamental problem associated with government and citizen partnerships is the perpetuation of the widespread belief that the private sector is more efficient in achieving results than the public and therefore should be given the responsibility to deliver the public goods. Setting aside the body of literature which has sought to compare the efficiency of public and private delivery of public goods, it is relevant for our purposes to focus more on a fundamental problem. If the premise is that the private sector is more efficient in service delivery, then partnerships in coproductive processes are preordained to be a means to move more responsibility away from the public sector and into the private sector. Such a reason for partnership in solving many of the problems faced in urban communities is misleading and misplaced. Private interests have indeed proven their efficiency in accomplishing private benefits, but matters of public interests are substantively different (Krumholz, 1984; Judd \& Parkinson, 1990; Kettl, 1993).

A third inherent difficulty with partnerships is what Mier (1993) has noted to be an inherent tendency in public/private partnerships to gravitate toward generic solutions for problems which are unique to a given community. To illustrate this point, he observes the tendency for most all urban redevelopment partnerships to generically call for tax increment financing as the 
solution without fully considering the specific considerations which have necessitated an urban renewal strategy in the first place (Mier, 1993: 170-71). Such a problem is indicative of an even more deeply rooted problem. Boyte (1990) notes a deficit of skills and experience that exist in both public and private sectors for appreciating diversity within the community through the political process. A partnership between public agents and citizens in which neither possess requisite skills for understanding the problem will not likely produce successful solutions.

A final constraint on the building of successful partnerships is the uneven distribution of resources among the partners. Just as the private sector has frequently been favored as possessing the abilities in efficiently delivering results, the public sector frequently holds many of the resources needed to address the problem. The advantages of more access to information, time and collective effort of the public partner far outweigh most citizen resource banks. Without the will or skill to make these resources available, the citizen participant in the partnership will be reduced to nominal participation (Moe, 1987) or outright co-optation (Selznick, 1949).

Though constraints on such partnerships in coproductive processes are numerous and potentially debilitating, the problems are not so much inherent in the concept of coproduction or partnerships, as it is the capacities of the participants in the partnership. In the following section, a renewed possibility for partnership is considered which focuses on increased capacities of the partners to expand the applicability and effectiveness of the concept of coproduction. Fundamental to this renewal is an enriched citizenship on the part of the participants and a synthesizing of public servant and citizen agency. 


\section{Generating Civic Agency}

Considerable attention has been given in the last decade on the current apathy of citizens and the need for a more active citizenship among those outside of government (Barber, 1984; Gawthrop, 1984; Ventris, 1985; and Berry et al., 1993). The arguments for active citizenship are not only made to advance citizen participation as an instrument to the achievement of larger aims, but also it has value in its own right. In this view, active citizenship is normatively valued because it draws on and develops the highest human capacities (Stivers, 1990).

Similarly, a call for a more active expression of citizenship has been made for those in public service as well where the need to be connected with the experiences and capacities of the community are seen to be an essential but largely missing element of public service (Cooper, 1984; Matthews, 1989; Boyte, 1993). Coproductive partnerships offer one important mechanism by which citizenship can be expanded in both agents of public service and in the citizenry at large. To do so, however, will require an understanding and practice of the joint capacities which both citizen and public agent can bring to the partnership. Three such capacities have emerged from the investigations in this study which could help point in the direction for a revitalized conceptualization of coproduction.

Practical wisdom. Citizens bring a level of understanding and experience which when transferred to the public arena provide a basis of informed action and problem solving. The unique perspectives and capabilities of individual citizens emanate from their living and working environments (Kemmis, 1990). This was seen in the case of managers exercising and putting 
into practice their acquired knowledge about the practical realities of their tenants and the environment of their residence to solve problems of recycling. Such experiences can be instructive to similar problems within the community that can be addressed with similar citizen capacities. To apply the practical wisdom of citizens in public arenas, however, citizens need the opportunity, the will and an empowered position within public process.

Possibilities. David Matthews (1989:277) observes that there are two characteristics of all successful reform efforts: "First, they began to view people in a different way. Second, they defined the problem in a different way, creating possibilities for combining effort that had not been there before." In this sense, citizen will is a function of possibility. Though government cannot create the will of those to be involved it can create the context for discovery and new possibilities for citizen involvement by focusing collective energy on the important problems of the community. Such were the possibilities unleashed for a political generation when President Kennedy challenged the nation to "ask not what your country can do for you, but rather what you can do for your country." These possibilities do not have to be grandiose or of dramatic consequence to unleash citizen potential. New roles and understanding of citizens in public processes can emerge in the practical day to day work of government: the city planner who practices critical listening and questioning skills to focus attention and bring organization to community design processes (Forester, 1981); the school board which invites students to be part of the needs assessment and priority setting for the schools; or the city recycling coordinator who rides with the garbage haulers on their routes to obtain community inputs in developing waste reduction strategies. Each yields new perspectives and possibilities for community problem solving and citizen involvement. John 
Kretzmann and John McKnight (1993) talk about "capacity-focused development" as a means of basing community development efforts on understanding and mapping community assets, capacities and abilities. This model is posed as an alternative to the "deficiency model" which results in modes of public servicing of citizen needs. A focus on citizen capacities as opposed to their deficiencies open new possibilities for community problem solving.

Citizen agency. Harry Boyte (1989) observes that citizenship begins with seeing oneself as a citizen, rather than consumers, clients, or beneficiaries of the state. Citizen agency can occur if citizens have the opportunity to see themselves as engaged in -- or inherently capable of engaging in - the exercise of governance, administrative discretion and problem solving; rather than "involved" simply to the extent of petitioning administrators to satisfy their needs." Such a transformation occurs through the focus, context and legitimization of our public institutions and public agents that share their knowledge and resource with their citizen partners to solve public problems. People learn by doing, or as the authors of a recent study in democratic reform put it, "the clearest and most direct benefit of participation is that one learns" (Berry, et al, 1993: 257). The experience of successfully solving a problem with recycling at a multifamily complex may not contribute significantly to solving the global problems of pollution, but it may be the one experience needed to both connect and prepare the citizen for a continuing involvement in public life as an active citizen. Moving from citizenship as a weak and attenuated concept to one that implies an active sense of agency involves new perspectives about one's role in society. This transformation is poignantly demonstrated by Boyte (1989) in relating the shared experiences of a member of a citizen task force who 
observed, "We began as a group of people who thought we were looking for a solution. When we were through, we realized we were the solution."

Thus, civic agency can be seen to be a synthesizing of government and citizen agency within the context of public problem-solving. As such, it can be seen as an essential complement to a reworked relationship between citizenry and governance. Toward that end government agencies must reconceive their appropriate function, emphasizing the ways in which they can become catalysts for public problem-solving. Citizens need to reconceive their role in society, as well, from a passive service recipient to one actively engaged in the affairs of their community and on the occasion of their opportunities, capacities and interests join with others in public works. In these ways, not only will coproduction realize its promise, but our democratic institutions and spirit will be nourished. 


\section{REFERENCES}

Adler, Sy and Gerald F. Blake. 1990. "The Effects of a Formal Citizen Participation Program on Involvement in the Planning Process: A Case Study of Portland, Oregon," State and Local Government Review, XXI 3743.

Bacot, H., A. McCabe, M. Fitzgerald, T. Bowen and D. Folz. 1993. "Practicing the Politics of Inclusion: Citizen Surveys and the Design of Solid Waste Recycling Programs," American Review of Public Administration, XXIII, 29-41.

Barber, Benjamin. 1984. Strong Democracy. Berkeley, CA: University of California Press.

Bardach, Eugene. 1977. The Implementation Game: What Happens After a Bill Becomes Law? Cambridge, MA: MIT Press.

Bellah, Robert N., Richard Madsen, William Sullivan, Ann Swidler, Steven Tipton. 1985. Habits of the Heart, Individualism and Commitment in American Life. New York, NY: Harper \& Row.

Berry, Jeffrey, Kent E. Portney and Ken Thomson. 1993. The Rebirth of Urban Democracy. Washington, D. C.: The Brookings Institution.

Blake, Gerald, Richard Katzev and Barry Messer. 1991. An Analysis of Recycling in Multifamily Residences within the Portland Metropolitan Area. Portland, OR: Center for Urban Studies, Portland State University.

Boyte, Harry. 1993. The New Citizenship: A Partnership Between Citizens and Government. Minneapolis, MN: Humphrey Center of Urban Affairs, University of Minnesota.

Boyte, Harry. 1990. "Politics as Education," Social Policy, XXIV, 35-42.

Boyte, Harry. 1989. "Overview: Rethinking Politics," National Civic Review, LXXVIII, 249-25.

Brudney, Jeffrey L. 1990. Fostering Volunteer Programs in the Public Sector: Planning, Initiating and Managing Voluntary Actions. San Francisco, CA: Jossey-Bass Publishers. 
Brudney, Jeffrey L. 1985. "Coproduction: Issues in Implementation," Administration \& Society, XVII, 243-256.

Brudney, Jeffrey L. 1984. "Local Coproduction of Services and the Analysis of Municipal Productivity," Urban Affairs Quarterly, XIX, 465-484.

Brudney, Jeffrey L. and Robert E. England. 1983. "Toward a Definition of the Coproduction Concept," Public Administration Review, XLIII, 59-65.

Burn, M., and S. Oskamp. 1986. "Increasing Community Recycling with Persuasive Communication and Public Commitment," Journal of Applied Social Psychology, XVI, 29-41.

Byrd, Jacqueline, Robert Fulton, Terry Schutten and Jon Walsh. 1989. "Recycling Policy and Implementation Strategies for Recycling," Resource Recycling, VIII, 34-36, 57,58.

Capek, Stella M. and John I. Gilderbloom. 1992. Community Versus Commodity: Tenants and the American City. Albany, NY: State University of New York Press.

Capek, Stella M. 1989. "Missing Social Actors: Tenants and Collective Organizing in Arkansas." Paper presented at Annual Southwest Social Science Association, Little Rock, Arkansas, March 31, 1989.

Carmines, Edward G. and Richard Zeller. 1988. Reliability and Validity Assessment. Newbury Park, CA: Sage.

Church, Thomas W., and Robert T. Nakamura. 1993. Cleaning Up the Mess: Implementation Strategies in Superfund, Washington D. C. Brookings Institution

Converse, Jean M. and Stanley Presser. 1988. Survey Questions: Handcrafting the Standardized Questionnaire. Newbury Park, CA: Sage.

Cook, T., and D. Campbell. 1979. Quasi-Experimentation: Design and Analysis Issues for Field Research. Boston, MA: Houghton Mifflin Co.

Cooper, T. L. 1984. "Citizenship and Professionalism in Public Administration," Public Adminstration Review, XVIV, 143-149. 
Cotter, Matt, John Genereux and Jason Cleveland. 1989. NEC Guideline Report: Multifamily Recycling: Critical Parameters for Choosing and Evaluating the Buildings. St. Paul, MN: Genereux Research in Social Sciences.

De Young, Raymond. 1986. "Some Psychological Aspects of Recycling: the Structure of Conservation Satisfactions," Environment and Behavior, XVIII, 435-486.

Elmore, Richard F. 1987. "Instruments and Strategies in Public Policy," Policy Studies, VII, 174-186.

Ferman, Barbara and Martin A. Levin. 1987. "Dilemmas of Innovation and Accountability: Entrepreneurs and Chief Executives," Policy Studies Review, VII, 187-99.

Ferris, James M. 1986. "The Use of Volunteers in Public Service Production: Some Demand and Supply Considerations," Social Science Quarterly, LXV, 3-23.

Foley, D. 1980 "The Sociology of Housing," Annual Review of Sociology, VI, $457-478$.

Folz, David H. 1991a. "Recycling Program Design, Management and Participation: A National Survey of Municipal Experience," Public Administration Review, LI, 222-231.

Folz, David H. 1991b. "Public Participation and Recycling Performance: Explaining Program Success," Public Administration Review, LI, 526-532.

Forester, John. 1981. "Questioning and Organizing Attention: Toward a Critical Theory of Planning and Administrative Practice," Administration \& Society, XIII, 161-205.

Fosler, R. Scott and Renee A. Berger. 1982. Public-Private Partnership in American Cities: Seven Case Studies. Lexington, MA: Lexington Books.

Fox, Charles. 1987. "Biases in Public Policy Implementation," Policy Studies Review, VII, 128-141.

Friedson, Eliot. 1968. "The Impurity of Professional Authority," in Institutions and the Person, Howard S. Becker, Blanche Geer, David Reisman, and Robert S. Weiss (Eds.). Chicago, IL: Aldane Publishing Co. 25-34. 
Gawthrop, L. C. 1984. "Civas, Civitas, and Civilitas: A New Focus for the Year 2000," Public Administration Review, XLIV, 101-106.

Glenn, Jim. 1992. "Efficiencies and Economies of Curbside Recycling," BioCycle XXXIII, 30-34.

Gilderbloom, John I. 1985. "Social Forces Affecting Landlords in the Determination of Rent," Urban Life, XIV, 155-179.

Gilderbloom John, I. and Richard Appelbaum. 1988. Rethinking Rental Housing. Philadelphia: Temple University Press.

Goggin, Malcom. 1987. Policy Design and the Politics of Implementation. Knoxville: University of Tennessee Press.

Goggin, Malcolm. 1984. "Too Few Cases/Too Many Variables' Problem in Implementation Research," Western Political Quarterly, XXXVIII, 328347.

Gottdiener, Mark. 1985. The Social Production of Urban Space. Austin, TX: University of Texas Press.

Gruder-Adams, Sherrie. 1990. "Recycling in Multifamily Units," BioCycle X, 3637.

Haeberle, Steven H. 1987. "Neighborhood Identity and Citizen Participation." Administration \& Society, XIX, 178-196.

Harvey, Davis. 1973. Social Justice and The City. London, England: Edward Arnold.

Hasenfeld, Yehskel and Thomas Brock. 1991. "Implementation of Social Policy Revisited." Administration and Society, XXII, 451-479.

Heberlein, T. and G. Warriner. 1983. "The Influences of Price and Attitude on Shifting Residential Electricity Consumption from On to Off Peak Periods," Journal of Economic Psychology, IV, 107-130.

Hood, Christropher. 1983. The Tools of Government. Boston, MA: Chatham House. 
Hopper, Joseph and Joyce Nielsen. 1991. "Recycling as Altruistic Behavior: Normative and Behavioral Strategies to Expand Participation in a Community Recycling Program," Environment and Behavior, XXIII, 195220.

Hormuth, Stefan. 1991. "Psychological Studies on Garbage Avoidance and Recycling," in R. Bechtel (Ed.), Healthy Environments: Proceedings of EDRA, XXII, 1-20.

Huebner and Lipsey. 1981. "The Relationship of Three Measures of Locus of Control to Environmental Activism," Basic and Applied Social Psychology, II, 45-58.

Judd, D., \& M. Parkinson. 1990. "Patterns of Leadership." In D. Judd \& M. Parkinsion (Eds.), Leadership and Urban Regeneration: Cities in North America and Europe. Newbury Park, CA: Sage. 295-307.

Kambur, Pamela and Barry Messer. 1992. "Success with Multifamily Recycling," Resource Recycling, XI, 37-44.

Katzev, Richard. 1994. "Can Commitment Change Behavior?" Journal of Social Behavior and Personality, IX, 13-26.

Katzev, Richard, Gerald Blake and Barry Messer. 1993. "Determinants of Participation in Multifamily Recycling Programs," Journal of Applied Social Psychology, XI, 374-385.

Katzev, Richard and A. Pardini. 1987-1988. "The Comparative Effectiveness of Reward and Commitment in Motivating Community Recycling," Journal of Environmental Systems, XVII, 93-113.

Katzev, R. and T. Johnson. 1987. Promoting Energy Conservation: An Analysis of Behavioral Research. Boulder, CO: Westview Press.

Kettl, Donald. 1993. Sharing Power: Public Governance and Private Markets. Washington, D. C.: Brookings Institution.

Kingdon, J. 1984. Agendas, Alternatives and Public Policies. Boston, MA: Little Brown.

Kemmis, Daniel. 1990. Community and the Politics of Place, Norman, OK: University of Oklahoma Press. 
Kretzmann, John P. and John L. McKnight. 1993. Building Communities from the Inside Out. Evanston, IL: Center for Urban Affairs and Policy Research, Northwestern University.

Krumholz, N. 1984. Recovery of Cities: and Alternative View." In P. R. Porter \& D. Sweet (Eds.), Rebuilding America's Cities: Roads to Recovery. New Brunswick, NJ: Center for Urban Policy Research, Rutgers University.

Lasswell, H. 1956. The Decision Process. College Park, MD: University of Maryland.

Lasswell, H. 1963. "The Decision Process: Seven Categories of Functional Analysis. In Polsby, Dentier and Smith (Eds.), Politics and Social Life. Boston, MA: Houghton Mifflin.

Levine, Charles H. 1985. "The Family as a Coproduction Unit: Some Second Thoughts," Urban Resources, IV, 2-17.

Levine, Charles. 1984. "Citizenship an Service Delivery: the Promise of Coproduction," Public Administration Review, XLIV, 178-187.

Lewin K. 1947. "Group Decision and Social Change." In T. Newcomb and E. Hardley (Eds.), Readings in Social Psychology. New York, NY: Henry Holt.

Linder, Stephen and Guy Peters. 1987. "A Design Perspective on Policy Implementation: The Fallacies of Misplaced Prescription," Policy Studies Review, VI, 473-475.

Lipsey, M. W. 1977. "The Personal Antecedents and Consequences of Ecologically Responsible Behavior: A Review," JSAS Catalog of Selected Documents in Psychology, VII, 70-71.

Lipsky, Michael. 1980. Street-Level Bureaucracy. New York, NY: Russell Sage Foundation.

Luyben, P. D.. and J. S. Bailey. 1979. "Newspaper Recycling Behavior: the Effects of Rewards and Proximity of Containers," Environment and Behavior, XI. 539-557.

MacNair, Ray H., Russell Caldwell and Leonard Pollane. 1983. "Citizen Participants in Public Bureaucracies," Administration \& Society, XIV, 507524. 
Matthews, David. 1989. "The Politics of Community," National Civic Review, LXXVIII, 271-278.

Mazmanian, Daniel A. \& Paul A. Sabatier. 1983. Implementation and Public Policy. Glenview, IL: Scott, Foresman.

Mier, Robert. 1993. Social Justice and Local Development Policy. Newbury Park, CA: Sage.

Moe, Ronald C. 1987. "Exploring the Limits of Privatization," Public Administration Review, XLVII,

Morgan, David L. 1990. Focus Groups as Qualitative Research. Newbury Park, CA: Sage.

Morgan, David R. and Robert E. England. 1988. "The Two Faces of Privatization," Public Administration Review, XX, 979-987.

Morris, Norval. 1974. The Future of Imprisonment. Chicago, IL: University of Chicago Press.

Nakamura, R. 1987. "The Textbook Policy Process and Implementation Research," Policy Studies Review, VII, 142-154.

Neiman, Max. 1988. "Government Directed Change of Everyday Life and Coproduction: the Case of Home Energy Use," Western Political Quarterly, XLII, 365-389.

Osborn, David and Ted Gaebler. 1992. Reinventing Government. New York, NY: Addison-Wesley.

Oskamp, S., M. Harrington, T. Edwards, D. Sherwood, S. Okuda and D. Swanson. 1991. "Factors Influencing Household Recycling," Environment and Behavior, XXIII, 494-519.

Ostrom, Vincent and F. P. Bish (eds.). 1977. Comparing Urban Service Delivery Systems. Beverly Hills, CA: Sage.

Palumbo, Dennis. 1987. "Implementation: What Have We Learned and Still Need to Know," Policy Studies Review VII, 91-102.

Pardini, A. and R. Katzev. 1983-1984. "The Effect of Strerigth of Commitment on Newspaper Recycling," Journal of Environmental Systems, XIII, 245254. 
Parks, B. B., C. Baker, L. L. Kiser, R. Oakerson, E. Ostrom, V. Ostrom, S. L. Percy, M. B. Vandivort, G. P. Whitaker and R. Wilson. 1981. "Consumers as Coproducers of Public Services: Some Economic and Institutional Considerations," Policy Studies Review, IX, 1001-1011.

Percy, Stephen L. 1984. "Citizen Participation in the Coprduction of Urban Services," Urban Affairs Quarterly, XIX, 43-446.

Percy, Stephen L. 1983. "Citizen Coproduction: Prospects for Improving Service Delivery," Journal of Urban Affairs, V, 203-210.

Rathje, William. 1992. Rubbish. New York, NY: Harper Collins.

Reid, D. H.., P. D.. Luyben, R. J.. Rawers, J. S. Bailey. 1976. "Newspaper recycling behavior: the effects of prompting and proximity of containers," Environment and Behavior, VIII, 471-481.

Rein, Martin. 1983. From Policy to Practice. Anoake, NY: M E. Sharpe.

Rich, Richard C. 1981. "Interaction of the Voluntary and Governmental Sector: Toward an Understanding of the Coprduction of Municipal Services," Administration and Society, XIII, 59-76.

Riley, Barbara. 1992. "Evaluation of Curbside Recycling Programs," BioCycle, XXXIII, 68-72.

Ripley, Randall B., And Grace H. Franklin. 1982. Bureaucracy and Policy Implementation. Homewood IL: Dorsey Press.

Rohe, W., and M. Stegman. 1994. "The Impact of Homeownership on the Social and Political Involvement of Low Income People," Urban Affairs Quarterly, XXX, 28-50.

Rosener, J. B. 1978. "Citizen Participation: Can We Measure It's Effectiveness," Public Adminstration Review, XXXVIII, 507-524.

Rosentraub, M. S. and E. B. Sharp. 1981. "Consumers as Producers of Social Services," Southern Review of Public Administration, IV, 502-539.

Ryan. 1976. Blaming the Victim. New York, NY: Penguin.

Sabatier, Paul. 1987. "Top-down and Bottom-up Approaches to Implementation," Journal of Public Policy, VI, 21-48. 
Salamon, L. and M. Lund (Eds.). 1989. Beyond Privatization: The Tools of Government Action. Washington, D. C.: Brookings Institute.

Savas, E. S. (1977). The Organization and Efficiency of Solid Waste Collection. Lexington, MA: D. C. Heath.

Savas, E. S. (ed.). 1977. Alternatives for Delivering Public Services: Toward Improved Performance. Boulder, CO: Westview. Pages 7-49.

Selznick, P. 1949. TVA and the Grass Roots. Berkeley, CA: University of California Press.

Sharp, E. B. 1980. "Toward a New Understanding of Urban Services and Citizen Participation: The Coproduction Concept," Midwest Review of Public Administration, XIV, 105-118.

Shuman and Presser. 1981. Questions and Answers in Attitude Surveys. New York, NY: Academic Press.

Spector, Paul E. 1988. Research Designs. Newbury Park, CA: Sage.

Stern, P., T. Dietz and J. Black. 1986. "Support for Environmental Protection. The Role of Moral Norms," Population and Environment, VIII, 204-222.

Steinberger, Peter J. 1984. "Urban Politics and Communality." Urban Affairs Quarterly, XX, 4-21.

Stivers, Camille. 1990. "The Public Agency as Polis," Adminstration \& Society, XXII, 86-105.

Stone, Deborah A. 1988. Policy Paradox and Political Reason. Glenview, IL: Scott, Foresman and Company.

Sundeen, Richard A. 1988. "Explaining Participation in Coproduction: A Study of Volunteers," Social Science Quarterly, LXIX, 547-568.

Sundeen, Richard A. 1985. "Coproduction and Communities: Implications for Local Administrators," Administration \& Society, XVI, 387-402.

T'Kach and Patricia Schoenecker. 1990. "Practical Approaches to Multifamily Recycling," BioCycle, IX, 52-54. 
Thomas, John Clayton. 1990. "Public Involvement in Public Management: Adapting and testing a Borrowed Theory." Public Administration Review, L, 435-445.

Ventris, Curtis. 1985. "Emerging Perspectives on Citizen Participation," Public Administration Review, XLV, 433-440.

Vining, Joanne and Angela Ebreo. 1990. "What Makes a Recycler? A Comparison of Recyclers and Nonrecyclers," Environment and Behavior, XXII, 55-73.

Vining, Joanne, and Angela Ebreo. 1989. "An Evaluation of the Public Response to a Community Recycling Education Program," Society and Natural resources, II, 23-46.

Wang, Theodore and Richard Katzev. 1990. “Group Commitment and Resource Conservation," Journal of Applied Social Psychology," XX, 265-275

Warren, R., M. S. Rosentraub, and K. S. Harlow. 1982. "Citizen Participation in the Production of Services: Methodological and Policy Issues in Coproduction Research," Southwestern Review of Management and Economics, II, 41-55.

Warren R. 1987. "Introduction to the Special Issue: Coproduction, Volunteerism, Privatization and the Public Interest," Journal of Voluntary Action Research, XVI, 5-10.

Wassmann, Dan. 1990. "Managers Key to Multifamily Programs," City \& State, XIX, G 13.

Waste, Robert J. 1989. The Ecology of City Policy Making. New York, NY: Oxford University Press.

Weiss, C. 1982. "Policy Research in the Context of Diffusion Decision Making," Policy Studies Review, VI.

Whitaker, Gordon P. 1980. "Coproduction" Citizen Participation in Service Delivery," Public Administration Review, XL, 240-247.

Wilson, R. K. 1980. "Citizen Coproduction as a Mode of Participation." Journal of Urban Affairs, III, 37-49.

Yuhas, Barbara and Jennifer Hyde. 1991. "Getting Multi-Family Residents into the Act," Solid Waste and Power, LX, 54-60. 
APPENDIX A

MANAGER QUESTIONNAIRE 
Interview i.d.

Date:

\section{Section A Background}

I would like to begin with asking you some general background questions about your position as a manager at this complex.

Are you a full time or part time manager?

Do you live on the premises?

Do you have any financial ownership in this complex?

Do you have any assistance for managing this complex?

\begin{tabular}{|c|c|c|}
\hline 11. & FT & PT \\
\hline $2 \%$ & Yes & No \\
\hline (1.3. & Yes & No \\
\hline 14. & Yes & \\
\hline
\end{tabular}

\section{Section B General Knowledge and Assessment of the Program}

Now I would like to ask some general questions about the multifamily recycling program in the City of Portland. First of all, I would like to know how familiar you are with the City's efforts to get recycling in multifamily complexes throughout the city.

On a scale of 1 to 3 with " 3 " being very familiar and " 1 " not familiar at all, please assess the amount of knowledge you have about the city's program.

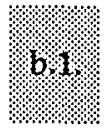

(3) (2) (1)

I am interested to know how you would evaluate the recycling program based on your personal experience. On a scale from 1 to 3 with " 3 " being excellent, " 1 " being not very good, I would like for you to rate each of the following:

The quality of the recycling educational information you received from the City

The quality of the assistance you received from the City in helping to make the program at your complex successful

The quality of the recycling equipment you received from the City

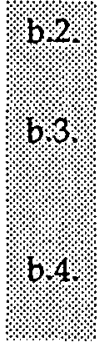

(2)

(1)

(3)

(2)

(1)

Now a few questions about the tenants at this complex. On a scale of 1 to 3 with " 3 " being high and " 1 " being low, I would like for you to respond to each of the following:

The amount of use of the recycling system by the tenants at this complex

The level of cooperation from the tenants in properly preparing and separating the recycling

The amount of interest tenants in general have displayed about recycling

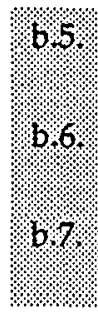

(3)

(3)

(3)
(2)

(2)

(2) 
Any Comments About the City's Recycling Program or About the Tenants Cooperation with Recycling:

\section{Recycling Experience}

I am going to now ask several questions regarding your personal experiences with the recycling program.

First of all, I am going to read a list of things that might keep managers from being supportive of a recycling program at their complex. Each time I read one, please tell me if it is one of the things that might discourage you from continuing to participate in the recycling program.

Amount of time it takes

Feeling frustration over the lack of cooperation from tenants

Not having lower garbage rates

The energy and effort involved

\begin{tabular}{|c|c|}
\hline c1. & yes $(0)$ \\
\hline & yes $(0)$ \\
\hline & yes $(0)$ \\
\hline 104 & yes $(0)$ \\
\hline
\end{tabular}

Now I would like to find out what kind of things you do with the recycling program here at this complex.

How often would you say that you take time to actively promote recycling with the tenants?

I.5.: $\quad$ very often (3) $\quad$ sometimes (2) infrequently (1) never (0)

Have there been any instances that come to mind where you have given assistance to tenants to help them recycle (other than passing out the REP brochure)?

8.6. yes no

(If yes) have you done any of the following?

Given extra information (e.g. newsletter, special flyer, etc.)

Taken additional recycling material from tenants to a depot

Help tenants take out or separate their recycling

Set up extra recycling equipment for additional recycling material

Other

\begin{tabular}{|c|c|c|}
\hline 07. & yes (2) & no $(0)$ \\
\hline 8.8. & yes (2) & no (0) \\
\hline $8 \%$ & yes (2) & no $(0)$ \\
\hline 10 & yes (2) & no $(0)$ \\
\hline$\% 1$ & yes (2) & no $(0)$ \\
\hline
\end{tabular}


Have you done anything to promote or assist any other managers or owners of complexes to implement a recycling program at their complex?

no

(If yes) have you done any of the following?

Given information about the recycling program

Recommend to start a recycling program

Other

$\begin{array}{lll}\text { 1. 3. } & \text { yes (2) } & \text { no (0) } \\ \text { 9.14. } & \text { yes (2) } & \text { no (0) } \\ \text {.5. } & \text { yes (2) } & \text { no (0) }\end{array}$

Any Comments about the Time it Takes to be Involved with Recycling or Inconveniences:

\section{Attitudes}

I am now going to ask some additional questions about recycling as well as some questions regarding broader issues concerning the environment, government and the community.

First, I would like to ask a couple of questions regarding how you view the community. Some people say they feel like they have a sense of community with the people in their neighborhood. Others don't feel that way. How about you. Would you say that you feel a strong sense of community with others in your neighborhood, very little sense of community, or something in between.

a.1. strong (2) in between (1) little (0)

Have you ever worked with others in this community (other than the recycling program) to try to solve some community problem?

व.2.: yes (1) no(0)

I would like to find out how motivated you consider yourself to be to be involved in the recycling program. On a scale of one to ten, with one being not very motivated and ten being very motivated, how would you rate your level of motivation to do what you can to make the recycling program at this complex a success?

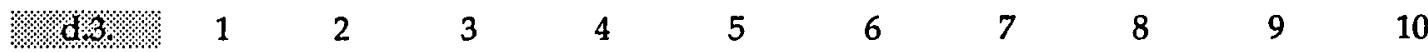

Of the many things you are expected to perform as manager of this complex, would you assess your motivation to assist and promote the recycling program more important, of equal importance or less important to most the other functions you perform?

\%. $\mathrm{d}$.4.: more important (2) as important (1) less important (0) DK 
I am going to read some statements that I would like for you to indicate whether you strongly agree, agree, disagree, strongly disagree or have no opinion.

The success of the recycling program at my complex depends in large measure on my direct involvement and the support I give it.

1.

The city's multifamily recycling program has provided a good opportunity for people like me to be more involved in helping to improve the environment.

: 9.6 :

People like me don't have any say about what government does.

\% 1 \%\% : strongly agree (2) agree (1) disagree (-1) strongly disagree no opinion (0)

3. $:$. :.

Sometimes politics and government seem so complicated that a person like me can't really understand what's going on.

\%.8. . strongly agree (2) agree (1) disagree (-1) strongly disagree no opinion (0)

... $.2 . ~(2)$

I can do the basic things to help with recycling (like keeping the area clean and handing out the brochures) but when it gets right down to it there isn't much I can do to get the tenants to recycle.

. d.9. strongly agree (2) agree (1) disagree (-1) strongly disagree no opinion (0)

(2)

Having the recycling program here at this complex is a good way for us to show that we care about our community and the environment.

व.10: strongly agree (2) agree (1) disagree (-1) strongly disagree no opinion (0) श. 1 (2)

Recycling is generally a good thing but it just takes too much of my time to be very involved with it.

d.1.1. strongly agree (2) agree (1) disagree (-1) strongly disagree no opinion (0)

In a way the role I play here with recycling at this complex is somewhat like being a partner with the City in helping to address an important problem facing this community and the environment.

đ.12. strongly agree (2) agree (1) disagree (-1) strongly disagree no opinion (0) (:.. . . . 
That is all the questions that $I$ would like to ask. Are there any additional comments you would like to make?

Any Comments or Questions:

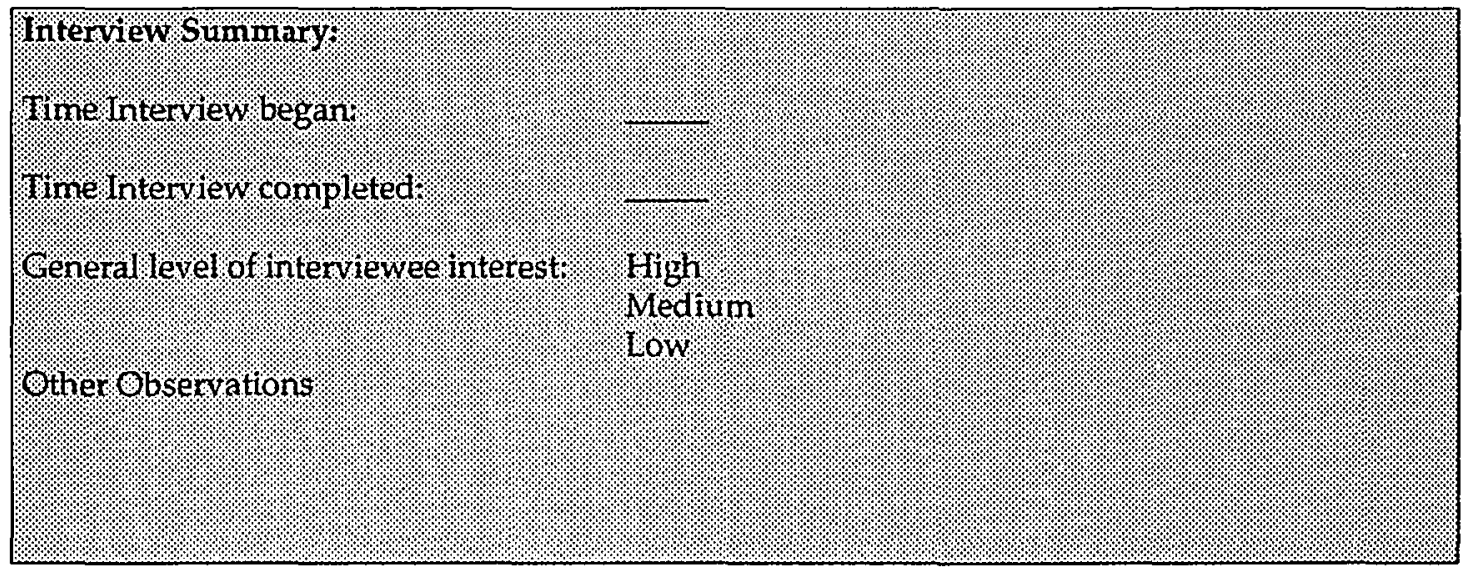




\section{APPENDIX B}

TENANT QUESTIONNAIRE 
Tenant Interview
Date of Interview:

Init:

Date of Entry:

Init:

Introduction: Read introduction

\section{Section I Participation in Recycling}

1. Does you household recycle any items"

(If yes, proceed to next question. If no, skip rest of Section I)

2 Do you or members in your household use the recycling system here at this complex?

3. For each of the following items, please indicate if you recycle all, most, some or none of each of the following items

\begin{tabular}{|l||l|l|l|l|}
\hline Material & None & Some & Most & All \\
\hline \hline Newspaper & & & & \\
\hline Glass & & & & \\
\hline Tin Cans & & & & \\
\hline Plastic Milk Jugs & & & & \\
\hline Magazines & & & & \\
\hline Cardboard & & & & \\
\hline Other: & & & & \\
\hline & & & & \\
\hline & & & & \\
\hline
\end{tabular}

4. As a general rule, when your household uses beverage bottles and aluminum cans, how often do you make sure that they are returned for a deposit.
Always
Usually
Sometimes
Never 
5. What percentage of your household trash would you estimate that is recycled.

6. On a scale of 1 to 10 , with "10" being very motivated and "1" being not very motivated, how would you rate your level of motivation to recycle?

$\begin{array}{llllllllll}1 & 2 & 3 & 4 & 5 & 6 & 7 & 8 & 9 & 10\end{array}$

7. Have you received recycling information and/or assistance in recycling from any one at the complex?

$7 \mathrm{a}$ If so, what did you receive?

7b From whom did you receive it?

8. Do you have any questions or observations about the recycling here at this complex? 


\section{Section II Household Data}

1. What is your apartment size?

Studio 1 bedroom 2 bedroom 3 bedroom

2. How many people live in your apartment?

3. How many children are under the age of 15 ?

4. What is your age?

5. What is the last grade completed in school:

6. What is the approximate household income for last year?

Thank you.

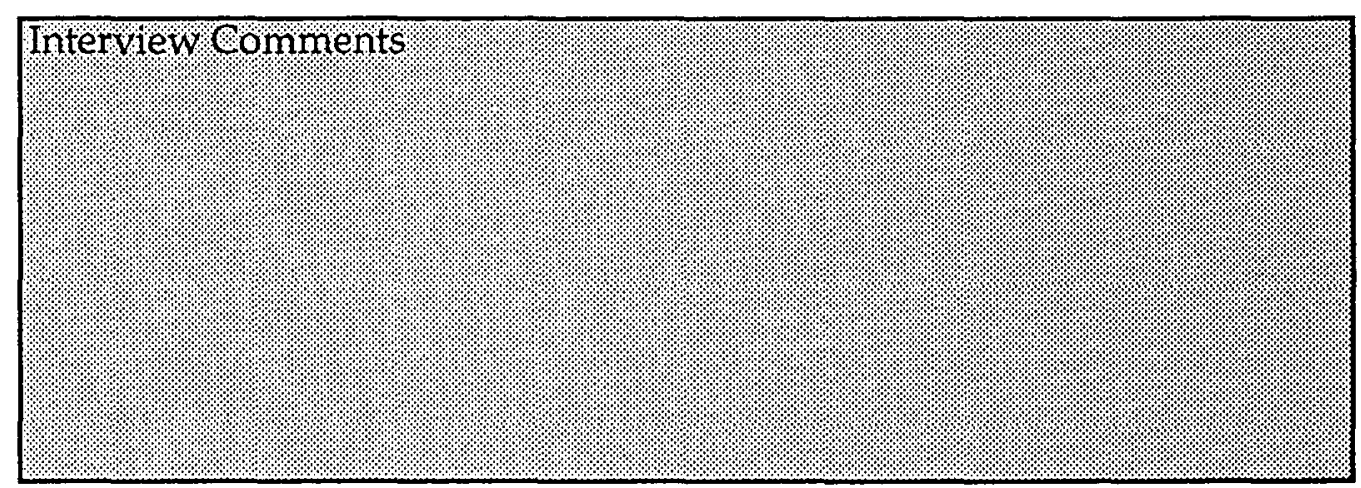




\section{APPENDIXC}

FIELD OBSERVATION DESCRIPTION AND FORMS 


\section{Field Measurement Description}

Research in this study involved the measurement of amounts and quality (i.e., level of contamination) of recycling at each of the subject multifamily complexes. The following describes the method utilized to obtain the measurements and record the observations of each of the following areas. (1) recycling and refuse amounts (2) recycling contamination levels and (3) recycling convenience indicator.

\section{Measurement of Recycling and Refuse Amounts.}

The number and types of containers for both the refuse and the recycling. Schedules for the collection of each recycling material and refuse was then ascertain from the hauler responsible for collecting these materials. Each site was then visited immediately preceding the arrival of the hauler each week to measure the volume of material in each container by noting the percent of container that was filled. In cases where the hauler serviced any of the containers more frequently than once a week, the researcher timed the measurement visitation to coincide with the other collection times during the week for those complexes. Where the hauler made collection visits less frequently than once a week, the researcher noted the previous weeks amount and the current weeks amount and subtracted the difference to represent the weeks volume for that material.

Any extra recycling material outside of the containers (i.e. cardboard for recycling or extra boxes containing recycling material) was measured and included in the field observation record. Any large items were set outside of the 
refuse container to be collected by the hauler (i.e. discarded furniture, appliances, etc.) was not included in the field observation. This occurred infrequently and for the few times this did occur it was not possible to determine if this material was salvaged or treated as refuse.

\section{Contamination of Recycling Levels}

In addition to the amounts of recycling at each complex, notes were taken on any contamination thi.t could be observed in the recycling collection containers. Contamination is defined in the study to be of two different types: (1) non-recyclable material in the collection container; (2) recyclable material in the wrong collection container; and/or (3) improperly prepared recyclable material. If contamination was observed the researcher evaluated the amount and seriousness of the contamination and rated the level of contamination as either "serious" (i.e. would be grounds for the collection company to reject the material) or "minimal" (i.e., needing correction but not likely to be rejected by the hauler).

\section{Measurement Sequence}

Measurement and contamination observations were conducted over a four consecutive weeks at the beginning of the study for a second 4 week interval of time approximately three to four months after the first interval. In four cases the four week observation sequence was interrupted by difficulties encountered in obtaining the measurements during one of the weekly observation periods (due to communication problems with the hauler). In each case, the four week sequence was started over. 


\section{Recycling Convenience Indicators}

A final area of field observation included the assessment of the convenience of the recycling system at each complex. This assessment included two considerations: (1) the proximity of the recycling shelter system to areas of highly traveled areas with the grounds of the complex; and (2) the accessibility of the recycling containers as determined by the presence of any physical or visual barriers to their location. Each of these factors were rated on a scale of 1 to 10 based using standard criteria for assessing each of these factors. 